\title{
Tennessee DUI Probation Followup Demonstration Project
}

\author{
R. T. Holden \\ L. T. Stewart \\ J. N. Rice \\ E. Manker
}

Tennessee Highway Safety Planning Division

Suite 1800-James K. Polk Building

Nashville, TN 37219

Contract No. DOT HS-5-01199

Contract Amount $\$ 994,191$

This document is available to the U.S. public through the National Technical Information Service, Springfield, Virginia 22161 
This document is disseminated under the sponsorship of the Department of Transportation in the interest of information exchange. The United States Government assumes no liability for its contents or use thereof. 
Technical Report Documentation Page

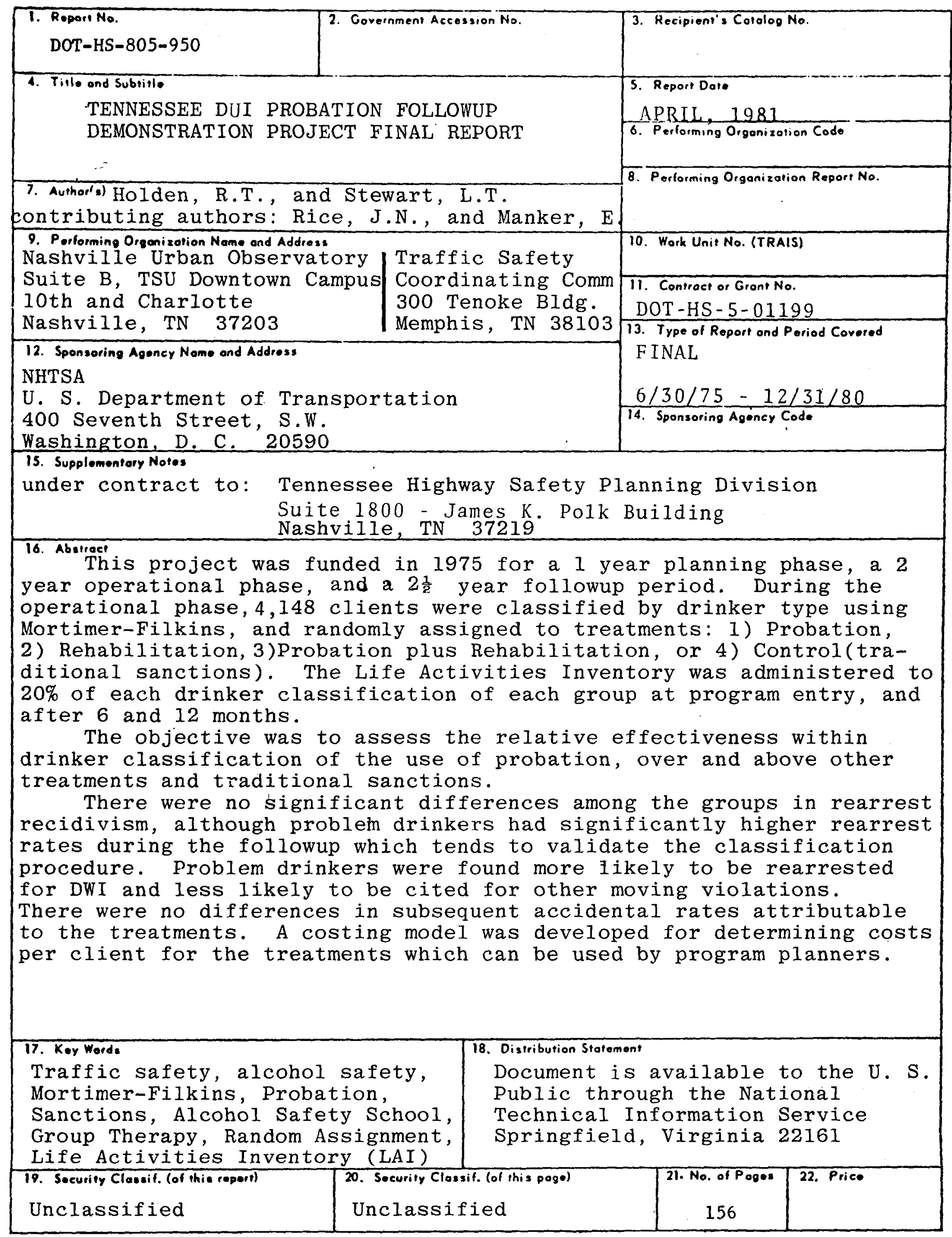

Form DOT F 1700.7 (0-72) Reproduction of form and completed page is authorized 


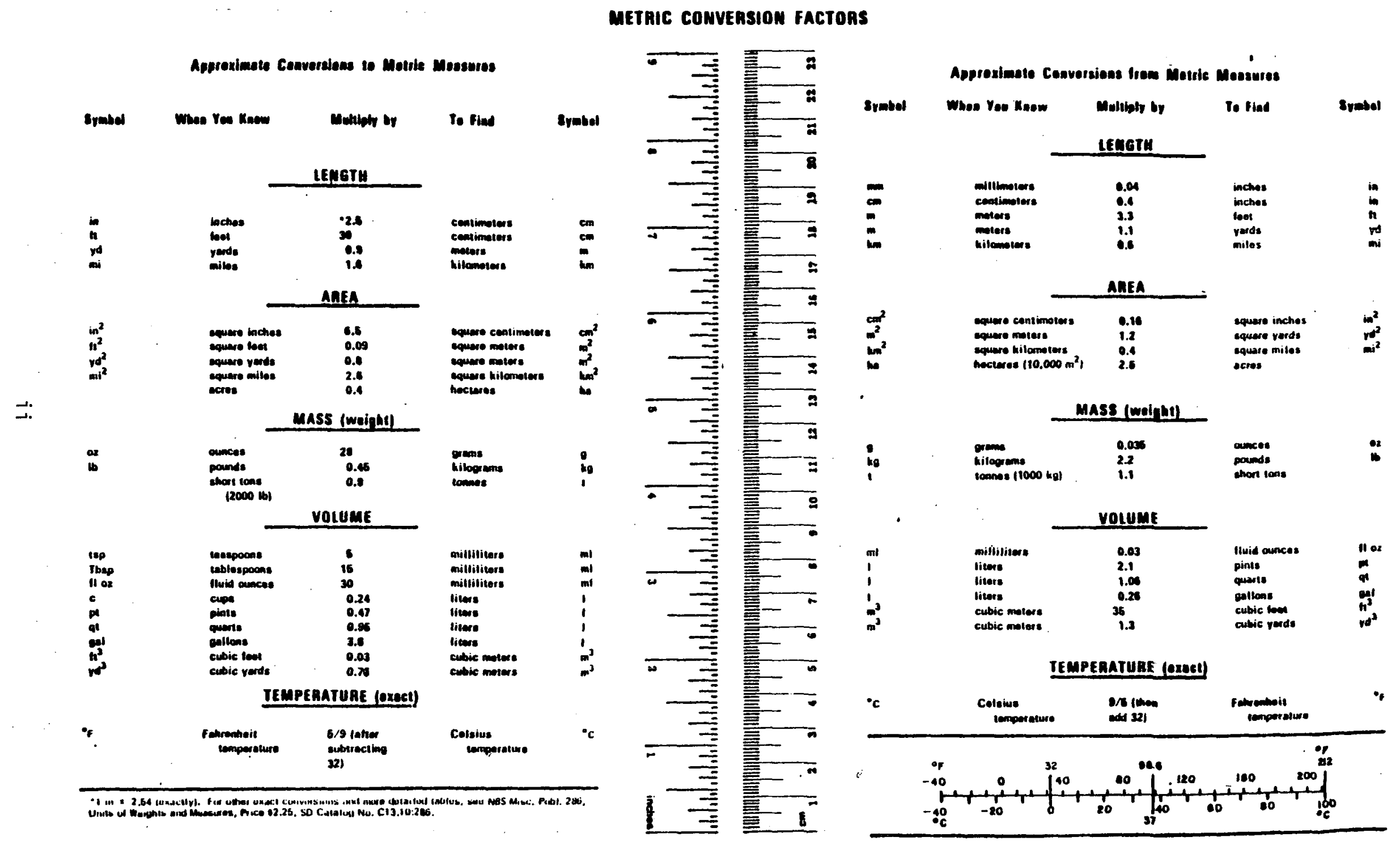




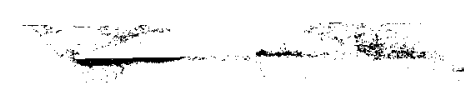

\section{PREFACE}

The authors would like to mention with gratitude some of the people and agencies involved in this demonstration without whom it could not have been a success.

Mr. Larry M. (Mike) Ellis, Director of the Tennessee Highway Safety Planning Division and contractor for this effort, has been invaluable tp this project from its inception for his astute combination of guidance when needed, and observant noninterference when things were proceeding properly.

The project has been fortunate to have had experienced and enlightened contract technical management in the persons of Mr. John Krause in early years, and Mr. Perry Yarrington in the crucial operational and followup periods. Their leadership was appreciated, as was the expertise of other NHTSA staff: Mr. Otto Hall, Mr. John Moulden, Mr. Phil Dozier, and Mr. Bill Evans. The beauracracy functions well through people like these.

Superior personnel at the demonstration site also contributed to the operation of the project. Not only the entire staff of the Traffic Safety Coordinating Committee, including Mr. David Simmons, DUI School Director, but also the director of Probation, Ms. Katheryn Walton, and the Judge of Division VIII, Mr. Robert Love, provided support in the business of actually processing clients. Lieutenant Joe Gurley and the Memphis and Shelby County DWI Squad not only provided us with law enforcement expertise, but with clients. Thanks are also due to Dr. Ralph Balyeat, Executive Director of the Nashville Urban Observatory, for his assistance to the evaluation staff.

During a long term project, there are many people who provide assistance in many ways - - to all those who did so for this project, thank you. We hope your association with us was as pleasant as ours with you.

As a final note, the reader will find that both DWI and DUI are used as acronyms for "driving while under the influence of intoxicants." The terms are used here interchangeably, and the usage of both reflects the lack of resolution of a five and one-half year debate between the management and evaluation staffs over which is the proper term. Since the evaluation staff was in charge of the production of this final report, they decided to use management's term (DWI) in the evaluation section as a sign of conciliation, and to use evaluation's preferred term (DUI) in the management section to show they haven't given up yet.

Lee T. Stewart, Evaluation Director Robert T. Holden, Assistant Evaluation Director
Ed Manker, Project Director Jim Rice, On-site Research Associate 
MANAGEMENT INFORMATION . . . . . . . . . . . . . . . . . 1

Background . . . . . . . . . . . . . . . . . . . . 1

Brief History of First Demonstration Site . . . . . 3

Demonstration Project Objectives . . . . . . . . . . . 4

$5 \frac{1}{2}$ Year Activity Summary . . . . . . . . . . . . . . . 6

System Description/Client Flow . . . . . . . . . . . 7

METHODOLOGY AND DATA COLLECTION . . . . . . . . . . . 13

Methodology. . . . . . . . . . . . . . . . 13

Collection of Intake Data. . . . . . . . . . . . . . . 14

Collection of Followup Data. . . . . . . . . . . . . . 15

DWI rearrests and other revocation data

Driving histories

Life Activities Inventories

Data Storage and Computer Programming. . . . . . . 27

EVALUATION OF TREATMENT EFFECTIVENESS. . . . . . . . . . 28

DWI Rearrests. . . . . . . . . . . . . . . . . 29

Crude treatment effects

Effects of treatment, LAI administration,

prior arrest, and diversion status

Effects of treatment, sex, and race

Non-Alcohol-Related Moving Traffic Violations. . . . 45

Crude treatment effects

Effects of treatment and prior violation

Accidents. . . . . . . . . . . . . . . . . . 53

Crude treatment effects

Effects of treatment and prior accident

Summary. . . . . . . . . . . . . . . . . . 58

Life Activities Inventories. . . . . . . . . . .61

Social drinkers

Problem drinkers

Summary

Additional Comments and Conclusion . . . . . . . . 68

References . . . . . . . . . . . . . . . . . 76

APPENDICES . . . . . . . . . . . . . . . . . . . 77

A. Court Disposition (referral) Times . . . . . . . 77

B. Effectiveness of the Randomization Procedure . . 81

C. Comparison of Problem and Social Drinkers. . . . . 86

D. Model for DWI Rearrest . . . . . . . . . . . . 91

E. Relationships Between Criterion Variables. . . . 94

F. Problems Encountered with the LAI. . . . . . . .100

G. Program Cost Estimation Procedures . . . . . . .106

H. Probation Evaluation . . . . . . . . . . . . .116

I. Management Information Data Summaries. . . . . .139 


\section{List of Tables}

Table

1

Distribution of DWI Rearrests Within 2 Years Following Referral to the Program for Social and Problem Drinkers . . . . . . . . . . . . . 17

Rates of Noncompliance by Treatment Modality and Drinker Type... . . . . . . . . . . 18

Rates of Arrest for Non-DWI Felonies and Misdemeanors (Within 2 Years Following Referral). . . . 19

Events Recorded From Driving Histories . . . . . . 20

Distributions of Number of Non-Alcohol-Related

Moving Violations, 2 Years Prior to Referral

and 18 Months Following Referral . . . . . . . . . . 21

Distribution of Number of Accidents, 2 Years

Prior to and 18 Months Following Referral. . . . . . 21

LAI Assignments by Drinker Type and Treatment

Modality. . . . . . . . . . . . . . . . . 22

Means and Standard Deviations of LAI Scale:s for

Social and Problem Drinkers, Initial Interview . . . 24

Means and Standard Deviations of LAI Scales for

Social and Problem Drinkers, 6-Month Interview . . 25

Means and Standard Deviations of LAI Scales for

Social and Problem Drinkers, 12-Month Interview. . . 26

Mean Number of DWI Rearrests Within 2 Years;

Following Referral to the Project, by Drinkier

Type and Treatment . . . . . . . . . . . . 30

Percentage Rearrested for DWI Within 2 Years

Following Referral to the Project, by Drinker

Type and Treatment . . . . . . . . . . . . . 31

Cross Tabulation of DWI Rearrest (Within 24

Months) with Predicator Variables (Social

Drinkers).

Cross Tabulation of DWI Rearrest (Within 24

Months) with Predicator Variables (Problem

Drinkers). . . . . . . . . . . . . . . . . 41

Tests of Log-Linear Models for Table 13

(Social Drinkers). 


\section{List of Tables (Continued)}

$\underline{\text { Table }}$

$\underline{\text { Page }}$

16

Test of Log-Linear Models for Table 14

(Problem Drinkers) . . . . . . . . . . . . . . 43

Tests of Log-Linear Models for Effects

of Treatment, Sex, and Race. . . . . . . . . . . . . 44

Mean Number of Non-Alcohol-Related Moving

Traffic Violations Within 18 Months

Following Referral to the Project, by

Drinker Type and Treatment . . . . . . . . . . . . . 46

Percentage with Non-Alcohol-Related

Moving Traffic Violations within

18 Months Following Referral to the

Project, by Drinker Type and Treatment . . . . . . . 47

20 Cross-Tabulation of Followup Non-Alcohol-

Related Moving Violations by Prior Violation

and Treatment Modality . . . . . . . . . . . 50

21 Tests of Log-Linear Models for Followup

Non-Alcohol-Related Moving Violations. . . . . . . . 51

22 Cross-Tabulation of Followup Non-Alcohol-

Related Moving Violations by Prior Violation

and Drinker Type... . . . . . . . . . . . . 52

23 Tests of Log-Linear Models for Table 22. . . . . . . 52

24 Mean Number of Accidents Within 18 Months

Following Referral to the Project, by

Drinker Type and Treatment . . . . . . . . . . . . . 54

25 Percentage with at Least One Accident Within

18 Months Following Referral to the Project,

by Drinker Type and Trcatment. . . . . . . . . . . . 55

26 Cross-Tabulation of Followup Accident by

Prior Accident and Treatment Modality. . . . . . . 58

27 Tests of Log-Linear Models for Followup

Accident . . . . . . . . . . . . . . . . . . 59

28 Cross-Tabulation of Followup Accident by

Prior Accident and Drinker Type. . . . . . . . . . . 60 


\section{List of Tables (Continued)}

Table

30

31

32

33

34

A1

A2

B].

B2

B3

C1

C2

D1

E1

Means for Six LAI Scales, Initial, 6 Months, and 12 Months, for Social Drinkers . . . . . . . . . . . . . . . . . . . . . . 62

Tests of Hypotheses for LAI Scores, Social Drinkers.

Means for Six LAI Scales, Initial, 6 Months, and 12 Months, for Problem Drinkers . . . . . . . . . . . . . . . . . 65

Tests for Hypotheses for LAI Scores, Problem Drinkers . . . . . . . . . . . . . 66

Two Year DWI Rearrest Rates for

Program Clients and Baseline

Sample

Median Time from Arrest to Referral to the Project, by Drinker Type and Diversion Status

Log-Rank Tests for Equality of the Distributions of Time from Arrest to Referral, for Drinker Type and Diversion

Status.

Characteristics of Social Drinkers in Various Treatment Groups..

Characteristics of Problem Drinkers

in the Various Treatment Groups.

Multivariate Comparisons of Client

Characteristics for Treatment Groups.

Univariate Comparison of Characteristics of Social and Problem Drinkers . . . . . . . . .

Tests of Log-Linear Models for Predicting Problem Drinking.

Tests of Log-Linear Models for Predicting

Rearrest

Cross-Tabulations of DWI Rearrest within

24 Months, Non-Alcohol-Related Moving

Violations wihtin 18 Months, and Accident

within 18 Months

Log-Linear Models for Table E1. 


\section{List of Tables (Continued)}

Table

Page

E3 Means for Six LAI Scales (Initial

Application) for Recidivists and

Nonrecidivists . . . . . . . . . . . . . . . . . 97

E4 Means for LAI Scales for DWI Recidivists

and Nonrecidivists . . . . . . . . . . . . . . . 98

E5 Tests of Hypotheses for LAI Scales for

Recidivists and Nonrecidivists . . . . . . . . . . . 99 


\section{List of Figures}

Figure

$\underline{\text { Page }}$

1

2

3

4

5

6

7

8

9

10

11

12

A1

Time from Referral to First DWI

Rearrest, for Social Drinkers,

by Treatment.

Time from Referral to First DWI

Rearrest, for Problem Drinkers,

by Treatment... . . . . . . . . . . . . 34

Time from Referral to First DWI

Rearrest, by Drinker Type and

LAI Administration . . . . . . . . . . . . 36

Time from Referral to First DWI

Rearrest, by Drinker Type and

Diversion Status . . . . . . . . . . . . 37

Time from Referral to First DWI

Rearrest, by Drinker Type and

Prior DWI Arrest... . . ... . . . . . . 38

Time from Referral to First

Citation for Social Drinkers,

by Treatment . . . . . . . . . . . . . . 4 48

Time from Referral to First

Citation for Problem Drinkers,

by Treatment

Time from Referral to First

Accident for Social Drinkers,

by Treatment. . . . . . . . . . . . . 56

Time from Referral to First

Accident for Problem Drinkers,

by Treatment . . . . . . . . . . . . . . . 57

Time from Initial Arrest to

First Rearrest, for Program

and Baseline Samples. . . . . . . . . . . 71

Time from Arrest to Subsequent

Arrest, for Baseline Sample. . . . . . . . . 73

Time from Arrest to Subsequent

Arrest, for all Program Clients. . . . . . . . . 74

Time from Arrest to Referral,

by Drinker Type and Diversion

Status. . . . . . . . . . . . . . . . . 79 


\section{List of Figures (Continued)}

Figure

I 1

12

I3

I4

I5
M.I.S. Report, 9/76 to 9/79. . . . . . . . . . 139

M.I.S. Report, $9 / 76$ to $9 / 79$. . . . . . . . . . 140

Client Flow Chart. . . . . . . . . . . . . .141

Fiscal Summary . . . . . . . . . . . . . .142

DWI Probation Followup . . . . . . . . . . . . . . . . . 


\section{MANAGFMFNT INFORMATION}

\section{Background}

The general objective of the Tennessee Probation Followup Demonstration Project was to demonstrate and evaluate the relative effectiveness of probation with various types of drinker-drivers. Basically, the demonstration operated in a system similar to that of many of the Alcohol Safety Action Projects (ASAPs). A major goal was the development of more complete information for the development of model protation approaches for use in the drinking: driver control system.

As stated in the original work statement for this Project, the origins of probation extend back to the English common 1 aw and the efforts to alleviate the severity of criminal sanctions. The use of suspension of sentence, often in conjunction with probation, also has its roots in English common law. The practice of probation began in the United States in the mid-19th century. However, probation as a disposition, as well as a total system, has made its greatest progress since 1900. Gradually the use of probation with convicted offenders grew throughout the country. The imposition of probation was first used in conjunction with a suspended sentence and is still commonly applied in this manner today. However, probation is being increasingly used as a sentence in itself. In this context, the American Bar Association Project on Standards for Criminal Justice (1970) defined probation as "A sentence not involving confinement which imposes conditions and retains authority in the sentencing court to modify the conditions of the sentence or to re-sentence the offender if he violates the conditions. Such a sentence should not involve or require suspension of the imposition or execution of any other sentence."

Several organizations, including the National Advisory Commission on Criminal Justice Standards and Goals, the National Council on Crime and Delinquency as well as the American Bar Association and others, have taken interest in the development of improved probation methods and systems in the United States.

The National Advisory Commission on Criminal Justice Standards and Goals in its report entitled Corrections published in 1973 stated that the "broad use of probation does not increase risk to the community. . . Although probation is viewed as the brightest hope for corrections, its full potential cannot be reached unless consideration is given to two major factors. The first is the development of a system for determining which offenders should receive a sentence of probation. The second is the development of a system that enables offenders to receive the support and services they need... . Currently, probation has failed to realize either of these."

A great variety of studies have been undertaken to demonstrate the effectiveness of probation. One major study was the Saginaw 
Project undertaken in Michigan between 1957 and 1962. The project achieved its three major objectives by working with $70-75 \%$ of the convicted offenders, not increasing the risk of community safety, and by saving tax dollars through the use of probation.* Numerous other studies have shown that failure rates of persons on probation were relatively low compared to other offenders. However, many of these studies were not conducted under controlled conditons, often lacking control, or even matched comparison groups as well as definitive information about such variables as types of services offered to probationers, various conditions of probation, etc.

Substantive information, then, about the effectiveness of probation was still lacking in 1975, the year of the beginning of this program. It should be noted that most studies concerning probation have focused on the use of probation with convicted offenders other than those who have been convicted of driving while under the influence (DUI) and other serious traffic offenses.

The probation process refers to the series of activities inter-relating the courts, the offender, and the community, and includes preparation of reports for the courts (particularly presentence reports), supervision of probationers, and providing or obtaining services for probationers.

Historically, most probation systems have dealt with persons who have committed major crimes and, as noted above, have 1argely ignored traffic offenders. Only in the past few years have courts applied the mechanisms of presentence investigation and probation to persons convicted while driving under the influence of alcohol. A relatively small percentage of courts with jurisdiction over this type of offender have dealt with him in this manner. For the most part, sentences have included fines and license actions as well as jail terms all or part of which may be suspended. Unfortunately, even these actions occurred in only a small percentage of cases. All too often in the past, courts failed to convict persons charged with DUI, and thus did not use probation.

The creation of NHTSAs Alcohol Safety Action Projects in 1970 was the first major effort to establish a systems approach to handling the drunk driver. In the 35 projects located in various States and communities around the country, a concerted enforcement effort was followed with a court program designed to identify problem drinkers and refer them to appropriate types of rehabilitation. A11 of the ASAP included some type of program to perform background investigations on convicted offenders. The investigations, done either on a pre or post sentence basis, were designed to differentiate between problem and social drinkers. The information obtained in this background investigation, as well as the

*National Probation and Parole Association, Michigan Council, The Saginaw Project, 1963. 
resulting classification of drinker type, would be used by the court in sentencing and in developing a rehabilitation referral recommendation.

The most direct and comprehensive attempt to develop a diagnostic procedure in a judicial setting for the identification of problem and social drinkers was conducted at the University of Michigan's Highway Safety Research Institute. Entitled "Court Procedures for Identifying Problem Drinkers," the study (sponsored by the National Highway Traffic Safety Administration) included an extensive literature search to obtain test items which would discriminate the problem drinker from the social drinker. The "Court Procedures," commonly called the "Mortimer-Filkens," has been used extensively at many of the Alcohol Safety Action Projects.

Many ASAPs employed the technique of probation followup in conjunction with, or in some cases in place of, referrals to various types of rehabilitation. However, the probation results from some ASAPs indicated that probation (in itself) may have some effects on convicted DUI offenders aside from any type of formal rehabilitation program.* However, this observation had not been substantiated through the use of any type of rigorous evaluation.

Thus, in early 1975 NHTSA issued an RFP for a DUI Probation Follow-up Demonstration Project. Two projects were subsequently funded, one to be conducted statewide in a number of small municipalities in Mississippi, and the other to be conducted at one site in Tennessee.

As indicated earlier, several studies in the probation field have indicated the beneficial effects of probation. However, these studies were not conducted with convicted DUIs or other serious traffic offenders. Probation for DUI offenders was a relatively new and little-used concept and its effectiveness remained to be evaluated. A major goal of this project, then, was the determination of which types of offenders are suitable for probation and the development of systems to provide probation services suitable to the needs of the probationers.

Brief History of the Nashville Site

In July 1975, the State of Tennessee was awarded a contract for a DUI Probation Followup Demonstration Project located in Nashville, Tennessee. The Urban Observatory of Metropolitan Nashville and Davidson County initiated the efforts to receive this project at the request of the Metropolitan Nashville General Sessions Court.

*Alcohol Safety Action Projects, Evaluation of Operations 1972, Chapter 5 Evaluation of Presentence Investigation and Probation Countermeasure Activities, obtained from NHTSA. 
Subsequent to receipt of the contract, Nashville's local administration changed. The new mayor had consolidation of services as one of his priorities and moved the Probation Division from the General Sessions Court to the Metropolitan Sheriff's Office.

Meetings among judges, the Mayor, the Sheriff, NHTSA, and Urban Observatory staff revealed the following:

1. The judges felt that probation administration was principally a judicial function,

2. The Mayor felt that all pre and posttrial diversiontype programs should be located in the County correction agency of the Sheriff's Office,

3. The Sheriff was principally interested in pretrial diversion programs, and

4. The Urban Observatory needed a stable probation administration with which to contract.

As negotiations continued, it became clear that the final placement and administration decisions concerning the Probation Division would not be made within the planned development period of the project. Because of this, and the fact that the new administration had other pressing priorities, the State of Tennessee notified the Project Technical Manager that they would be unable to implement the Project as planned in Nashville due to failure of the Probation Division (anticipated subcontractor) to provide services as stated in the contract.

In January 1976, it was decided by the Prime Contractor and the Uirban Observatory to request a change of Project site from Nashville to Memphis. Preliminary discussions with Memphis governmental officials, including judges, indicated that Memphis would be both willing and able to serve as the Project site.

By request, the State of Tennessee was granted a brief period to complete negotiations with Memphis and submit a position paper documenting relevant aspects of Memphis as a demonstration site. This site change request document was sent to NHTSA on February 5, 1976. The following sections describe the overall system as developed and implemented in the new site of Memphis, Tennessee.

\section{Demonstration Project Objectives}

The Tennessee Probation Followup Demonstration Project had as its major goal to demonstrate and evaluate the relative effectiveness of probation upon various types of drinking drivers. The purpose of the proposed project was to determine what interventions are effective in local courts which handle DWI cases, in order to 
develop model probation approaches for use in the drinking driver control system.

The Project was structured to develop information needed in three areas:' (a) the determination of which type of offenders are suitable for the various intervention options, (b) the use of available data by the court in sentencing and in formulating a rehabilitation referral recommendation, and (c) the development of a system to provide needed support and services.

Ultimately, the goal of this endeavor was to increase community traffic safety, while saving tax dollars, through the use of probation.

\section{Program Objectives}

1. The first program objective was to obtain an adequate sample size. At least 4,000 cases were used in project results analyses.

2. The second objective was to classify all offenders as either problem or nonproblem (social) drinkers, based primarily on Mortimer-Filkins questionnaire and interview scores and BAC at time of arrest.

3. A third program objective was to create a controlled situation in which the behavior of offenders could be monitored and analyzed. Convicted DUI offenders were assigned by random selection into four groups for comparative evaluation: comparison group (subjected to traditional sanctions), probation only group, rehabilitation only, and probation plus rehabilitation. For evaluation purposes, each of these groups were subdivided into problem drinkers and nonproblem drinkers.

4. The fourth program objective was to operate probation and rehabilitation programs for DUI offenders. The probation period was one year, emphasizing fairly intensive (monthly) contact between the probationer and the probation officer. A standard rehabilitation program was utilized throughout the project period: All offenders assigned to rehabilitation participated in an educative component (the Alcohol Safety Course), while in addition, those identified as problem drinkers were referred to a group therapy type of program.

5. The fifth major objective of the project was to evaluate the relative effectiveness of the various interventions. This evaluation is presented later in this Report.

6. Another major purpose of this project was to assess costeffectiveness. See Appendix $G$ for a discussion of the costing model developed. 


\section{Activity Summary by Project Period}

The Tennessee DUI Probation Followup Demonstration Project was implemented in the following time frame:

- Planning Period--July 1975 through August 1976. Originally designed to be a 9 -month period for planning the project to be totally conducted in Nashville, Tennessee, lack of anticipated governmental cooperation caused the site to be changed to Memphis, Tennessee. The Tennessee Highway Planning Division (contractor) subcontracted with the Memphis and Shelby County Traffic Safety Coordinating Committee for project management, and with the Memphis City Courts' Probation Division for project probation services. The Nashville Urban Observatory, originally the sole subcontractor for the Nashville site, retained responsibility for project evaluation. A Detailed Plan was submitted in June of 1976, key personnel were hired, space obtained and equipment purchased during the summer of 1976. A Probation Seminar was held for probation and other key project personnel, and program operations were begun in September 1976.

- Operational Period--September 1976 through August 1978. Clients were randomly assigned to the Driver Improvement Program beginning in September of 1976, and subsequently 4,148 clients were processed through the Demonstration Project, with approximately 25\% of that total in each of the Program's four components (see Appendix $B$ for an examination of the random assignment procedures.) Appendix I-1 and I-2 show some assignment data by month. Approximately $20 \%$ of the clients in each component were administered the Life Activities Inventory (LAI) at intake, and at six and twelve months after intake (see Appendix $F$ for a discussion of the LAI as used in this Project). Appendix I-3 and the following section describe the client flow process. Several Detailed Plan changes were submitted and approved during this period, the purposes of which were to make sure the Plan accurately reflected project operation, and to balance the subcontract budgets on a yearly basis. A probation consultant examined the Project probation operations during this period and presented a report (see Appendix $\mathrm{H}$ for the main findings of that report).

\section{- Followup Period--September 1978 through August 1980.} During this period, project probation activities were phased out, i.e., transferred to the regular City Probation Division, clients' records were monitored for rearrest, and selected clients were administered followup LAIs. Appendices A, C, and E present details of analyses concerning court disposition times, problem/social drinker comparisons, and criterion variable relationships. Appendix G presents the description of the cost-effectiveness procedures developed, and published during this period. Complete client data computer files were established and updated during this period. 
- Final Peport Period--September 1980 through December 1980 . Completion of client followup data collection, evaluation analyses, and Final Report writing took place during this period.

\section{Client Flow System Description}

The Tennessee DUI Probation Followup Demonstration Project

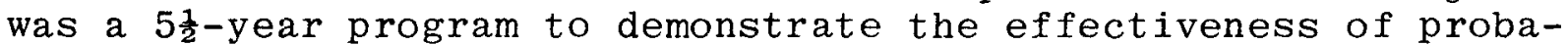
tion for DUIs relative to other forms of treatment and traditional sanctions. The project was composed of four stages: (a) Planning and Development ( 14 months), (b) Operational (2 years), (c) Followup Period and Records Monitoring ( 2 years), and (d) Analyses and Final Report ( 4 months).

Beginning in September of 1976, in the operational stage, the Project objective was to process DUI offenders through a Driver Improvement Program. These clients were those who were arrested in the City of Memphis, adjudicated in Division VIII of City Court (which had sole jurisdiction of DUIs), classified as problem or nonproblem drinkers, and randomly assigned to one of the following intervention groups:

1. Control (traditional sanctions of fine and/or court costs, and/or jail time, and/or unsupervised informal probation).

2. Probation (formal supervised probation consisting of one 30 minute visit per month for 11 months and 29 days).

\section{Rehabilitation}

a. For problem drinkers, 5 weeks of Alcohol Safety School followed by 4 weeks ( 8 sessions) of Assertive Training group therapy. School.

b. For nonproblem drinkers, 5 weeks of Alcohol Safety

4. Probation with Rehabilitation (Probation and rehabilitation as described above).

The Prime Contractor (the Tennessee Office of Urban and Federal Affairs, Highway Safety Planning Division) subcontracted for services with the following:

1. The Memphis and Shelby County Trafflc Safety Coordinating Committee (TSCC)--for Project Management.

2. The City of Memphis, City Court Probation Division--for probation services.

3. The Urban Observatory of Metropolitan Nashville/University Centers (U/O)--for evaluation. 
Following the four stages of this Project (ending in December 1980), the project was to have demonstrated the following for each drinker type:

1. The relative effectiveness of probation, compared to other treatments and traditional sanctions, in reducing DUI recidivism, and if possible, crashes and fatalities;

and

2. The cost effectiveness of each treatment intervention;

3. Changes in lifestyle, and attitude changes associated with each treatment in intervention.

The program participants were those arrested within the city limits of lemphis. In 1975, 5,495 arrests for DUI were made in this area, compared with 855 in Shelby County outside the city. Only city arrests for DUI were eligible for participation for the following reasons:

and

1. The vast majority of arrests were made within the city;

2. City arrests for DUI were all processed in Division VIII of City Court, which had sole jurisdiction over DUI cases.

The arrest process began with an officer stopping a driver for probable cause (a citable offense such as reckless driving, stop sign or light violation, etc.). Upon suspicion by the officer that alcohol is involved, the driver was asked to perform standard field sobriety tests:

1. Finger-to-Nose

2. Balance (e.g., picking up coins)

3. Walk-the-Line.

If these tests indicated the necessity, the officer called by radio for a mobile breath testing unit. This unit was a modular van equipped with a Gas-Chromatograph Intoximeter and a trained technician. The driver was kept under observation by the arresting officer until the van arrived. Upon entering the van, the driver had explained to him his right to refuse testing and the results of refusal under the implied consent law of Tennessee (i.e., automatic 6-month revocation of license). either:

If the breath tests results were below .06 BAC, the officer

1. Cited the driver for the probable cause offense and released him; or 
2. If behavioral evidence warranted, asked the driver for a urine sample for a drug screen. If the drug screen results were negative, the driver was cited for the probable cause offense and released. If the drug screen results were positive, the driver was arrested for DUI.

When the breath test results were .06 BAC or greater, the driver was arrested for DUI. After arrest for DUI, the driver was transported to jail, booked, allowed a telephone call, and held for a minimum of 5 hours. If the offender was able to post bond, he was told of his arraignment date and released. If he was unable to post bond, he remained in jail until the next court session. Both those who posted bond and those who did not made their first appearance within 24 hours, except for weekends and holidays. Public agency services such as the Public Defender's office and pretrial release services were available to indigent offenders prior to their first court date.

The first court appearance of DUI offenders was for arraignment in Division VIII of the Memphis City Court. This court had exclusive jurisdiction over DLI cases, and was funded by a 402 grant for a 3-year period. This funding provided for a judge, a prosecutor, three clerks, and one court officer. This DUI court began operation on January 1, 1976.

The Driver Improvement Program (of the Project) used the following eligibility criteria:

1. No Prior DUI Record.

a. Eligible for Diversion. Under Tennessee State Law, certain first offenders (DUI included) were, upon a guilty plea, eligible to be diverted from the normal judicial process. Sentencing for these individuals was deferred for 11 months and 29 days. At the end of the diversion period, if the offender had complied with the rules of diversion that the judge had imposed, the offender's attorney could request expungement of the public records of the case. The eligibility requirement for diversion was no prior record of a misdemeanor or felony.

b. Not eligible for diversion, but first DUI offense on record. The Driver Improvement Program was also available for those who did not qualify for diversion because of prior non-DUI conviction. These offenders became eligible for the program after a guilty plea or conviction for DUI.

At the first court appearance (arraignment), the offender's attorney could make application for diversion for his client. If the offender had no attorney, his case was continued to allow him to secure these services. It was the policy of the court that no offender should proceed within the system without the services of an attorney. It was further the policy of the court that an offender who could financially afford to drink and operate a motor 
vehicle, could afford the services of private counsel. The court had, therefore, made only limited use of the services of the public defender.

At the point in the arraignment proceedings when an offender appeared with an attorney, a trial date was set. Trial dates were originally being set 30 to 60 days after arraignment. After the trial date was set, the offender's attorney could make application for diversion for his client. If application fór diversion was made, the DUI probation Unit at court interviewed the client, gathering preliminary information for the postsentence investigation.

If an applicant for diversion did not qualify for diversion (e.g., had a prior record) the record was examined to determine if the client was eligible for the Driver Improvement Program (e.g., no prior DUI record). Only first offense DUIs were included in the Program. It was originally expected that including only first DUI offenders in the Program would have little effect on the sample sizes of the demonstration, since the majority of those appearing in Division VIII were first DUI offenders. Preliminary court records searches and estimates by the DUI judge and prosecutor indicated that $85-90 \%$ of those appearing in Division VIII since its beginning in January 1, 1976, were first offenders.

After diversion qualification procedures for those who applied, all offenders appeared for trial. At trial, those offenders who applied for diversion and had been found to qualify were placed into the Driver Improvement Program by the judge as a condition of their diversion.

Those who applied for diversion, who were not qualified for diversion, but who qualified for the Program (first DUI offender), entered the Program as a result of a conviction for DUI, and as a condition of probation. Those who did not apply for diversion, but who were first DUI offenders and thus eligible for the Program, were sentenced to the Program upon conviction.

After trial and assignment to the Program the offender was instructed to proceed immediately (within 24 hours) to the DUI Probation Unit, located in the Traffic Safety Coordinating Commmittee (TSCC) office complex. These offices were located two blocks from the Division VII courtroom and contained the following:

1) The DUI Probation Followup Project management

2) The Alcohol Safety School component

3) The assertive training component

4) The DUI Probation Unit

5) The on-site evaluation personnel. 
At the Probation Unit office, a probation counselor conducted a brief initial interview during which the client was classified as problem or nonproblem drinker. After classification, the client was taken to the intake clerk who collected a program fee (or set up a payment plan) and randomly assigned the client to intervention groups. Assignments were made from a computer-generated random list drawn up previously. The probation counselor then finished the initial interview by completing the social history section of the client report (see Appendix I-5) and explained the client's particular program (e.g., school, school and assertive training, monthly probation visits, scheduling, etc.). A randomly selected subsample of each intervention group was administered the LAI at this time. These subsamples of approximately $20 \%$ of each of the eight intervention groups were identified at initial random assignment by the intake clerk.

The program outlined by the probation counselor at the initial interview was one of the following intervention groupings:

\section{Traditional Sanctions (control).}

Regardless of drinker status, clients assigned to this group were told that they were being placed upon informal probation, with the only condition being that they refrain from DUI and serious legal problems. They were informed that a subsequent conviction for any serious misdemeanor or felony during the next 11 months and 29 days would result in the following:

A. For those on diversion: a revocation of diversion and subsequent conviction on the pending DUI charge which would result in sentencing to the penal farm.

B. For those not on diversion: a revocation of probation with similar sanctions as in diversion cases (A above).

A further condition for a subsample of $20 \%$ of this group was to return to the Probation Unit at 6 and 12 months following entry into the program to complete the second and third LAI. In addition to scheduling these LAI appointments at the initial interview, the probation counselor made written contact with the client, as a reminder, one or two weeks prior to the scheduled appointments. Barring client behavior which resulted in revocation proceedings, the initial interview and two subsequent LAI interviews were the only contact that control group clients had with the Driver Improvement Program.

\section{Probation Only.}

Regardless of drinker-type classification, members of this intervention group were told that they were on formal probation for 11 months and 29 days. This probation consisted of monthly visits by the client to the probation 
counselor for an average duration not to exceed 30 minutes. There was only one visit per month. A subsample of clients were told they would complete $\# 2$ and $\# 3$ at 6 months following program entry and at the end of their probation, during one of their regularly scheduled meetings.

III. Rehabilitation Only.

A. Nonproblem Drinkers. Those classifed as nonproblem drinkers we told that they were to successfully compiete the TSCC DUI School, and were given a schedule for their attendance. They were also informed of the results of noncompliance (i.e., of nonattendance at the school, or reconviction for a serious misdemeanor or felony during their 11 months and 29 days of informal probation):

1. For those on diversion, noncompliance with the rules of diversion would result in a conviction on the pending charge and sentencing to the penal farm.

2. For those not on diversion, noncompliance (nonattendance or reconviction) would be considered a violation of informal probation and result in similar sanction to 1 above.

B. Problem Drinkers. Those classified as problem drinkers were informed that they must successfully complete the TSCC DUI School and then complete the one-month assertative training therapy. They were informed of the results of noncompliance, which were no different than those for nonproblem drinkers (see A above).

A subsample of problem and nonproblem drinkers were informed that they must complete the LAI at 6 months following entry to the program and at the end of their informal probation period (11. months and 29 days).

IV. Probation P1us Rehabilitation.

Those assigned to this group were informed by their counselors of their individual programs which consisted of the following:

A. For nonproblem drinkers, the DUI school and probation as oulined above.

B. For problem drinkers, the DUI school, assertive training therapy, and probation as outlined above.

Regardless of drinker type, those assigned to this group had regular monthly probation meetings beginning with entry into the program (i.e., concurrently with the school or school and therapy). 


\section{METHODOLOGY AND DATA COLLECTION}

\section{Methodology}

The evaluation of the project was based on two seperate completely-randomized experiments. During the intake session each client was assigned by the probation department to one of four treatment modalities on the basis of a computer-generated, randon assignment schedule provided by the evaluation staff. The four treatment modalities (described above) were the following:

\section{Control}

2. Supervised probation-on 1 y

3. Rehabilitation-only

4. Supervised probation-plus-rehabilitation.

Because the rehabilitation treatment for clients classified as problem drinkers differed from the rehabilitation treatment for social drinkers it was necessary to perform comparisons seperately for the social and for problem drinkers. Thus, there was a fourgroup design for social drinkers and a seperate four-group design for problem drinkers.

The relative effectiveness of the treatments in preventing recidivism was determined by comparing the clients in the treatment groups with respect to four criterion variables:

\section{DWI rearrest}

2. Non-alcohol-related moving violations

3. Accidents

4. Lifestyle changes (as measured by the South Dakota Life Activities Inventory Review).

The first three variables were measured for followup periods (of varying length) beginning at the date of the clients' referral to the Project (approximately the date of treatment assignment). Life Activities Inventory (LAI) data were collected during the intake session and 6 and 12 months later.

NHTSA had specified that the treatment groups were to be compared with a series of two-group contrasts of means (where the means might in some cases be proportions). Thus, for each of the first three criterion variables, $F, x^{2}$, and $t$ tests for differences between treatment means were performed $\bar{a}$ appropriate. LAI scores were analyzed with a repeated-measures analysis of variance, which amounted to an ANOVA of various sums and differences of scores for the three LAI applications (see Dixon \& Brown, 1979). 
During the course of the Project it became apparent that the recidivism data should be analyzed in relation to predictor variables other than treatment. Thus, certain analyses not specified in the Detailed plan were performed. Those analyses required comparisons of recidivism measures with respect to several predictors simultaneously. For those analyses the criterion variables (DWI rearrest, non-alcohol-related citation, accident) were dichotomized and contingency table methods used. The methods avoided the problem of heteroscedasticity which would have been present if ANOVA or regression methods had been used. They were especially appropriate since all of the predictor variables were either dichotomous or categorical.

The significance of relationships between sets of variables included in the contingency tables was determined by testing various log-linear models for the cell frequencies (see Bishop, Fienberg, \& Holland, 1975). Two statistical criteria were used for model selection. First, for each model the overall goodness-of-fit was tested. That is, a likelihood ratio chi-square statistic was computed from the observed cell frequencies and the cell frequencies predicted by the model. In addition, the change in the chi-square statistic (which was itself a chi-square statistic) was computed when terms were added to or deleted from a model. The models tested (for example in Table 15) are described by a set of sufficient marginal configurations, the observed marginal totals which the expected frequencies must satisfy in order to yield a satisfactory fit to the contingency table. Those configurations ("effects") are denoted by a set of letters representing the variables involved. For example, inclusion of the term 'RP' in Model (5) of Table 15 implies that the probability of a clients having both a prior arrest and a followup arrest cannot be known from the probability of a prior arrest and the probability of a followup arrest; that is, prior arrest is related to rearrest. Inclusion of ' $\mathrm{RDP}$ ' in Model (7) implies that information about the one- and two-way marginal distributions of $R, D$, and $P$ is insufficient to compute the frequencies in the three-way distribution; that is, since rearrest ( $R$ ) is considered a dependent variable, there is an interactive effect of diversion status and prior arrest on rearrest.

Depending on the purpose for which an analysis was to be used, varying strategies were used to determine the order in which effects were tested. Those strategies are described with the analytic results.

\section{Collection of Intake Data}

At each client's intake probation session the counselor to which he or she was assigned filled out a Client Intake Form (appended to this report). That form served two purposes. First, it recorded information needed by the probation department for dealing with the client. Second, the form provided the basic 
client background and program assignment data needed by the evaluation staff.

Intake data of interest to the evaluation staff included the following:

1. Demographics such as sex, race, and age;

2. Social characteristics such as education, income, and marital status;

3. Classification as problem or social drinker;

4. BAC at time of arrest;

5. Mortimer-Filkins score;

6. Diversion status.

Data on the intake forms were coded by the evaluation staff, punched, and stored on a magnetic disk. Those data were later merged with followup data for analysis. Descriptions of the clients based on the intake data can be found in appendices $B$ and $C$.

\section{Collection of Followup Data}

Three types of followup data on the Project clients were collected:

1. Data on probation and diversion revocations (including revocations for subsequent DWI) and on revocable offenses following the probation or diversion period;

2. Tennessee Department of Safety driving histories for those clients for whom driver's license numbers were known;

3. Results of three administrations of the LAI interview for a sample of clients.

Collection procedures for each type of data will be described separately.

DWI Rearrests and Other

Revocation Data

Clients entered the project during a period of 2 years. Clients entering early in the Project could be observed over a much longer followup period than could later clients. The evaluation staff's procedures for collection of followup DWI arrest data provided a minimum followup period of 2 years for all clients; clients who entered the project during the early part of the intake phase were observed for up to $3 \frac{1}{2}$ years. Followup arrest data were obtained in several ways. 
Each client was under the jurisdiction of the DWI Probation Department for 11 months and 29 days after court referral. The DWI probation staff routinely obtained information about violations of clients' probation or diversion during that $11 / 29$ period. Violations were of three types: rearrests for DWI, arrest for a non-DWI offense, and noncompliance.

Each probation counselor was responsible for initiating revocation procedures on his or her own clients. Information leading to revocation might arise from any of the following sources:

1. Probation or rehabilitation records. (This would include cases of noncompliance for failure to complete or pay for rehabilitation, failure to make monthly probation visits, etc.)

2. Clients. (A1l clients were required to report all arrests occurring during the $11 / 29$ period to their probation counselor.)

3. Record checks. (A daily printout of all arrests in Memphis and Shelby County was cross-checked with a file of all program clients by the probation office. Any arrest that was classified as a felony or a misdemeanor was noted.)

Since the arrest reports only included Shelby County, arrests outside of the county were known only if reported by the client.

After completing a year of diversion or probation, clients were no longer under the jurisdiction of the DWI Probation Department, and no further arrest information about the client was collected by the probation staff. Arrest records for the second year of followup were obtained by the evaluation staff by checking each client's name (along with other identifying information such as date of birth and date of first DWI arrest) with the Memphis and Shelby County Criminal Justice computer system. AlI arrests during the second year which would have resulted in revocation if they had occurred during the first year were recorded.

Late in the followup phase of the project an additional source of data was found. The evaluation staff was able to check the records of the Memphis Police Department's Breath Testing unit for subsequent encounters with Project clients. It was found that most of the clients' encounters with the breath test unit during the first 2 years of followup had previously been recorded as a result of probation and evaluation staff checks of other data sources. Occasionally, breath test events were found which had not been located from other sources. If the client had shown a BAC of at least . $10 \%$ or had refused to take the test, those events were recorded as DWI arrests. The police breath test files provided most of the data on DWI arrests after the first 2 years of followup.

Table 1 shows the marginal distributions of DWI rearrests during the first 2 years of followup for social drinkers and problem drinkers. The highest number of rearrests within 2 years 
was four, but only five of the 4,128 clients were rearrested four times. In fact, it was rare for a client to have multiple rearrests, since on 1 y $16.1 \%$ of those who were rearrested were rearrested more than once.

TABLE 1. DISTRIBUTION OF DWI REARRESTS WITHIN 2 YEARS FOLLOWING REFERRAL TO THE PROGRAM FOR SOCIAL AND PROBLEM DRINKERS

\begin{tabular}{cccc}
\hline $\begin{array}{c}\text { Number of } \\
\text { Rearrests } \\
(\mathrm{K})\end{array}$ & $\begin{array}{c}\text { Social } \\
\text { Drinkers } \\
\text { with K } \\
\text { Rearrests }\end{array}$ & $\begin{array}{c}\text { Problem } \\
\text { Drinkers } \\
\text { with K } \\
\text { Rearrests }\end{array}$ & $\begin{array}{c}\text { Total } \\
\text { Clients } \\
\text { with K } \\
\text { Rearrests }\end{array}$ \\
\hline 0 & 2184 & 1314 & 3498 \\
1 & $(87.2 \%)$ & $(81.0 \%)$ & $(84.7 \%)$ \\
2 & 277 & 250 & 527 \\
3 & $(11.1 \%)$ & $(15.4 \%)$ & $(12.8 \%)$ \\
4 & $(1.4 \%)$ & $(2.8 \%)$ & 82 \\
& $(0.3 \%)$ & $9.0 \%)$ & 16 \\
& 2 & $(0.6 \%)$ & $(0.4 \%)$ \\
Sample Size & $(0.1 \%)$ & $(0.2 \%)$ & 5 \\
& 2506 & 1622 & $(0.1 \%)$ \\
& $(100.1 \%)$ & $(100.0 \%)$ & $(100.0 \%)$ \\
\hline
\end{tabular}

In addition to dates of arrests subsequent to referral to the Project, the breath test files also provided dates of arrests (or breath tests) prior to referral. Although all of the Project clients were, according to the court, DWI first offenders, it was found that $140(3.5 \%)$ of the clients had had encounters with the Breath Test Squad prior to the arrest that led to referral to the project. A code indicating a prior arrest was entered into the folowup data records of those clients, regardless of the outcome of the test.

The rates of filings of revocations for noncompliance for clients in the various treatment modalities are shown in Table 2 . Revocations for noncompliance were filed for only $1.7 \%$ of the social drinkers and $4.1 \%$ of the problem drinkers. It is obvious that noncompliance was not distributed evenly among the various treatments: clients assigned to the control groups had the lowest rates of noncompliance while the probation-plusrehabilitation groups had the highest rates, and groups assigned to supervised probation had higher noncompliance rates than groups not assigned to supervised probation. 
TABLE 2. RATES OF NONCOMPLIANCE BY TREATMENT MODALITY AND DRINKER TYPE

Rate of Noncompliance
Social Drinkers
$1.7 \%$
Control
Probation-only
Rehabilitation-only
Probation-plus-Rehabilitation
$0.3 \%$
$2.5 \%$
$1.1 \%$
$2.8 \%$
Problem Drinkers
$4.1 \%$
Control
$0.7 \%$
Probation-only
$4.3 \%$
Rehabilitation-on $1 y$
Probation-plus-Rehabilitation
$2.2 \%$
$9.2 \%$

The different rates of noncompliance cannot be viewed as different rates of "success" for the various treatment modalities-they simply reflect differing demands made on clients assigned to various treatments. Only five control clients were cited for. noncompliance due to the fact that there were essentially no programmatic conditions control clients were required to meet. At the other extreme, clients assigned to supervised probation-plusrehabilitation were required to keep monthly appointments with probation counselors, and to attend education (and sometimes. therapy) sessions. As a result, 56 probation-plus-rehabilitation clients had diversion or probation revoked for noncompliance.

Compliance with conditions of probation or diversion was not considered to be a valid criterion for evaluation of the treatments. Also, it was not used as a predictor or control variable for analyzing recidivism because of the relatively low rates of noncompliance and because of the selection biases which would have been introduced.

In addition to arrests for DWI, a large number of clients were arrested during the 2-year followup period for other felonies and misdemeanors. Table 3 shows that about $8 \%$ of the clients (353 clients) had such arrests. Arrest reports showed an amazing variety of offenses committed, including fraud, various types of larceny and robbery, assault, firearms violations, murder, rape, indecent exposure, drug possession, and many other offenses.

The evaluation staff is unaware of any literature on the relationship between DWI and other types of offenses. It appears that DWI offenders are usually viewed as distinct from other types 
of law violators although data on the Memphis offenders suggest that they are not. No provisions were made in the present contract for examining non-DWI felonies and misdemeanors.

TABLE 3. RATES OF ARREST FOR NON-DWI FELONIES AND MISDEMEANORS (WITHIN 2 YEARS FOLLOWING REFERRAL)

Treatment Modality

Social Drinkers

Control

Probation-only

Rehabilitation-only

Probation-plus-Rehabilitation

Problem Drinkers

Control

Probation-only

Rehabilitation-on1y

Probation-plus-Rehabilitation
Arrest Rate

\section{$7.9 \%$}

$6.7 \%$

$7.7 \%$

$8.1 \%$

$9.0 \%$

$9.5 \%$

$11.4 \%$

$7.4 \%$

$11.9 \%$

$7.1 \%$

\section{Driving Histories}

The Tennessee Department of Safety maintains a computerized history file for all licensed drivers in Tennessee (including those with expired, revoked, or otherwise invalid licenses). The history for each driver can be accessed only if his driver's license number is known.

Driver's license numbers for the Project clients, if available, were obtained when the clients entered the program. Those numbers were then used to obtain printed Moving Violation Records (MVRs) from the Department of Safety. MVRs were obtained for $2,876(68.3 \%)$ of the 4,146 Project clients.

The MVRs contained records of many different types of events, some of which were of interest to the Project and some of which were not. Project data coders examined the MVRs and recorded dates of events which were of interest for the evaluation. Those events included accidents and several types of moving violations. Table 4 shows the events which were recorded. Many of the possible types of events were rarely, if ever, recorded. Fatal accidents, for example, were rare, and suicides nonexistent. The most common type of violation was speeding.

Dates on which any of the previously described events occurred were recorded in a computer file, along with a code noting whether an accident, a violation, or both, had occurred. Hence, the data 
consisted of dates, not offenses; all violations on a single date were considered to be a single event.

TABLE 4. EVENTS RECORDED FROM DRIVING HISTORIES

Events Recorded as Accidents

$\mathrm{ACl} \quad$ Contributing to the occurrence of a motor vehicle accident resulting in bodily injury

AC2 Contributing to the occurrence of a motor vehicle accident resulting in property damage

AC3 Violation of a motor vehicle law not resulting in damage to persons or property but considered an accident

AC4 Involvement in an accident--no indication of fault

FAl Violation of a motor vehicle law resulting in the death of another person

FA2 Violation of a motor vehicle law resulting in one's own death

FA3 Suicide by motor vehicle

Events Recorded as Moving Violations

$\begin{array}{ll}\text { FO } & \text { Following too closely (and related offenses) } \\ \text { IL } & \text { Improper lane change, running off road, etc. } \\ \text { MS } & \text { Miscellaneous } \\ \text { PA } & \text { Improper passing } \\ \text { RK } & \text { Reckless driving and similar offenses } \\ \text { RW } & \text { Right-of-way violations } \\ \text { SC } & \text { Improper signaling } \\ \text { SI } & \text { Speeding } \\ \text { SP } & \text { Turning violations } \\ \text { TU } & \text { Driving wrong direction } \\ \text { WW } & \end{array}$

Table 5 shows the distribution of the number of non-alcoholrelated moving violations within 24 months prior to referral to the Project and within 18 months following referral. Just over $37 \%$ of the clients in the sample had prior violations, while $29.5 \%$ had followup violations. About $13.5 \%$ had more than one prior violation, and about $5.9 \%$ had more than one followup violation.

Table 6 shows the distribution of number of accidents within 24 months prior to referral and 18 months following referral. More than half of the clients (53.6\%) had at least one prior accident, and more than $14 \%$ had more than one prior accident. About $23 \%$ had at least one followup accident, but on $1 \mathrm{y} 4.1 \%$ had more than one accident during the followup period. 
TABLE 5. DISTRIBUTIONS OF NUMBER OF NON-ALCOHOL-RELATED MOVING VIOLATIONS, 2 YEARS PRIOR TO REFERRAL AND 18 MONTHS FOLLOWING REFERRAL

\begin{tabular}{crr}
\hline $\begin{array}{c}\text { Number of } \\
\text { Events } \\
(\mathrm{K})\end{array}$ & $\begin{array}{c}\text { Clients with } \\
\text { K Prior } \\
\text { Violations }\end{array}$ & $\begin{array}{c}\text { Clients with } \\
\text { K Followup } \\
\text { Violations }\end{array}$ \\
\hline 0 & $1809(62.9 \%)$ & $2017(70.5 \%)$ \\
1 & $681(23.7 \%)$ & $646(22.6 \%)$ \\
2 & $264(9.2 \%)$ & $153(5.3 \%)$ \\
3 & $82(2.9 \%)$ & $29(1.0 \%)$ \\
4 & $28(1.0 \%)$ & $13(0.5 \%)$ \\
5 or more & $13(0.4 \%)$ & $2(0.1 \%)$ \\
Sample Size & $2877(100.1 \%)$ & $2860(100.0 \%)$ \\
\hline
\end{tabular}

TABLE 6. DISTRIBUTIONS OF NUMBER OF ACCIDENTS, 2 YEARS PRIOR TO AND 18 MONTHS FOLLOWING REFERRAL

\begin{tabular}{crr}
\hline $\begin{array}{c}\text { Number of } \\
\text { Events } \\
(\mathrm{K})\end{array}$ & $\begin{array}{c}\text { Clients with } \\
\text { K Prior } \\
\text { Violations }\end{array}$ & $\begin{array}{c}\text { Clients with } \\
\text { K Followup } \\
\text { Accidents }\end{array}$ \\
\hline 0 & $1342(46.6 \%)$ & $2211(77.3 \%)$ \\
1 & $1121(39.0 \%)$ & $530(18.5 \%)$ \\
2 & $333(11.6 \%)$ & $101(3.5 \%)$ \\
3 & $63(2.2 \%)$ & $15 \quad(0.5 \%)$ \\
4 & $14(0.5 \%)$ & $3 \quad(0.1 \%)$ \\
5 or more & $4(0.1 \%)$ & 0 \\
Sample Size & $2877(100.0 \%)$ & $2860(99.9 \%)$ \\
\hline
\end{tabular}

\section{Life Activities Inventories}

The printed schedule by which clients were randomly assigned to the four treatment modalities also included assignments to LAI and non-LAI groups. Assignments to take or not take the LAI were crossed:with and independent of treatment assignment.

Assignment to the LAI meant that the client was to be interviewed three times. In addition to an initial interview during the intake session, each LAI client was supposed to be reinterviewed 6 and 12 months later. Clients not assigned to supervised probation, who were not required to maintain contact with the probation department, had to be called in by probation counselors just to take the followup interviews. Additional remarks on this and other aspects of the LAIs can be found in Appendix F. 
It was originally planned that $20 \%$ of the clients would be assigned to take the LAIs. However, late in the Project it was determined that a sample of problem drinkers greater than $20 \%$ was needed, so during the last few weeks of the intake period all clients classified as problem drinkers were assigned to take LAIs.

Table 7 shows the numbers of clients in various treatment groups assigned to take LAIs and numbers of clients interviewed. About $19.4 \%$ of the social drinkers were assigned to take the LAI while $24.6 \%$ of problem drinkers were assigned. Of social drinkers assigned to take the LAI, at least one interview form was obtained by the evaluation staff for $98.1 \%$, and at least one followup interview form was obtained for $92 \%$. At least one form was obtained for $99.3 \%$ of the problem drinkers assigned to take the LAI, and at least one followup form was obtained for $89.4 \%$. Several additional forms were obtained for clients whose records showed they were not assigned to take the LAI.

\section{TABLE 7. LAI ASSIGNMENTS BY DRINKER TYPE AND TREATMENT MODALITY}

\begin{tabular}{lccc}
\hline & $\begin{array}{c}\text { Number } \\
\text { Assigned } \\
\text { to LAI }\end{array}$ & $\begin{array}{c}\text { At Least } \\
\text { One LAI } \\
\text { Obtained* }\end{array}$ & $\begin{array}{c}\text { At Least } \\
\text { One Followu } \\
\text { LAI Obtained** }\end{array}$ \\
\hline Social Drinkers & 478 & 469 & 440 \\
Control & 127 & 127 & 119 \\
Pro.-only & 120 & 119 & 114 \\
Rehab.-only & 117 & 115 & 103 \\
Pro.+Rehab. & 114 & 108 & 104 \\
Problem Drinkers & 404 & 401 & 361 \\
Control & 107 & 106 & 92 \\
Pro.-only & 100 & 99 & 93 \\
Rehab.-only & 101 & 101 & 90 \\
Pro.+Rehab. & 96 & 95 & 86 \\
\hline
\end{tabular}

*In addition, LAIs were obtained for 24 clients not assigned. **In addition, followup LAIs were obtained for 17 clients not assigned.

The existence of an interview form for a client did not guarantee the existence of usable data for that client. Interview forms were often incomplete due to the nature of the questions and to procedures used to fill them out (see Appendix F). Problems with data collection were exacerbated by the fact that each LAI application responses to whole sets of items were needed in order to compute certain scales for analysis. Even more important, since there were three applications of the LAI it was necessary to have complete data from all three applications for 
analysis. Sample sizes for the treatment comparisons (see below) were far smaller than those indicated by Table 7 due to incomplete information.

\section{Description of the LAI}

The South Dakota Life Activities Inventory (LAI), Section 3 , is an 81-item interview protocol. Items are to be completed in a face-to-face interview between probation counselor and client. Questions contained in the interview assess potentially observable behavior, self-reported by the client, which might indicate the influence of alcohol use in the individual's Iife situation.

Items on the protocol are to be combined into six scales, which are presumed to measure the following characteristics:

1. Employment/economic stability

2. Current drinking pattern

3. Family status (marriedness)

4. Social interaction/involvement

5. Current physical health problems

6. Immoderate drinking behavior.

The scales are presumably mutually orthogonal (see Ellingstad \& Struckman-Johnson, 1977, for a justification of the scales).

Ellingstad (1977) gives the instructions for constructing the six scales from the LAI interview schedules. He describes the instructions as "a simple step-wise procedure which starts with the set of client responses obtained on an administration of the LAI . . ., and which culminates in the calculation of a set of standardized and scaled factor scores" (p. 1). Remarks about Ellingstad's instructions can be found in Appendix F.

Several steps were involved in constructing the six scales:

1. Construction of a set of "salient variables." This involved extensive recoding and combining of responses on various items. It also meant ignoring much information on the schedules which evidently was not salient.

2. Standardization of the salient variables. Ellingstad gives means and standard deviations of the variables based on an STR client sample. The evaluation staff did not deem it appropriate to substitute the means and standard deviations of the Memphis client scores for the presumed estimates of population parameters presented by Ellingstad. The logic of using different weights depending on the group taking the LAI was unclear.

3. Summation of the salient variables into six scales. Six scales were constructed as the sums of certain mutually-exclusive subsets of salient variables. 
4. Standardization of the scales. Ellingstad presents formulas for transforming the scales in order to obtain a mean of 500 and a standard deviation of 100 for each scale.

It can be seen in tables 8,9 , and 10 that sample sizes varied for different applications of the LAI and for different scales. Not only did the number of clients completing the LAI vary, but the number of clients providing sufficient information for computation of particular scales also varied. Many of the LAIs were self-administered in order to save time for probation staff (see Appendix F) and that procedure allowed clients to skip questions they did not like. Clients were especially likely to omit responses to questions for Scale 6 (Immoderate Drinking Behavior) in the followup administrations, since responses to those questions could affect their probation or diversion status. (However, that is also reason to doubt that responses were truthful when they were made.) Sample-size problems were greatly exacerbated by the need for scale scores for all three applications for the repeated-measures analyses used in the treatment evaluations.

TABLE 8. MEANS AND STANDARD DEVIATIONS OF LAI SCALES FOR SOCIAL AND PROBLEM DRINKERS, INITIAL INTERVIEW

\begin{tabular}{|c|c|c|c|c|c|c|c|}
\hline \multirow[b]{2}{*}{ Scale } & \multirow[b]{2}{*}{ Group } & \multirow{2}{*}{$\begin{array}{c}\text { Sample } \\
\text { Size }\end{array}$} & \multirow[b]{2}{*}{ Mean } & \multirow[b]{2}{*}{ SD } & \multicolumn{3}{|c|}{ Denominator } \\
\hline & & & & & $\mathrm{F}^{*}$ & $\mathrm{df} * *$ & $p$ \\
\hline 1 & $\begin{array}{l}\text { Social Drinkers } \\
\text { Problem Drinkers } \\
\text { A11 }\end{array}$ & $\begin{array}{l}333 \\
289 \\
622\end{array}$ & $\begin{array}{l}531.99 \\
523.12 \\
527.87\end{array}$ & $\begin{array}{l}68.22 \\
74.71 \\
71.39\end{array}$ & 2.40 & 620 & .122 \\
\hline 2 & $\begin{array}{l}\text { Social Drinkers } \\
\text { Problem Drinkers } \\
\text { A11 }\end{array}$ & $\begin{array}{l}392 \\
339 \\
731\end{array}$ & $\begin{array}{l}461 \cdot 47 \\
461 \cdot 38 \\
461 \cdot 43\end{array}$ & $\begin{array}{l}123.90 \\
134.37 \\
128.77\end{array}$ & 0.00 & 729 & .995 \\
\hline 3 & $\begin{array}{l}\text { Social Drinkers } \\
\text { Problem Drinkers } \\
\text { A11 }\end{array}$ & $\begin{array}{l}374 \\
328 \\
702\end{array}$ & $\begin{array}{l}506.50 \\
494.21 \\
500.76\end{array}$ & $\begin{array}{l}114.48 \\
110.73 \\
112.83\end{array}$ & 2.08 & 700 & .150 \\
\hline 4 & $\begin{array}{l}\text { Social Drinkers } \\
\text { Problem Drinkers } \\
\text { All }\end{array}$ & $\begin{array}{l}366 \\
307 \\
673\end{array}$ & $\begin{array}{l}512.53 \\
484.07 \\
499.55\end{array}$ & $\begin{array}{l}70.76 \\
68.36 \\
71.05\end{array}$ & 27.84 & 671 & .000 \\
\hline 5 & $\begin{array}{l}\text { Social Drinkers } \\
\text { Problem Drinkers } \\
\text { AII }\end{array}$ & $\begin{array}{l}369 \\
323 \\
692\end{array}$ & $\begin{array}{l}471 \cdot 23 \\
488.62 \\
479.34\end{array}$ & $\begin{array}{l}115.80 \\
126.80 \\
121.28\end{array}$ & 3.55 & 690 & .060 \\
\hline 6 & $\begin{array}{l}\text { Social Drinkers } \\
\text { Problem Drinkers } \\
\text { All }\end{array}$ & $\begin{array}{l}370 \\
325 \\
695\end{array}$ & $\begin{array}{l}475 \cdot 71 \\
506.53 \\
490.12\end{array}$ & $\begin{array}{r}75.16 \\
121.39 \\
100.60\end{array}$ & 16.60 & 693 & .000 \\
\hline
\end{tabular}

*Test for equality of social and problem drinker means. **Numerator $\underline{\mathrm{df}}=1$. 
TABLE 9. MEANS AND STANDARD DEVIATIONS OF LAI SCALES FOR SOCIAL AND PROBLEM DRINKERS, 6-MONTH INTERVIEW

\begin{tabular}{|c|c|c|c|c|c|c|c|}
\hline \multirow[b]{2}{*}{ Scale } & \multirow[b]{2}{*}{ Group } & \multirow{2}{*}{$\begin{array}{c}\text { Sample } \\
\text { Size }\end{array}$} & \multirow[b]{2}{*}{ Mean } & \multirow[b]{2}{*}{$\mathrm{SD}$} & \multicolumn{3}{|c|}{ Denominator } \\
\hline & & & & & $F^{*}$ & $\mathrm{df} * *$ & $\mathrm{p}$ \\
\hline 1 & $\begin{array}{l}\text { Social Drinkers } \\
\text { Problem Drinkers } \\
\text { A11 }\end{array}$ & $\begin{array}{l}329 \\
278 \\
607\end{array}$ & $\begin{array}{l}529.79 \\
520.07 \\
525.34\end{array}$ & $\begin{array}{l}68.93 \\
82.78 \\
75.68\end{array}$ & 2.49 & 605 & .115 \\
\hline 2 & $\begin{array}{l}\text { Social Drinkers } \\
\text { Problem Drinkers } \\
\text { All }\end{array}$ & $\begin{array}{l}326 \\
255 \\
581\end{array}$ & $\begin{array}{l}460.77 \\
466.77 \\
463.31\end{array}$ & $\begin{array}{l}117.01 \\
119.85 \\
118.20\end{array}$ & 0.34 & 579 & .558 \\
\hline 3 & $\begin{array}{l}\text { Social Drinkers } \\
\text { Problem Drinkers } \\
\text { Al1 }\end{array}$ & $\begin{array}{l}390 \\
321 \\
711\end{array}$ & $\begin{array}{l}503.76 \\
495.27 \\
499.93\end{array}$ & $\begin{array}{l}116.89 \\
110.21 \\
113.92\end{array}$ & 0.98 & 709 & .323 \\
\hline 4 & $\begin{array}{l}\text { Social Drinkers } \\
\text { Problem Drinkers } \\
\text { All }\end{array}$ & $\begin{array}{l}382 \\
321 \\
703\end{array}$ & $\begin{array}{l}505.49 \\
489.12 \\
498.01\end{array}$ & $\begin{array}{l}70.69 \\
71.85 \\
71.64\end{array}$ & 9.22 & 702 & .003 \\
\hline 5 & $\begin{array}{l}\text { Social Drinkers } \\
\text { Problem Drinkers } \\
\text { All }\end{array}$ & $\begin{array}{l}388 \\
312 \\
700\end{array}$ & $\begin{array}{l}475.93 \\
493.63 \\
483.82\end{array}$ & $\begin{array}{l}108.94 \\
131.51 \\
119.76\end{array}$ & 3.79 & 698 & .052 \\
\hline 6 & $\begin{array}{l}\text { Social Drinkers } \\
\text { Problem Drinkers } \\
\text { All }\end{array}$ & $\begin{array}{l}150 \\
118 \\
268\end{array}$ & $\begin{array}{l}481.53 \\
487.47 \\
484.15\end{array}$ & $\begin{array}{l}75.75 \\
71.43 \\
73.80\end{array}$ & 0.42 & 266 & .514 \\
\hline
\end{tabular}

\footnotetext{
*Test for equality of social and problem drinker means. $* *$ Numerator $\underline{\mathrm{df}}=1$.
}

Tables 8, 9, and 10 show the sample means and standard deviations for the Memphis clients on the six LAI scales. The mean scores were all in the neighborhood of 500 and the standard deviations were on the order of 100. Discrepancies of the means and standard deviations from the presumed population values were not considered important for purposes of project evaluation.

Of greatest interest to the evaluation staff were the comparisons of the scale scores for social and problem drinkers. Social drinkers scored significantly higher than problem drinkers on Scale 4 for all three LAI applications (that is, social drinkers had more "social interaction/involvement").

Although the only consistent difference was found for Scale 4 other significant differences were found for some scales. Social drinkers scored significantly higher than problem drinkers on Scale 1 (Employment/Economic Stability) for the 12-month followup application but not on the first two applications. One-sided 
tests would have shown problem drinkers higher on scale 5 (Current Physical Health Problems) for the first two applications.

TABLE 10. MEANS AND STANDARD DEVIATIONS OF LAI SCALES FOR SOCIAL AND PROBLEM DRINKERS, 12-MONTH INTERVIEW

\begin{tabular}{|c|c|c|c|c|c|c|c|}
\hline \multirow[b]{2}{*}{ Scale } & \multicolumn{3}{|c|}{ Sample } & \multirow[b]{2}{*}{ SD } & \multicolumn{3}{|c|}{ Denominator } \\
\hline & Group & Size & Mean & & $F^{*}$ & $\mathrm{df} * *$ & $\mathrm{p}$ \\
\hline 1 & $\begin{array}{l}\text { Social Drinkers } \\
\text { Problem Drinkers } \\
\text { A11 }\end{array}$ & $\begin{array}{l}317 \\
261 \\
578\end{array}$ & $\begin{array}{l}536.42 \\
519.97 \\
528.99\end{array}$ & $\begin{array}{l}63.88 \\
83.10 \\
73.58\end{array}$ & 7.23 & 576 & .007 \\
\hline 2 & $\begin{array}{l}\text { Social Drinkers } \\
\text { Problem Drinkers } \\
\text { A11 }\end{array}$ & $\begin{array}{l}295 \\
233 \\
528\end{array}$ & $\begin{array}{l}461.56 \\
450.93 \\
456.87\end{array}$ & $\begin{array}{l}114.12 \\
126.52 \\
119.75\end{array}$ & 1.03 & 526 & .312 \\
\hline 3 & $\begin{array}{l}\text { Social Drinkers } \\
\text { Problem Drinkers } \\
\text { A11 }\end{array}$ & $\begin{array}{l}378 \\
295 \\
673\end{array}$ & $\begin{array}{l}495.76 \\
486.29 \\
491.61\end{array}$ & $\begin{array}{l}113.78 \\
108.62 \\
111.57\end{array}$ & 1.19 & 671 & .275 \\
\hline 4 & $\begin{array}{l}\text { Social Drinkers } \\
\text { Problem Drinkers } \\
\text { A11 }\end{array}$ & $\begin{array}{l}355 \\
287 \\
642\end{array}$ & $\begin{array}{l}499.16 \\
485.95 \\
493.25\end{array}$ & $\begin{array}{l}66.38 \\
66.63 \\
66.76\end{array}$ & 6.26 & 640 & .013 \\
\hline 5 & $\begin{array}{l}\text { Social Drinkers } \\
\text { Problem Drinkers } \\
\text { A11 }\end{array}$ & $\begin{array}{l}368 \\
281 \\
649\end{array}$ & $\begin{array}{l}473 \cdot 81 \\
479 \cdot 44 \\
476.25\end{array}$ & $\begin{array}{l}116.77 \\
117.42 \\
116.95\end{array}$ & 0.37 & 647 & .543 \\
\hline 6 & $\begin{array}{l}\text { Social Drinkers } \\
\text { Problem Drinkers } \\
\text { All }\end{array}$ & $\begin{array}{l}127 \\
100 \\
227\end{array}$ & $\begin{array}{l}474.89 \\
484.08 \\
478.94\end{array}$ & $\begin{array}{l}58.21 \\
79.37 \\
68.33\end{array}$ & 1.01 & 225 & .316 \\
\hline
\end{tabular}

*Test for equality of social and problem drinker means. **Numerator $\underline{\mathrm{df}}=1$.

Although two of the LAI scales purport to measure drinking behavior, neither was consistently related to problem drinking (as measured by the Project's criteria). Problem drinkers were significantly higher on Scale 6 (Immoderate Drinking Behavior) for the initial interview only. But there were no significant differences on Scale 2 (Current Drinking Pattern). It should be noted that it was generally in the clients' interest to be less than honest about drinking problems (see Appendix F). The relationship between the LAI scale and DWI recidivism are discussed in Appendix E.

Overall, it must be concluded the LAI scales do not measure dimensions on which problem and social drinkers (as classified by the Project's criteria) differed. While subsequent analyses 
will show that the Project's classification procedure was valid (in that it predicted recidivism), it is shown in Appendix $E$ that the LAI scales did not predict recidivism.

\section{Data Storage and Computer Programming}

The evaluation staff made extensive use of the facilities of the Vanderbilt University Computer Center (VUCC) for data storage and analysis. Data generated by the Project were stored on a private disk pack at VUCC, with backup files on magnetic tapes. The disk pack and tapes were accessible only to the Project evaluation staff. Although some preliminary data analysis were done on the VUCC Sigma-7 computer, all of the analyses used for the final evaluation of the Project were performed on the VUCC DECSystem 1099 .

All computer programming required for the Project was done by the Project evaluation staff. Several types of programming were necessary in order to obtain the final evaluation results.

First, since most of the followup data was stored in the form of dates of particular types of events it was necessary to transform the data into variables which could be analyzed with common statistical programs. FORTRAN programs were written to take the followup data together with program referral dates and determine the following: length of followup period (at least 2 years for observation of DWI rearrests and $\frac{1}{2}$ years for MVR data, unless shortened by death); number of events (rearrest/

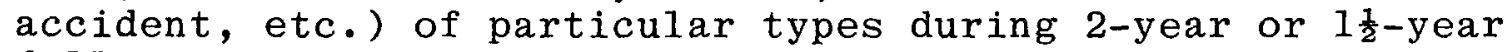
followup period; number of non-DWI moving violations and number of accidents within 2 years prior to referral; time in days from arrest to referral; and time in days from referral to first DWI rearrest, first moving violation, and first accident (if any).

The transformed followup data were then in a form which could be analyzed with available statistical packages. The analyses presented in this report involved a number of different programs. Most univariate tests were performed using the cross-tabulation and ANOVA facilities of SPSS (Nie et al., 1975). Mulitway contingency tables were analyzed using BMDP3F, and the repeated LAI interviews were analyzed with BMDP2V (Dixon \& Brown, 1979). The plots were based on statistics generated by the SPSS SURVIVAL (life table) routine, which were read into a FORTRAN program which used various CALCOMP plotting routines to drive VUCCs Zeta plotter. 


\section{EVALUATION OF TREATMENT EFFECTIVENESS}

Three types of event were used for evaluation of the effectiveness of the treatments--rearrests for DWI, convictions for nOn=aleghol-related moving traffic violations, and accidents. (FQ1 10wu LAI interviews were also used, but will be treated separately,) Each type of criterion event was analyzed separately for each drinker type.

Fer each type of event, eight hypotheses were tested (as speeified in the Detailed plan). If $\mu$ denotes the mean of a group en any ef the three exiterion measures and the subscripts $\underline{c}, \mathfrak{p}$, r, pr, S, and p refer to control, probation-only, rehabilitationQn 1 probation-plus-rehabilitation, social drinker, and problem drinker, respectively, the hypotheses can be written as follows:

1. There will be differences between the recidivism rates frer the four groups. $H_{0}: \mu_{c}=\mu_{p}=\mu_{r}=\mu_{p r}$.

2. The groups receiving either or both of supervised probation or rehabilitation will have lower recidivism rates than the eontrol groups. $H_{0}: \mu_{c} \leq 1 / 3\left(\mu_{p}+\mu_{r}+\mu_{p r}\right)$.

3. The supervised probation-only groups will have lower reeidivism rates than the control groups. $\mathrm{H}_{\mathrm{o}}$ : $\mu_{\mathrm{c}} \leq \mathrm{w}_{\mathrm{p}}$.

4. The rehabilitation-only groups will have lower recidivism rates than the control groups. $\mathrm{H}_{\mathrm{O}}: \mu_{\mathrm{c}} \leq \mu_{\mathrm{c}}$.

5. The probation-plus-rehabilitation groups will have lower recidivism rates than the control groups. $\mathrm{H}_{\mathrm{o}}: \mathrm{m}_{\mathrm{c}} \leq \mu_{\mathrm{p} r}$

6. The probation-plus-rehabilitation groups will have lower recidivism rates: than the probation-only groups. Ho: Ho $_{0} \leq$ prom $^{\infty}$

7. The probation-plus-rehabilitation groups will have lower recidivism rates than the rehabilitation-only groups;.

$\mathrm{H}_{\mathrm{g}}: \mu_{\mathrm{r}} \leq \mu_{\mathrm{pr}}$

8. Social drinkers; will have lower recidivism rates than problem drinkers. $\mathrm{H}_{\mathrm{O}}$ : $\mathrm{H}_{\mathrm{R}} \leq \mathrm{s}$

For each of the three types of criterion event, simplies effrects of the four treatments (using no control variabless), were analyzed in three ways:

1. Analysis of variance of mean numbers of events durimg $a_{1} f_{1} i x e d$ followup period ( 2 years; for DWI, li years; for aceidemts and for other vilolations);

2. Comparison of percentage of clients; who expeniemced att lieast one event during; the fixed followap peniod; 
3. Life table analysis of the distributions of time from referral to the first event.

Although it would be surprising to obtain grossly disparate results from the three types of analyses, it was felt that the three analyses presented a more complete picture of the results; in particular, the life table analyses made use of data collected over longer than the minimum fixed followup period that was used for the other types of analysis. Due to the multiplicity of the tests employed, as well as to their nonorthogonality, the precise confidence level of the findings is unknown. However, it will be seen that the nature of the findings makes any quibbling about the confidence level pointless.

Data on prior DWI arrests, interim DWI arrests, prior nonDWI traffic violations, and prior accidents were also available to the evaluation staff. Additional analyses of the followup data were performed using the data on prior events along with the treatment variable and other predictors. Both additive and interactive effects were examined. Also, analyses of DWI rearrests were performed controlling for variables which are shown in Appendix B to be unevenly distributed among the treatment groups.

\section{DWI Rearrests}

\section{Crude Treatment Effects}

The project was designed to allow a 2 year followup period (from date of referral by the court) for all clients. Therefore, tables 11 and 12, which summarize data on DWI rearrests within a 2 year followup period, include all clients except those who died during that period.

Table 11 shows the average number of DWI rearrests of clients in the various treatments during the first two years following referral to the project. Social drinkers averaged 0.15 rearrests while problem drinkers averaged 0.23 rearrests. The mean for problem drinkers was significantly higher than that for social drinkers, indicating that the procedure for classifying the clients was effective in distinguishing a higher-risk group from a lowerrisk group. (The same conclusion can be drawn from Table 12.)

Among social drinkers, those in the control group had the lowest average number of rearrests (0.12) while those in the group that received only probation supervision had the highest average rearrests $(0.18)$. An F test indicated that the means did not differ significantly from each other. Because the control group had the lowest average number of rearrests, the one-sided $t$ tests were nonsignificant.

Among problem drinkers, the control group and the group receiving both rehabilitation and probation supervision had the 
TABLE 11. MEAN NUMBER OF DWI REARRESTS WITHIN 2 YEARS FOLLOWING REFERRAL TO THE PROJECT, BY DRINKER TYPE AND TREATMENT

\begin{tabular}{lrc}
\hline Treatment & $\begin{array}{c}\text { Sample } \\
\text { Size }\end{array}$ & $\begin{array}{c}\text { Mean Number } \\
\text { of Rearrests }\end{array}$ \\
\hline Social Drinkers & 2506 & 0.15 \\
Control & 613 & 0.12 \\
Probation-only & 633 & 0.18 \\
Rehabilitation-only & 627 & 0.15 \\
Probation + Rehabilitation & 633 & 0.15 \\
& & 0.23 \\
Problom Drinkers & 1622 & 0.22 \\
Control & 419 & 0.23 \\
Probation-only & 396 & 0.25 \\
Rehabilitation-only & 399 & 0.22 \\
Probation + Rehabilitalion & 408 &
\end{tabular}

Significance Tests $\begin{gathered}\text { Statis- } \\ \text { tic* }\end{gathered}$ Value df $\quad p$

Social Drinkers

Overall test for treatment

differences

All other treatments vs. Con.

Pro.-only vs. Con.

Rehab.-only vs. Con.

Pro. + Rehab. vs. Con.

Pro. + Rehab. vs. Pro.

Pro. + Rehab. vs. Rehab.

$\begin{array}{rrrr}\frac{F}{t} & 1.712 & 3,2502 & .163 \\ \frac{t}{t} & -1.787 & 2502 & ---- \\ \frac{t}{t} & -2.249 & 2502 & ---- \\ \frac{t}{t} & -0.946 & 2502 & ---- \\ \underline{t} & -1.199 & 2502 & ---- \\ & 1.314 & 2502 & .099 \\ & 0.257 & 2502 & .399\end{array}$

Problem Drinkers

Overall test for treatment

differences

All other treatments vs. Con.

Pro.-only vs. Con.

Rehab.-only vs. Con.

Pro, + Rehab. vs. Con.

Pro. + Rehab. vs. Pro.

Pro. + Rehab. vs. Rehab.

$\begin{array}{rrrr}\frac{F}{t} & 0.360 & 3,1618 & .782 \\ \frac{t}{t} & -0.258 & 1618 & ---- \\ \frac{t}{t} & -0.085 & 1618 & ---- \\ \frac{\mathrm{t}}{\mathrm{t}} & -0.767 & 1618 & --- \\ \bar{t} & 0.227 & 1618 & .408 \\ & 0.308 & 1618 & .373 \\ & 0.986 & 1618 & .170\end{array}$

Social Drinkers vs. Problem

Drinkers

$\underline{\mathrm{t}} \quad 5.560 \quad 4126 \quad .000$

*t tests are one-sided. For each drinker type, tests are based on a pooled estimate of variance for all four groups. A negative value of $t$ indicates difference in direction opposite that hypothesized. 
TABLE 12. PERCENTAGE REARRESTED FOR DWI WITHIN 2 YEARS FOLLOWING REFERRAL TO THE PROJECT, BY DRINKER TYPE AND TREATMENT

\begin{tabular}{|c|c|c|c|}
\hline Treatment & $\begin{array}{c}\text { Sample } \\
\text { Size }\end{array}$ & $\begin{array}{c}\text { Number } \\
\text { Rearrested }\end{array}$ & $\begin{array}{l}\text { Percentage } \\
\text { Rearrested }\end{array}$ \\
\hline Social Drinkers & 2506 & 322 & 12.8 \\
\hline Control & 613 & 65 & 10.6 \\
\hline Probation-onjy & 633 & 90 & 14.2 \\
\hline Rehabilitation-only & 627 & 83 & 13.2 \\
\hline Probation + Rehabilitation & 633 & 84 & 13.3 \\
\hline Problem Drinkers & 1622 & 308 & 19.0 \\
\hline Control & 419 & 78 & 18.6 \\
\hline Probation-on $1 y$ & 396 & 78 & 19.7 \\
\hline Rehabilitation-only & 399 & 80 & 20.1 \\
\hline Probation + Rehabilitation & 408 & 72 & 17.6 \\
\hline
\end{tabular}

Significance Tests $\begin{gathered}\text { Statis- } \\ \text { tic* Value }\end{gathered}$ df

Social Drinkers

Overall test for treatment

differences

Al1 other treatments vs. Con.

pro.-only vs. Con.

Rehab.-only vs. Con.

Pro. + Rehab. vs. Con.

Pro. + Rehab. vs. Pro.

Pro. + Rehab. vs. Rehab.

$\begin{array}{crcc}\chi^{2} & 4.004 & 3 & .261 \\ \frac{t}{t} & -1.911 & 2502 & --- \\ \frac{t}{t} & -1.906 & 2502 & --- \\ \frac{t}{t} & -1.386 & 2502 & ---- \\ \frac{t}{t} & 0.506 & 2502 & ---- \\ -0.017 & 2502 & .307 \\ & & \end{array}$

Problem Drinkers

Overall test for treatment

differences

All other treatments vs. Con.

Pro.-only vs. Con.

Rehab.-only vs. Con.

Pro. + Rehab. vs. Con.

Pro. + Rehab. vs. Pro.

Pro. + Rehab. vs. Rehab.

$\begin{array}{crcc}\chi^{2} & 0.937 & 3 & .817 \\ \frac{t}{t} & -0.232 & 1618 & ---- \\ \frac{\mathrm{t}}{\mathrm{t}} & -0.393 & 1618 & ---- \\ \frac{\mathrm{t}}{\mathrm{t}} & 0.522 & 1618 & ---\overline{-} \\ \mathrm{t} & 0.755 & 1618 & .362 \\ & 0.869 & 1618 & .230 \\ & & 1618 & .192\end{array}$

Social Drinkers vs. Problem

Drinkers

t $\quad 5.313 \quad 4126 \quad .000$

*t tests are one-sided. For each drinker type, tests are based on a pooled estimate of variance of all four groups. A negative value of $\underline{t}$ indicates a difference in direction opposite that hypothesized. 
smallest average rearrests $(0.22)$ while the rehabilitation-only group had the highest average (0.25). The $F$ test was not significant, nor were any of the contrasts between treatments.

Table 12 disregarded the number of rearrests during the 2 year period and considered only whether or not a rearrest occurred. It shows that $12.8 \%$ of the social drinkers were rearrested at least once while $19.0 \%$ of the problem drinkers were rearrested.

Among social drinkers, the control group had the lowest rearrest rate $(10.6 \%)$ while the probation-only group had the highest $(14.2 \%)$. A chi-square test indicated no differences between the 2 year rearrest rates for the four treatments. None of the $t$ tests were significant. Similarly, there were no significan $\bar{t}$ differences between the 2 year rearrest rates for the four treatments for problem drinkers. Among problem drinkers, the probationplus-rehabilitation group had the lowest rearrest rate $(17.6 \%)$ while the rehabilitation-only group had the highest rate $(20.1 \%)$.

Life table estimates of the cumulative rearrest rates for up to 42 months ( $3 \frac{1}{2}$ years) are shown in Figure 1 and Figure 2. In Figure 1 it can be seen that the control group for social drinkers had the lowest rearrest rate, represented by the lowest 1 ine on the graph, while the probation-only group had the highest rearrest rate. Log-rank tests (not tabled) for equality for the four distributions showed no statistically significant differences between the distributions.

Figure 2 shows the cumulative arrest rates for problem drinkers. All four distributions are very close together throughout the followup period. Log-rank tests (not tabled) once more confirmed that there were no statistically significant differences between the distributions.

Figures 1 and 2 are drawn to the same scale, and it can be seen that all of the lines in Figure 2 are higher than the lines in Figure 1. This indicates that the rearrest rates for all of the problem drinker groups were higher than the rearrest rates for the social drinker groups. While $19 \%$ of the problem drinkers were rearrested within two years, the 2 year rearrest rate for social drinkers was only $12.8 \%$. Both $\mathrm{F}$ and $x^{2}$ tests were performed (on the 24 month means and percentages respectively) and are included on tables 11 and 12. The tests showed that problem drinkers had significantly higher rearrest rates than social drinkers (beyond the .001 level of significance).

In summary, the above analyses, which compared the DWI rearrest rates of the four treatment groups for each drinker type without controlling for any other possible explanatory variables, showed no evidence of recidivism-reduction effects of any of the treatments. It was found, however, that problem drinkers had significantly higher rearrest rates than social drinkers, a result that tends to validate the drinker-type classification procedure. 


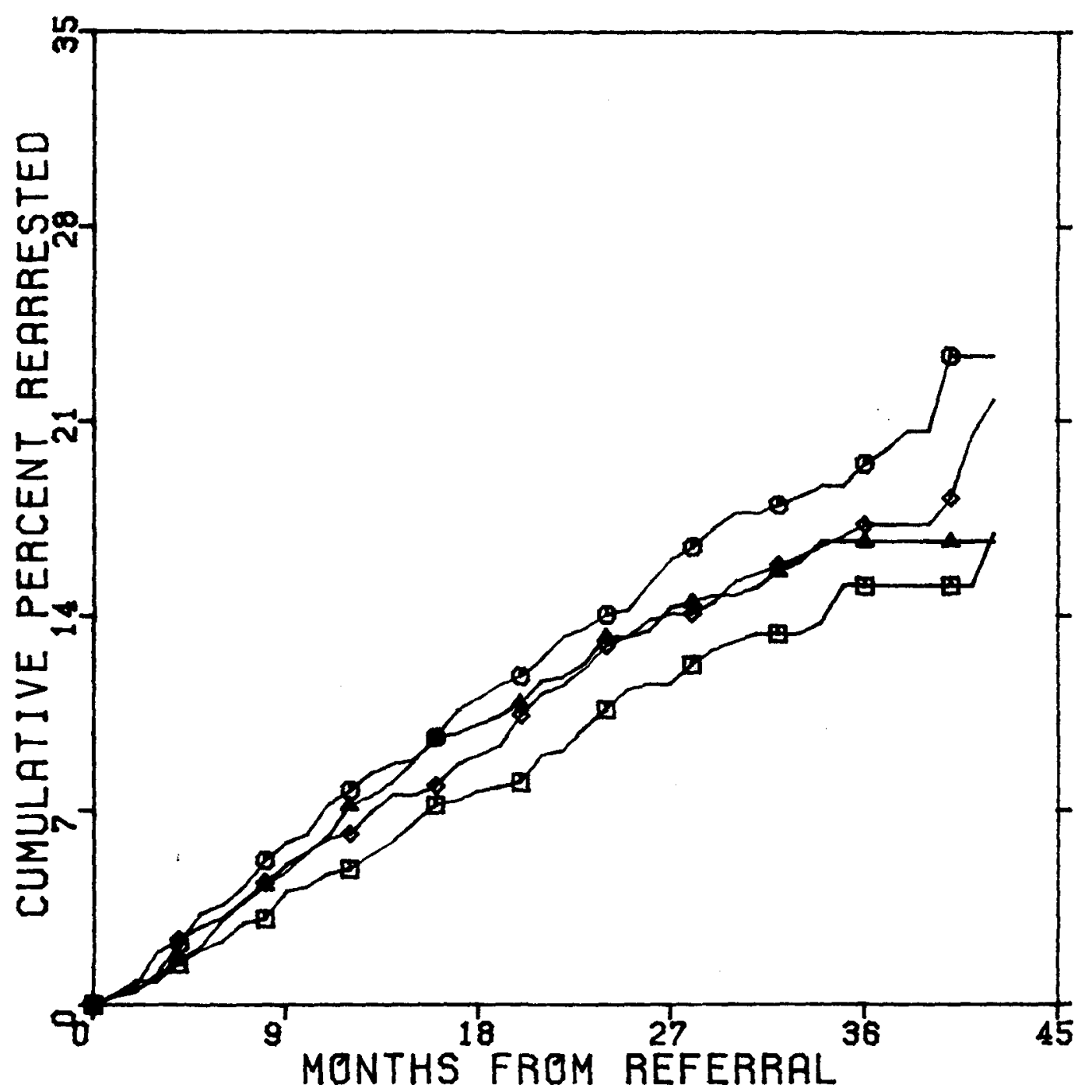

(] CONTROL

$\triangle$ REHAB-ONLY
O PROBATION-ONLY

- PRUBATN-REHAB

FIGURE 1. TIME FROM REFERRAL TO FIRST DWI REARREST, FOR SOCIAL DRINKERS, BY TREATMENT 


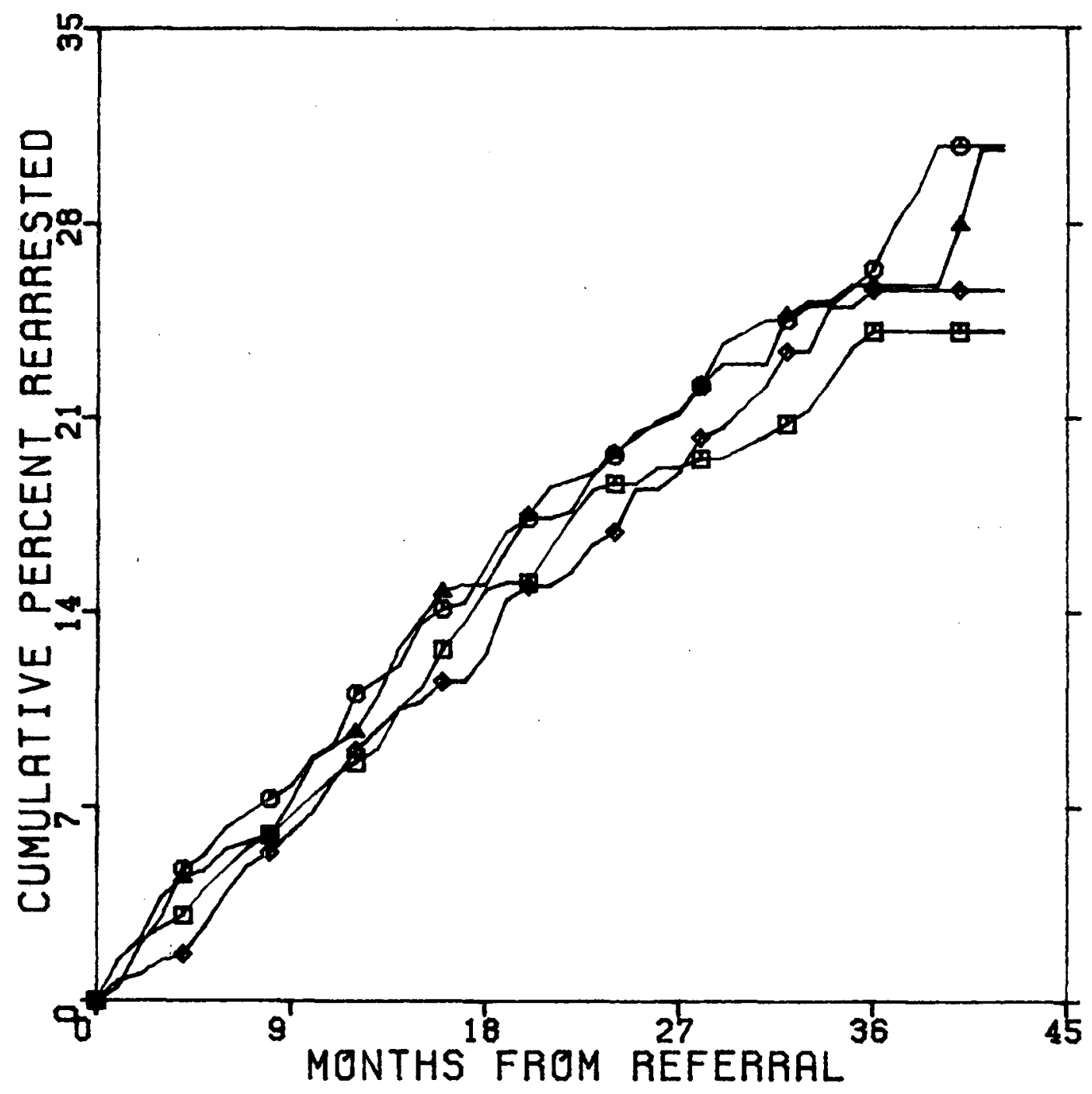

๑ CONTROL

$\triangle$ REHAB-ONLY
(1) PROBATION-ONLY

$\diamond$ PRUBATN-REHAB

FIGURE 2. TIME FROM REFERRAL TO FIRST DWI REARREST, FOR PROBLEM DRINKERS, BY TREATMENT 
Effects of Treatment, LAI Administration,

prior Arrest, and Diversion Status

In the previous section DWI rearrests were analyzed without regard to the possible effects of any other variables. However, there are several other variables which might be hypothesized to have effects on recidivism, and those variables might conceivably interact with treatment variables.

It has been hypothesized (see Appendix F) that the administration of the Life Activities Inventory (LAI) might serve by itself to reduce recidivism, since the LAI administrations required long-term periodic contact of the client with the DWI Probation staff. Further, it might be hypothesized that any such effect could be most evident in the control groups, since those groups otherwise had the least contact with the counselors. While there is no evidence in Figure 3 of any crude effects of LAI administration, given the above hypothesis it is still worthwhile to look for interactions of LAI administration with treatment modality.

If indeed there was an interactive effect of LAI with treatment on rearrest, it is not unlikely that other factors are also involved. Two other variables of particular interest are diversion status and prior DWI arrest. Because nondiversion-qualified clients had previous criminal records, those clients might be expected to have a high risk of subsequent arrests. Figure 4 shows that, indeed, diversion clients classified as social drinkers did have lower DWI rearrest rates than nondiversion social drinkers. However, diversion clients classified as problem drinkers did not have significantly lower rearrest rates than nondiversion problem drinkers. Log-rank tests (not tabled) confirmed the impressions from the graph: social drinkers on diversion had significantly lower rearrest rates than the other three groups, while the other three groups did not differ among themselves. Hence, diversion status interacted with drinker type in affecting recidivism, and it may be worthwhile to explore the possibility of other interactions.

Finally, as has already been mentioned in this report, even though all of the clients were regarded by the court as first offenders at DWI, many had actually been arrested (i.e., asked to take breath test) prior to the arrest that resulted in referral to the project. It can clearly be seen in Figure 5 that clients with prior arrests had much higher rates of subsequent arrest than those without prior arrests.

Multidimensional contingency table methods were used to simultaneously test for effects of the various predictor variables on DWI rearrest. The methods were chosen because they were not subject to the problem of heteroscedasticity, and because interactive effects of the predictors could be handled easily. Separate analyses were performed for social and for problem drinkers. The variables which were cross tabulated are the following: 


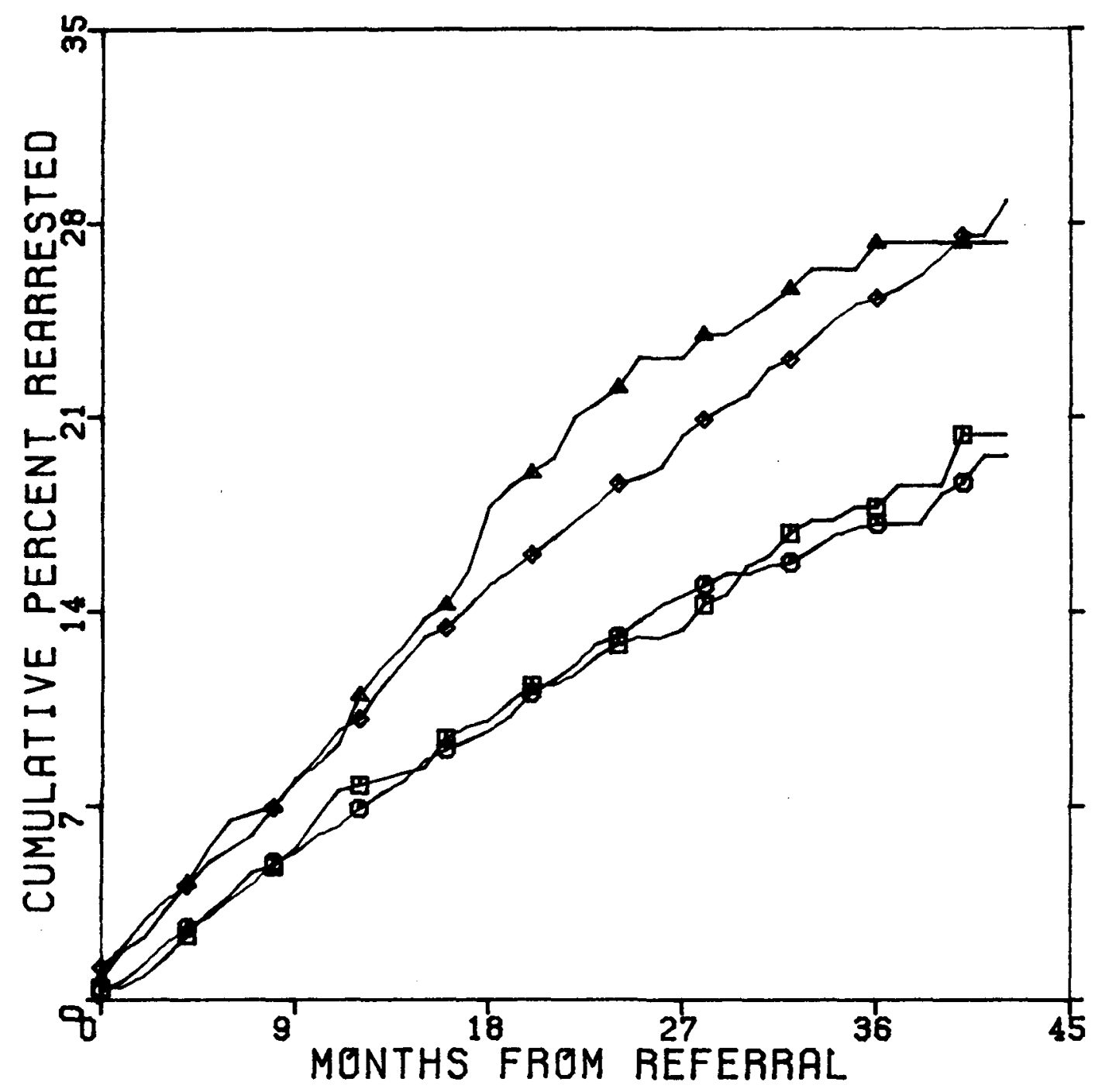

$\begin{array}{ll}\square \text { SOCIAL-LAI } & \text { (1) SOCIAL-NO LAI } \\ \triangle \text { PROBLEM-LAI } & \diamond \text { PROBLEM-NO LAI }\end{array}$

FIGURE 3. TIME FROM REFERRAL TO

FIRST DWI REARREST, BY DRINKER

TYPE AND LAI ADMINISTRATION 


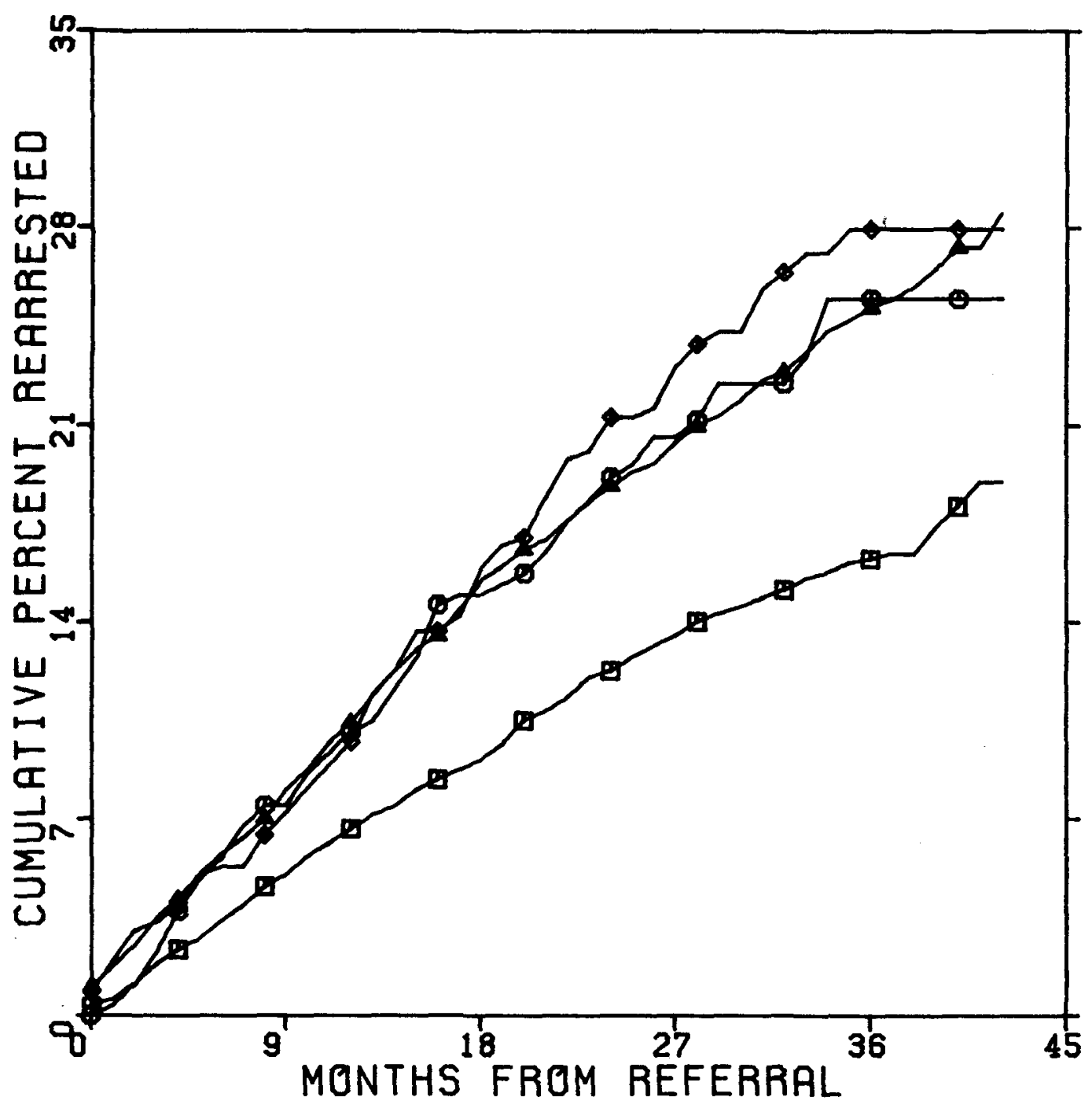

(7) SOCIAL-DIVERSN

(1) SOCIAL-NONDIV

$\triangle$ PROBLM-DIVERSN

$\diamond$ PROBLM-NONDIV

FIGURE 4. TIME FROM REFERRAL TO

FIRST DWI REARREST, BY DRINKER

TYPE AND DIVERSION STATUS 


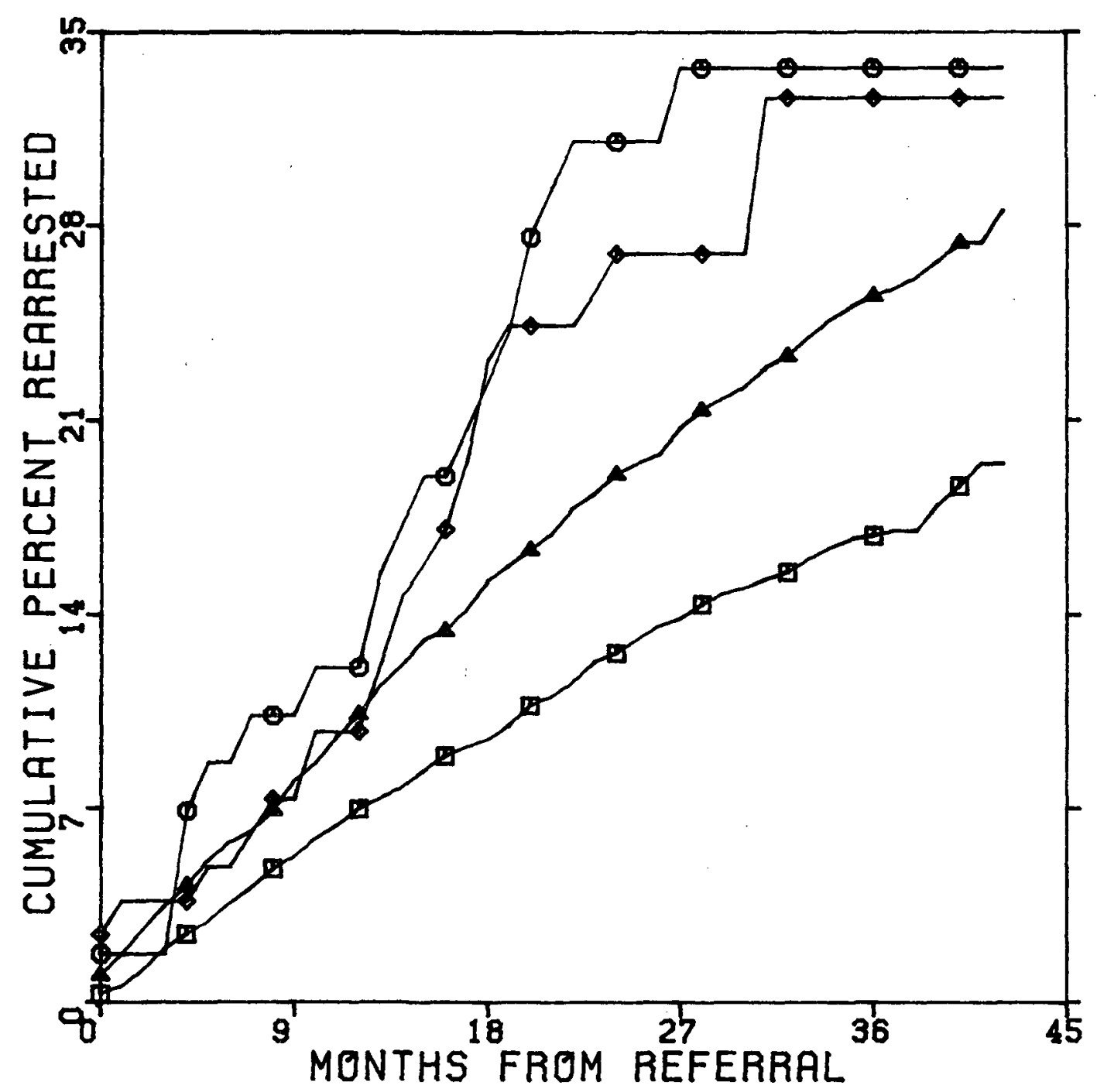
(]) SOCIAL-NONE
(1) SOCIAL-PRIOR
$\triangle$ PROBLEM-NONE
$\diamond$ PROBLEM-PRIOR

FIGURE 5. TIME FROM REFERRAL TO

FIRST DWI REARREST, BY DRINKER

TYPE AND PRIOR DWI ARREST 
1. DWI rearrest within 24 months (yes or no);

2. Treatment (Categories: Control, Probation-onlyRehabilitation-only, Probation-plus-Rehabilitation);

3. LAI administration (yes or no);

4. Diversion status (on diversion or not);

5. Prior arrest (yes or no).

The results of the cross tabulations are shown in tables 13 and 14.

In order to determine the effects of the predictor variables on recidivism it was necessary to first obtain parsimonious loglinear models (for each drinker type) for the relationships among the variables. A criterion of parsimony was that the models contain the fewest possible relationships involving the dependent variable rearrest. Therefore, the first model considered was saturated with respect to the predictors, and treated rearrest as independent of the predictors. Then a forward stepwise procedure was used to test for significant relationships between rearrest and the other variables. Higher-order terms involving rearrest were tested only if all subsumed lower-order terms were significant. Finally, unnecessary relationships among the predictors were eliminated. Overall fit of a model to the data was necessary but not sufficient for final model acceptability.

Table 15 shows the results of various log-linear models for Table 13. The first model inciudes all possible relationships between the predictors, but none involving rearrest. It can be seen that the model did not give a satisfactory fit to the data. Models (2), (3), (4), and (5) each included the effects of a single predictor on rearrest. Both diversion status and prior arrest added significantly to the fit of the model. Further, both variables made independent contributions to the model, as shown by the fact that diversion status still had a significant effect even when prior arrest was included in the mode1. In Model ( 7 ), an interactive effect of diversion status and prior arrest on rearrest was added, and found to contribute significantly. An additional model ( 8 ), which included an interactive effect of LAI administration and treatment on rearrest was also tried, but the added effect did not contribute significantly to the predictive power of the model. (This model violated the rules described above, given the results of models (3) and (4), but it was tried because its appropriateness had been suggested by preliminary results from the Mississippi DWI Probation Follow-Up Demonstration Project.)

Simplification of the model with respect to the predictors was accomplished by dropping all relationships involving treatment and LAI administration. This was justified since it had been shown that neither variable was related to rearrest, and since neither variable was related to the other predictors as a result of random assignment (see Appendix $B$ ). Hence, the final model included only the three-way relationship between rearrest, prior arrest, and diversion status, and provided a satisfactory fit 
TABLE 13. CROSS TABULATION OF DWI REARREST (WITHIN 24 MONTHS) WITH PREDICTOR VARIABLES (SOCIAL DRINKERS)*

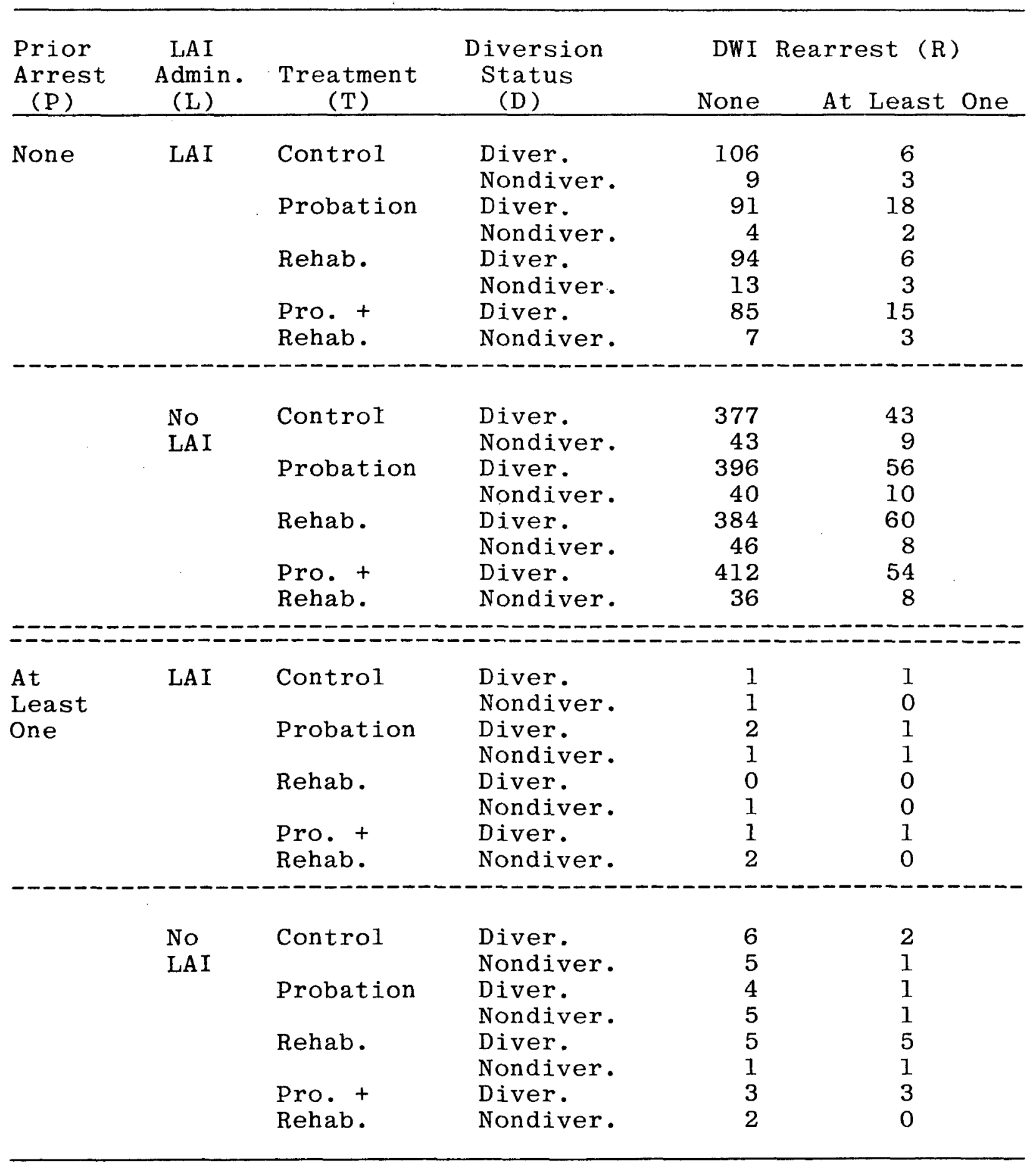

* Total sample size $=2505$ 
TABLE 14. CROSS TABULATION OF DWI REARREST (WITHIN 24 MONTHS) WITH PREDICTOR VARIABLES (PROBLEM DRINKERS)*

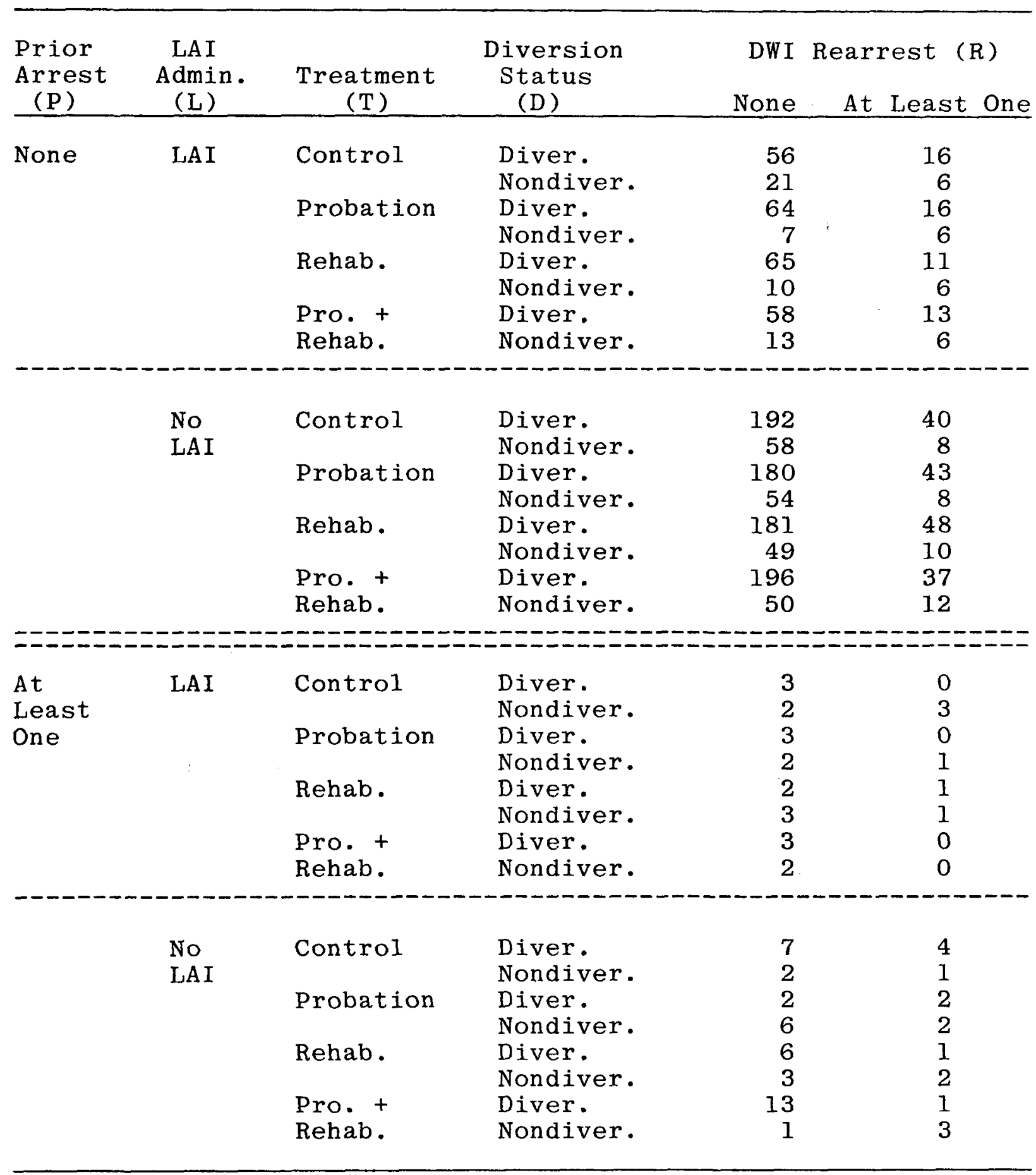

*Total sample size $=1622$ 
to the entire five-way contingency table. For further explanation of relationships involving DWI rearrest, see Appendix D.

TABLE 15. TESTS OF LOG-LINEAR MODELS FOR TABLE 13 (SOCIAL DRINKERS )

\begin{tabular}{|c|c|c|c|c|c|c|}
\hline Model & $\begin{array}{l}x^{2} \text { for } \\
\text { Effects } \\
\text { Added or } \\
\text { Deleted* }\end{array}$ & $\mathrm{df}$ & $\mathrm{p}$ & $\begin{array}{l}x^{2} \text { for } \\
\text { Model } \\
\text { Fit* }\end{array}$ & $d f$ & $\mathrm{p}$ \\
\hline $\begin{array}{l}\text { (1) DTLP, R** } \\
\text { (2) DTLP, RD [add RD to (1)] } \\
\text { (3) DTLP, RT [add RT to (1)] } \\
\text { (4) DTLP, RL [add RL to (1)] } \\
\text { (5) DTLP, RP [add RP to (1)] } \\
\text { (6) DTLP, RP, RD } \\
\text { [add RD to (5)] } \\
\text { (7) DTLP, RDP [add RDP to (6)] } \\
\text { (8) DTLP, RDP, RTL } \\
\text { [add RTL to (7)] } \\
\text { (9) T, L, RDP [delete relations } \\
\text { involving T\&L from (7)] }\end{array}$ & $\begin{array}{r}--\overline{1} \\
12.90 \\
3.92 \\
0.10 \\
23.53 \\
7.65 \\
5.57 \\
7.33\end{array}$ & $\begin{array}{r}- \\
1 \\
3 \\
1 \\
1 \\
1 \\
1\end{array}$ & $\begin{array}{l}.--- \\
.000 \\
.271 \\
.748 \\
.000\end{array}$ & $\begin{array}{l}58.07 \\
45.07 \\
54.16 \\
59.97 \\
34.55\end{array}$ & $\begin{array}{l}31 \\
30 \\
28 \\
30 \\
30\end{array}$ & $\begin{array}{l}.002 \\
.037 \\
.002 \\
.002 \\
.260\end{array}$ \\
\hline
\end{tabular}

\footnotetext{
* Likelihood ratio $x^{2}$.

**Variable codes are as follows:

(R) DWI rearrest within 24 months

(T) Treatment modality

(D) Diversion status

(L) LAI administration

(P) Prior DWI arrest.
}

The procedure that was used for the social-drinker data was used separately to obtain a model for the problem-drinker data (Table 14). As shown in Table 16, Model (1), which excluded any relationships between the predictors and rearrest, gave a satisfactory fit. However, the forward stepwise procedure was still used to test for significant contributions of relationships involving rearrest.

Only the relationship between prior arrest and rearrest made a statistically significant contribution to the fit of the model, although the relationships involving both LAI administration and diversion status made almost-significant contributions. However, from models (6) and (7) it can be seen that with the prior arrestrearrest term in the model, there were no significant relationships between either LAI administration or diversion status and rearrest. Further, Model (8) shows no interactive effects of LAI and treatment on rearrest. 
TABLE 16. TESTS OF LOG-LINEAR MODELS FOR TABLE 14 (PROBLEM DR INKERS )

\begin{tabular}{|c|c|c|c|c|c|c|}
\hline Model & $\begin{array}{l}x^{2} \text { for } \\
\text { Effects } \\
\text { Added or } \\
\text { Deleted* }\end{array}$ & $\mathrm{df}$ & $p$ & $\begin{array}{l}x^{2} \text { for } \\
\text { Mode1 } \\
\text { Fit* }\end{array}$ & $\mathrm{df}$ & $\mathrm{p}$ \\
\hline $\begin{array}{l}\text { (1) DTLP, R** } \\
\text { (2) DTLP, RD [add RD to (1)] } \\
\text { (3) DTLP, RT [add RT to (1)] } \\
\text { (4) DTLP, RL [add RL to (1)] } \\
\text { (5) DTLP, RP [add RP to (1)] } \\
\text { (6) DTLP, RP, RL } \\
\text { [add RL to (5)] } \\
\text { (7) DTLP, RP, RD } \\
\text { [add RD to (5)] } \\
\text { (8) DTLP, RP, RTL } \\
\text { [add RTL to (5)] } \\
\text { (9) T, L, DP, RP [delete re- } \\
\text { lations involving T\&L } \\
\text { from (5)] }\end{array}$ & $\begin{array}{l}---- \\
2.03 \\
0.92 \\
3.12 \\
7.21 \\
2.61 \\
1.20\end{array}$ & $\begin{array}{c}-- \\
1 \\
3 \\
1 \\
1\end{array}$ & $\begin{array}{l}--- \\
.154 \\
.821 \\
.078 \\
.007 \\
.106\end{array}$ & $\begin{array}{l}39.47 \\
37.43 \\
38.55 \\
36.35 \\
32.25 \\
29.64\end{array}$ & $\begin{array}{l}31 \\
30 \\
28 \\
30 \\
30 \\
\\
\\
29\end{array}$ & $\begin{array}{l}.142 \\
.165 \\
.089 \\
.200 \\
.356 \\
.432\end{array}$ \\
\hline
\end{tabular}

*Likelihood ratio $\chi^{2}$.

**Variable codes are as follows:

(R) DWI rearrest within 24 months

(T) Treatment modality

(D) Diversion status

(L) LAI administration

(P) Prior arrest.

In Model (9) all relationships involving LAI administration and treatment were removed from the model, because of their independence of the other variables. This left only the relationships between rearrest and prior arrest and that between prior arrest and diversion in the model, but nevertheless provided an adequate fit to the full five-way contingency table.

In summary, there was no evidence of any interaction of treatment with LAI affecting DWI rearrest for either social or problem drinkers. Nor were there any simple effects of treatment or LAI. However, effects of both prior arrest and diversion status were found (see Appendix $D$ for further analyses).

\section{Effects of Treatment, Sex, and Race}

It is shown in Appendix $B$ that the treatment groups were not well-equalized with respect to sex and race composition despite the randomized treatment-assignment procedure. In this 
section the effects of sex and race will be examined along with those of treatment to determine if, by some strange coincidence, the previous finding of no treatment effects was due to differences in the compositions of the treatment groups.

It is not the purpose of these analyses to identify interactive effects of sex or race with treatment on DWI rearrest. Such interactive effects would not depend on the actual compositions of the treatment groups and are a logical possibility not only for sex and race but for any of the variables considered in the previous section. However, given the slightly unequal distributions of sex and race among the treatment groups there is a possibility that logarithmicly additive effects of the treatments were hidden by the relationships between treatment and sex and race.

The approach that was used was to first consider a Model (1) that was saturated with respect to sex (S), race (Q), and treatment ( $T$ ), and included all two-way relationships involving rearrest (R). Table 17 shows that the model provided a satisfactory fit to the data for both social and problem drinkers. In Model (2) the treatment-rearrest relationships was removed. Table 17 shows that the reduced model still provided an adequate fit, and that the fit was not significantly diminished by the removal of the treatment-rearrest term, for either social or problem drinkers. These results can be interpreted to indicate that there were no treatment effects, controlling for sex and race.

TABLE 17. TESTS OF LOG-LINEAR MODELS FOR EFFECTS OF TREATMENT, SEX, AND RACE

\begin{tabular}{|c|c|c|c|c|c|c|}
\hline Mode1 & $\begin{array}{l}\text { for } \\
\text { fects } \\
\text { Deleted* }\end{array}$ & $\mathrm{df}$ & $\mathrm{p}$ & $\begin{array}{l}x^{2} \text { for } \\
\text { Model } \\
\text { Fit* } \\
\end{array}$ & $\mathrm{df}$ & $\mathrm{p}$ \\
\hline \multicolumn{7}{|l|}{ Social Drinkers } \\
\hline $\begin{array}{c}\text { (1) TSP, RT, RS, RQ** } \\
\text { (2) TSQ, RS, RQ [delete } \\
\text { RT from (1)] }\end{array}$ & 3.86 & -- & .277 & $\begin{array}{l}13.34 \\
17.20\end{array}$ & $\begin{array}{l}10 \\
13\end{array}$ & $\begin{array}{r}.205 \\
.190\end{array}$ \\
\hline \multicolumn{7}{|l|}{ Problem Drinkers } \\
\hline $\begin{array}{c}\text { (1) } \mathrm{TSQ}, \mathrm{RT}, \mathrm{RS}, \mathrm{RQ} \\
\text { (2) TSQ, RS, RQ [delete } \\
\mathrm{RT} \text { from (1)] }\end{array}$ & 0.72 & -- & .870 & 10.17 & 10 & $\begin{array}{l}.489 \\
.680\end{array}$ \\
\hline
\end{tabular}

*Likelihood ratio $x^{2}$.

**Variable codes are as follows:

(R) DWI rearrest within 24 months

(T) Treatment modality

(S) Sex

(Q) Race. 
Non-Alcohol-Related Moving Traffic Violations

Crude Treatment Effects

Due to limitations of the data-collection procedures, the longest followup period for which driving history data could be collected for every client was 18 months. Table 18 shows the mean number of non-alcohol-related violations (number of dates on which moving violations not associated with a DWI charge occurred) during the 18 month followup period. The average number of violations for social drinkers during the 18 month period was 0.42 , which was significantly higher than the 0.33 average for problem drinkers.

Among social drinkers, clients in the control group had the lowest average number of violations (0.37), while those in the group receiving both probation and rehabilitation had the highest average $(0.46)$. A similar pattern was found for problem drinkers, with the control group and the probation-only groups having the lowest average of 0.30 violations, while the probation-plusrehabilitlation group had the highest average $(0.38)$. However, neither of the $F$ tests was significant, nor were any of the contrasts between the treatment means.

Table 19 shows the percentage of clients who had non-DWI violations within the 18 month followup period. There were no significant differences in the percentages for the various treatments for either social drinkers or problem drinkers. The findings in Table 19 are consistent with those in Table 18.

The entire distributions of time-to-violation are shown in figures 6 and 7 , for social drinkers and problem drinkers respectively. Figure 6 shows that among problem drinkers, the control and probation-only groups generally had the lowest citation rates, while the rehabilitation and probation-plus-rehabilitation groups had the highest rates. However, the distributions did not differ significantly from each other, as shown by a log-rank test (not tabled).

Figure 7 shows that among problem drinkers the rehabilitationonly group consistently had the highest citation rate, but it is hard to distinguish between the other three groups. A logrank test indicated no significant difference among the four distributions.

Surprisingly, while $31.0 \%$ of the social drinkers had nonalcohol-related moving vioations, on $1 \mathrm{y} 26.7 \%$ of the problem drinkers had such violations. That difference was statistically significant. Thus, even though problem drinkers were more likely to be rearrested for DWI, they were less likely to be cited for other violations. 
TABLE 18. MEAN NUMBER OF NON-ALCOHOL-RELATED MOVING TRAFFIC VIOLATIONS WITHIN 18 MONTHS FOLLOWING REFERRAL TO THE PROJECT, BY DRINKER TYPE AND TREATMENT

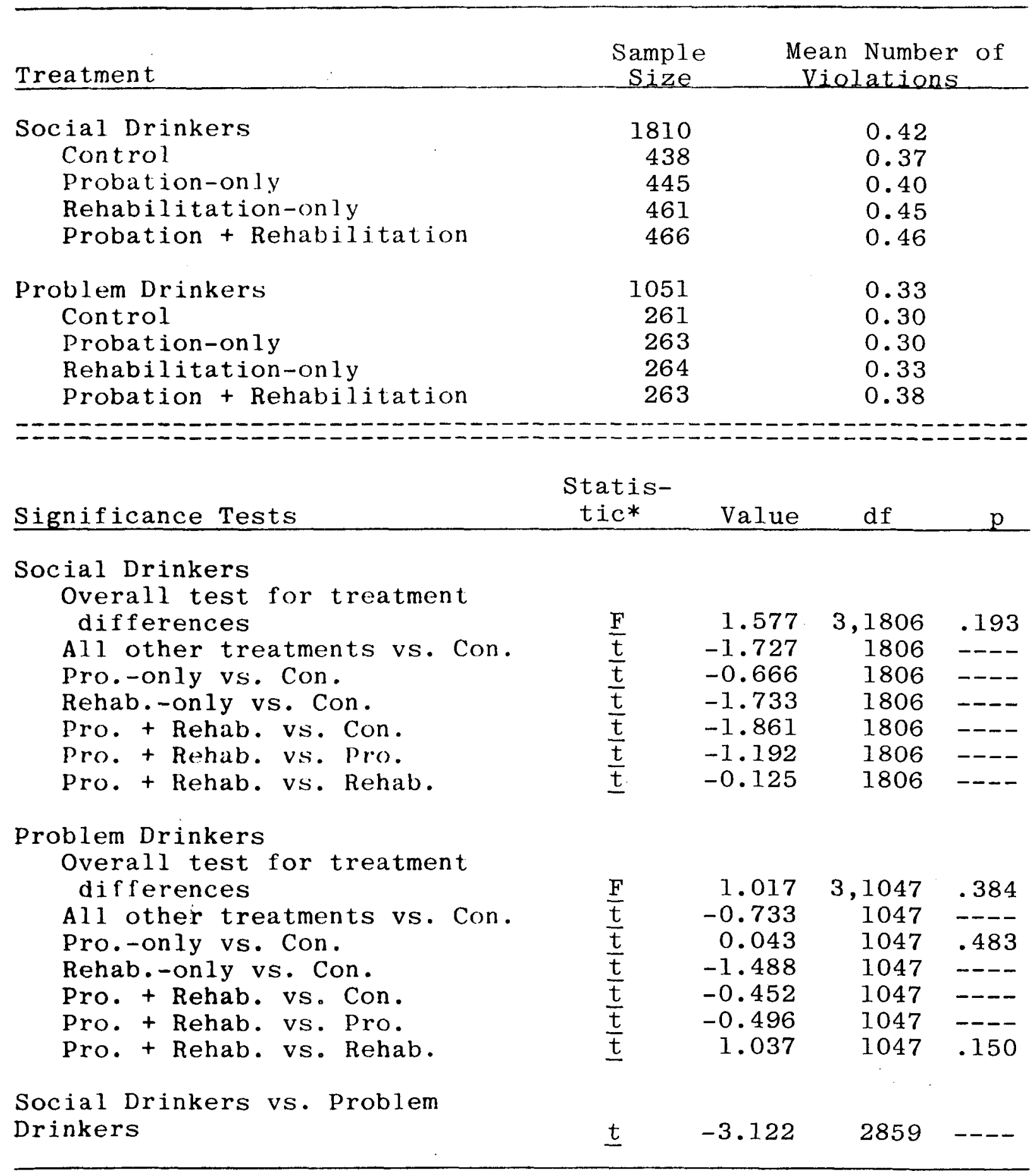

*t tests are one-sided. For each drinker type, tests are based on a pooled estimate of variance for all four groups. A negative value of $t$ indicates a difference in direction opposite that hypothesized. 
TABLE 19. PERCENTAGE WITH NON-ALCOHOL-RELATED MOVING TRAFFIC VIOLATIONS WITHIN 18 MONTHS FOLLOWING REFERRAL TO THE PROJECT, BY DRINKER TYPE AND TREATMENT

\begin{tabular}{lrrr}
\hline Treatment & $\begin{array}{c}\text { Sample } \\
\text { Size }\end{array}$ & $\begin{array}{c}\text { Number w/ } \\
\text { Violations }\end{array}$ & $\begin{array}{c}\text { Percentage w/ } \\
\text { Violations }\end{array}$ \\
\hline Social Drinkers & 1810 & 562 & 31.0 \\
Control & 438 & 120 & 27.4 \\
Probation-only & 445 & 130 & 29.2 \\
Rohabililalion-only & 461 & 150 & 32.5 \\
Probation + Rehabilitation & 466 & 162 & 34.8 \\
Problem Drinkers & 1051 & 281 & 26.7 \\
Control & 261 & 65 & 24.9 \\
Probation-only & 263 & 67 & 25.5 \\
Rehabilitation-only & 264 & 81 & 30.7 \\
Probation + Rehabilitation & 263 & 68 & 25.9 \\
- & & & \\
\hline
\end{tabular}

\section{Significance Tests}

Statis-

Social Drinkers

Overall test for treatment

differences

All other treatments vs. Con.

Pro.-only vs. Con.

Rehab. -only vs. Con.

Pro. + Rehab. vs. Con.

Pro. + Rrhab. vs. Pro.

Pro. + Rehab. vs. Rehab.

$\begin{array}{cccc}\chi^{2} & 6.910 & 3 & .075 \\ \frac{t}{t} & -1.882 & 1806 & --- \\ \frac{t}{t} & -0.584 & 1806 & -- \\ \frac{t}{t} & -1.666 & 1806 & --- \\ \frac{t}{t} & -1.811 & 1806 & -- \\ & -0.733 & 1806 & --- \\ & & & \end{array}$

Problem Drinkers

Overall test for treatment

differences

All other treatments vs. Con.

Pro.-only vs. Con.

Rehab.-only vs. Con.

Pro. + Rehab. vs. Con.

Pro. + Rehab. vs. Pro.

Pro. + Rehab. vs. Rehab.

$\begin{array}{crcc}\chi^{2} & 2.863 & 3 & .413 \\ \frac{t}{t} & -0.770 & 1047 & ---- \\ \frac{t}{t} & -0.148 & 1047 & ---- \\ \frac{t}{t} & -1.495 & 1047 & --- \\ \frac{t}{t} & -1.495 & 1047 & ---- \\ & 1.251 & 1047 & .105\end{array}$

Social Drinkers vs. Problem Drinkers

$\underline{t} \quad 2.392 \quad 2857$

*t tests are one-sided. For each drinker type, tests are based on a pooled estimate of variance for all four groups. A negative value of $t$ indicates a difference in direction opposite that hypothesized. 


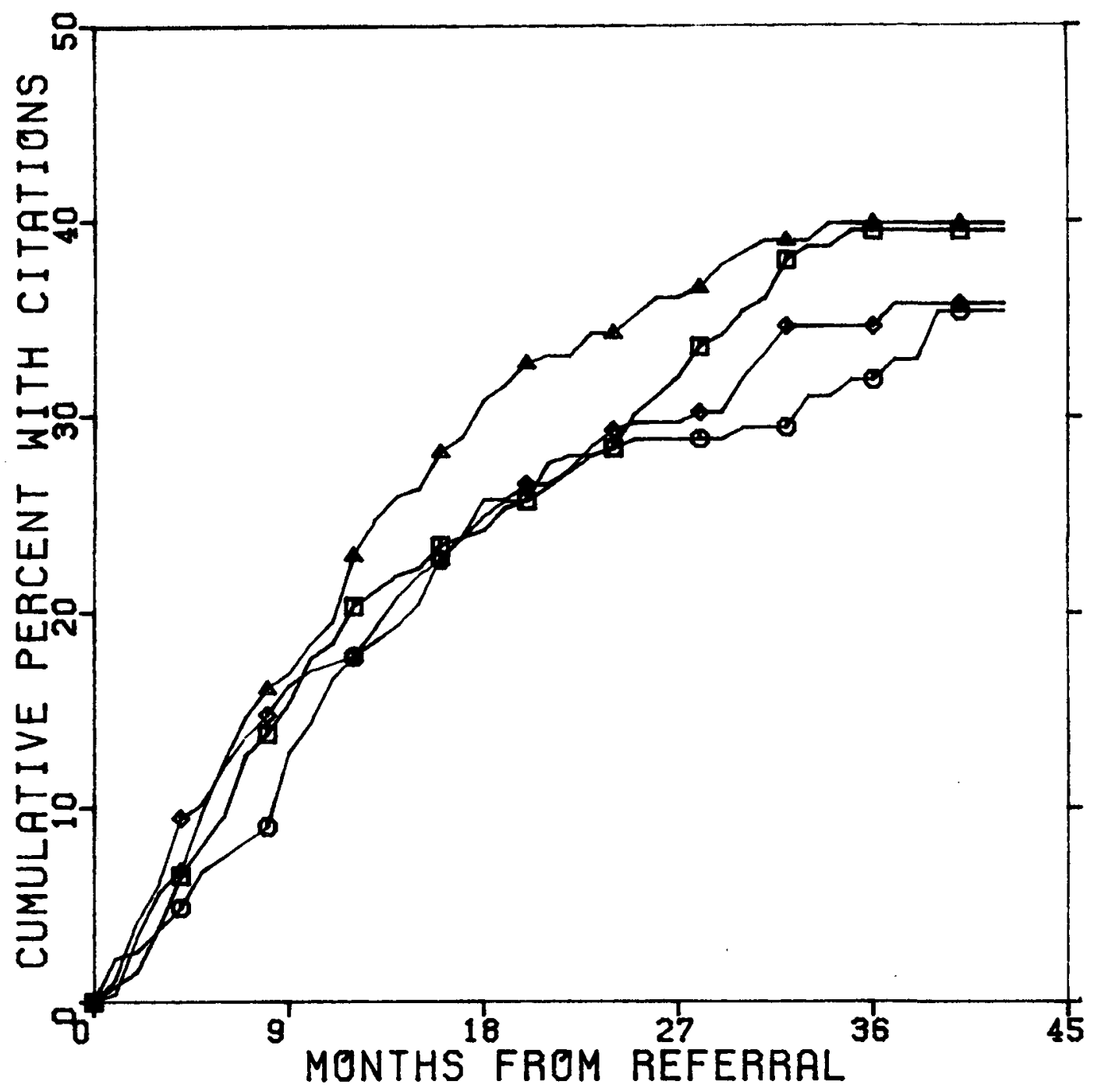

CONTROL

$\triangle$ REHAB-ONLY

(1) PROBATION-ONLY

$\diamond$ PRUBATN-REHAB

FIGURE 6. TIME FROM REFERRAL TO FIRST CITATION FOR SOCIAL DRINKERS, BY TREATMENT 


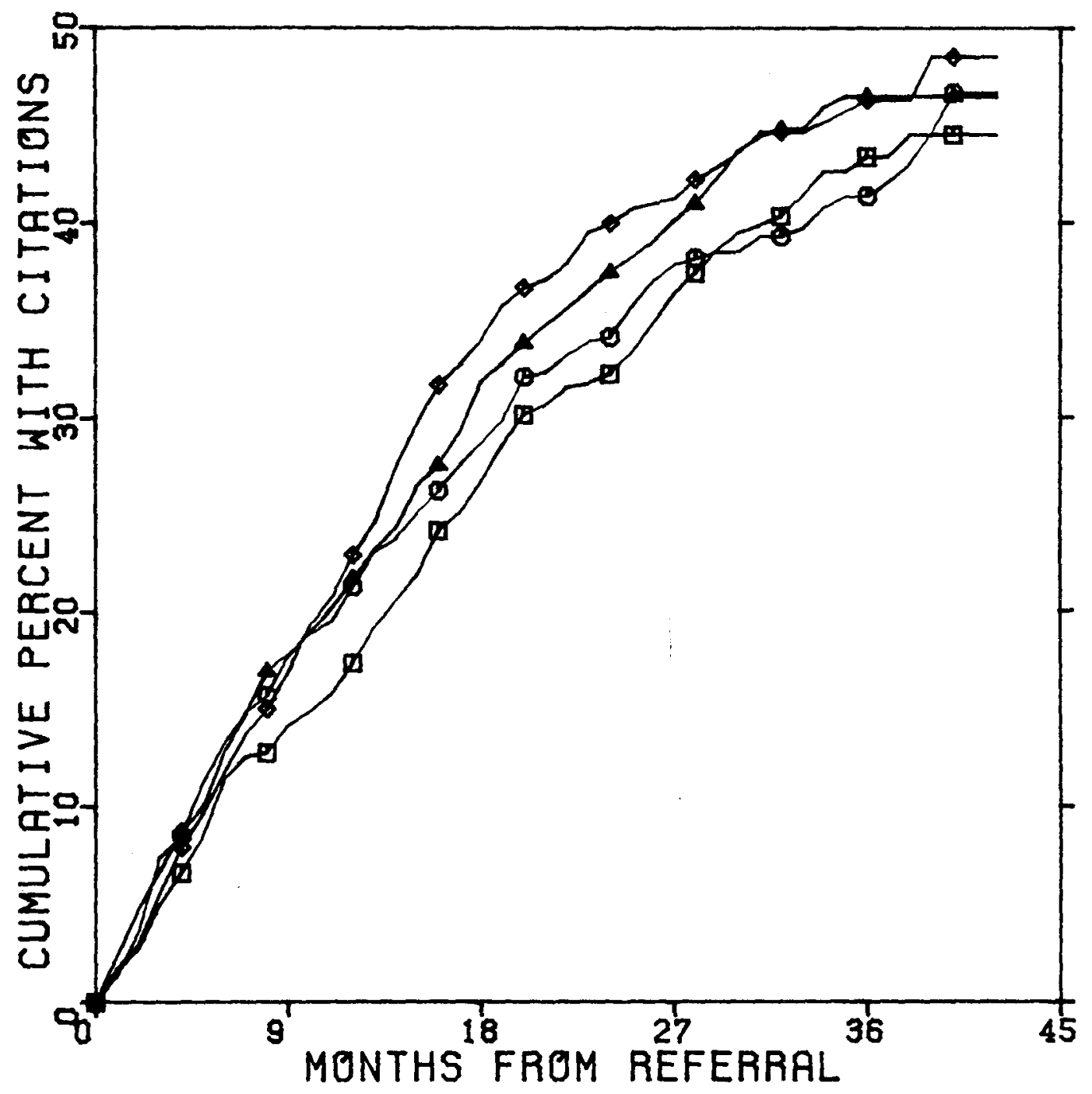

CONTROL

$\triangle$ REHAB-ONLY
(1) PROBATION-ONLY

- PRUBATN-REHAB

FIGURE 7. TIME FROM REFERRAL TO

FIRST CITATION FOR PROBLEM

DRINKERS, BY TREATMENT 
Effects of Treatment and

Prior Violation

In addition to data on non-alcohol-related moving violations during the 18 month followup period, data were obtained on violations within the 24 months prior to referral to the project. Since prior violations were likely to be closely related to followup violations, and since it was possible that clients who had prior violations were not evenly dispersed in the various treatment modalities, treatment effects were reanalyzed with regard to those of prior violations.

Both variables "prior violation" and "followup violation" were dichotomized, with one value representing no violation and the other representing at least one violation. Contingency table methods were used for the analysis in order to avoid the problem of heteroscedasticity.

Table 20 shows cross-tabulations of followup violation by prior violation and treat modality, for social and problem drinkers. It can be seen that clients with prior violations had consistently higher rates of followup violation than did clients with no prior violations, but no other patterns are obvious.

TABLE 20. CROSS-TABULATIONS OF FOLLOWUP NON-ALCOHOL-RELATED MOVING VIOLATIONS BY PRIOR VIOLATION AND TREATMENT MODALITY.

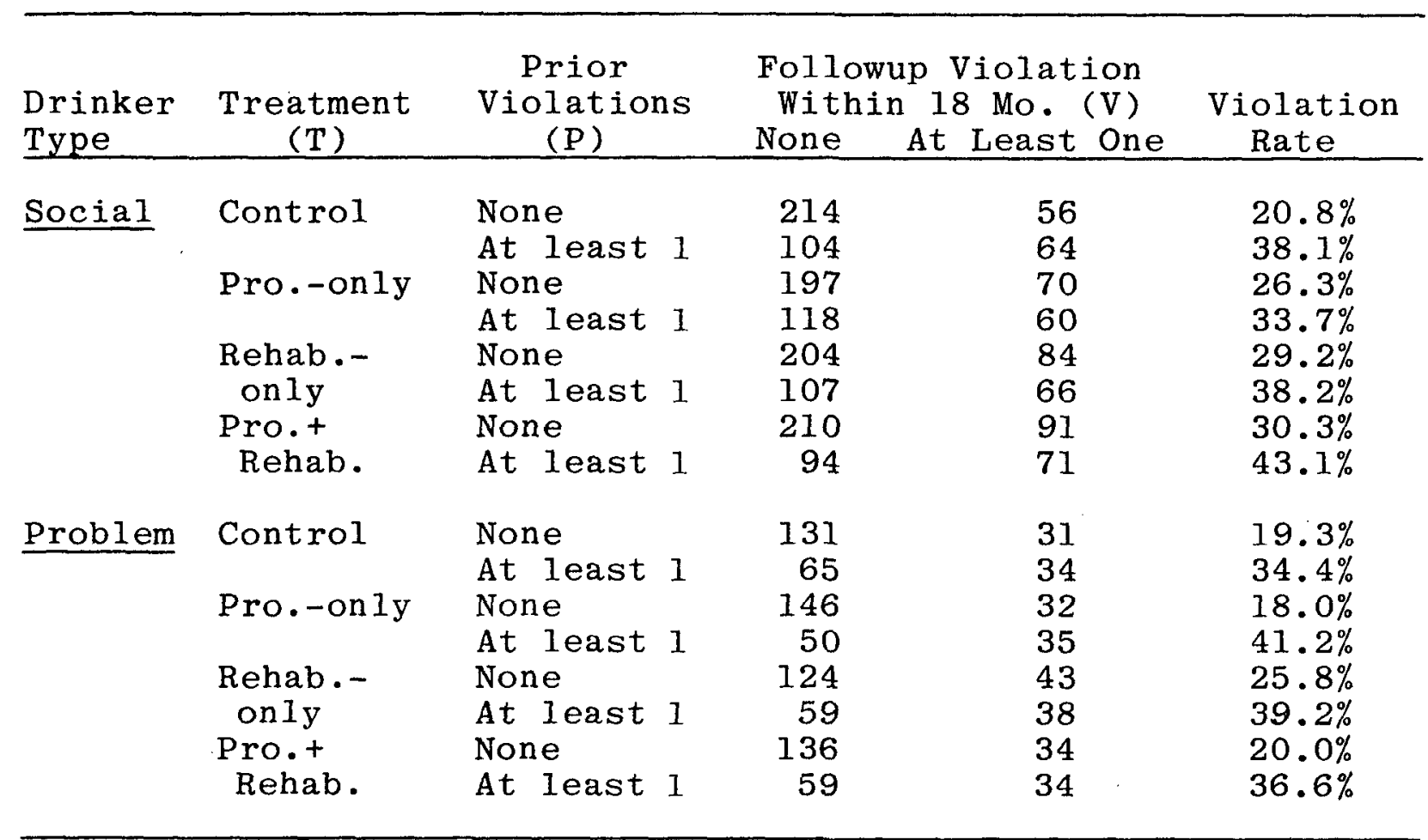


Table 21 shows tests of various log-linear models for the frequencies in Table 20. Since followup violation (V) is considered a dependent variable, the tests of Model (2) are tests of interaction between treatment and prior violation on followup violation. There were no such interactive effects. Likewise, the tests of Model (4) show that there were no simple effects of treatment on followup violation. However, followup violation was highly related to prior violation. Thus, it must again be concluded that there were no differences in subsequent violation rates due to the various treatment modalities.

TABLE 21. TESTS OF LOG-LINEAR MODELS FOR FOLLOWUP NON-ALCOHOLRELATED MOVING VIOLATIONS

\begin{tabular}{llll} 
& $x^{2}$ for & & \\
& Effects & & $x^{2}$ for \\
Mdded or & & Mode1 \\
Mode1 & Deleted* df $\quad p \quad$ & Fit* \\
\hline
\end{tabular}

Social Drinker

(1) VPT** [saturated]

(2) VP, VT, PT [delete VPT from (1)]

(3) VT, PT [delete VP from (2)]

(4) VP, PT [delete VT from (2)]

(5) VP, VT [delete PT from (2)]

$\begin{array}{rrrrrr}-\ldots & - & ---1 & -\ldots- & - & \ldots \\ 3.26 & 3 & .353 & 3.26 & 3 & .353 \\ 26.57 & 1 & .000 & 29.83 & 4 & .000 \\ 7.76 & 3 & .051 & 11.02 & 6 & .088 \\ 3.01 & 3 & .390 & 6.28 & 6 & .393\end{array}$

Problem Drinkers

(1) VPT [saturated]

(2) VP, VT, PT [delete VPT from (1)]

(3) VT, PT [delete VP from (2)]

(4) VP, PT [delete VT from (2)]

(5) VP, VT [delete PT from (2)]

$\begin{array}{rrrrrr}1.86 & 3 & .601 & 1.86 & 3 & .601 \\ 34.71 & 1 & .000 & 36.58 & 4 & .000 \\ 2.73 & 3 & .435 & 4.59 & 6 & .597 \\ 1.95 & 3 & .582 & 3.82 & 6 & .701\end{array}$

*Likelihood ratio $\chi^{2}$.

**Variable codes are as follows:

(V) Followup violation within 18 months

(P) Prior violation within 24 months

(T) Treatment modality. 
It was found above that social drinkers had a higher rate of followup non-alcohol-related moving violations than did problem drinkers. Table 22 shows that social drinker violation rates were higher than those of problem drinkers even when prior violations were controlled for. However, it is also true that social drinkers included a higher percentage of persons with prior violations.

The relationships in Table 22 are explored further in Table 23. The test of Model (4) indicates that there was a significant relationship between drinker type and followup non-alcohol-related moving violations, while there was no significant relationship between drinker type and prior violations (Model [5]). That is, social drinkers did have a significantly higher violation rate than problem drinkers.

TABLE 22. CROSS-TABULATION OF FOLLOWUP NON-ALCOHOL-RELATED MOVING VIOLATION BY PRIOR VIOLATION AND DRINKER TYPE

\begin{tabular}{|c|c|c|c|c|}
\hline $\begin{array}{l}\text { Drinker } \\
\text { Type (K) }\end{array}$ & $\begin{array}{c}\text { Prior } \\
\text { Violation (P) } \\
\end{array}$ & $\begin{array}{l}\text { Followup } \\
\text { None }\end{array}$ & $\begin{array}{l}\text { Violation (V) } \\
\text { At Least One }\end{array}$ & $\begin{array}{c}\text { Violation } \\
\text { Rate }\end{array}$ \\
\hline Social & $\begin{array}{l}\text { None } \\
\text { At least one }\end{array}$ & $\begin{array}{l}825 \\
423\end{array}$ & $\begin{array}{l}301 \\
261\end{array}$ & $\begin{array}{l}26.8 \% \\
38.2 \%\end{array}$ \\
\hline Problem & $\begin{array}{l}\text { None } \\
\text { At least one }\end{array}$ & $\begin{array}{l}537 \\
233\end{array}$ & $\begin{array}{l}110 \\
141\end{array}$ & $\begin{array}{l}17.0 \% \\
37.7 \%\end{array}$ \\
\hline
\end{tabular}

TABLE 23. TESTS OF LOG-LINEAR MODELS FOR TABLE 22

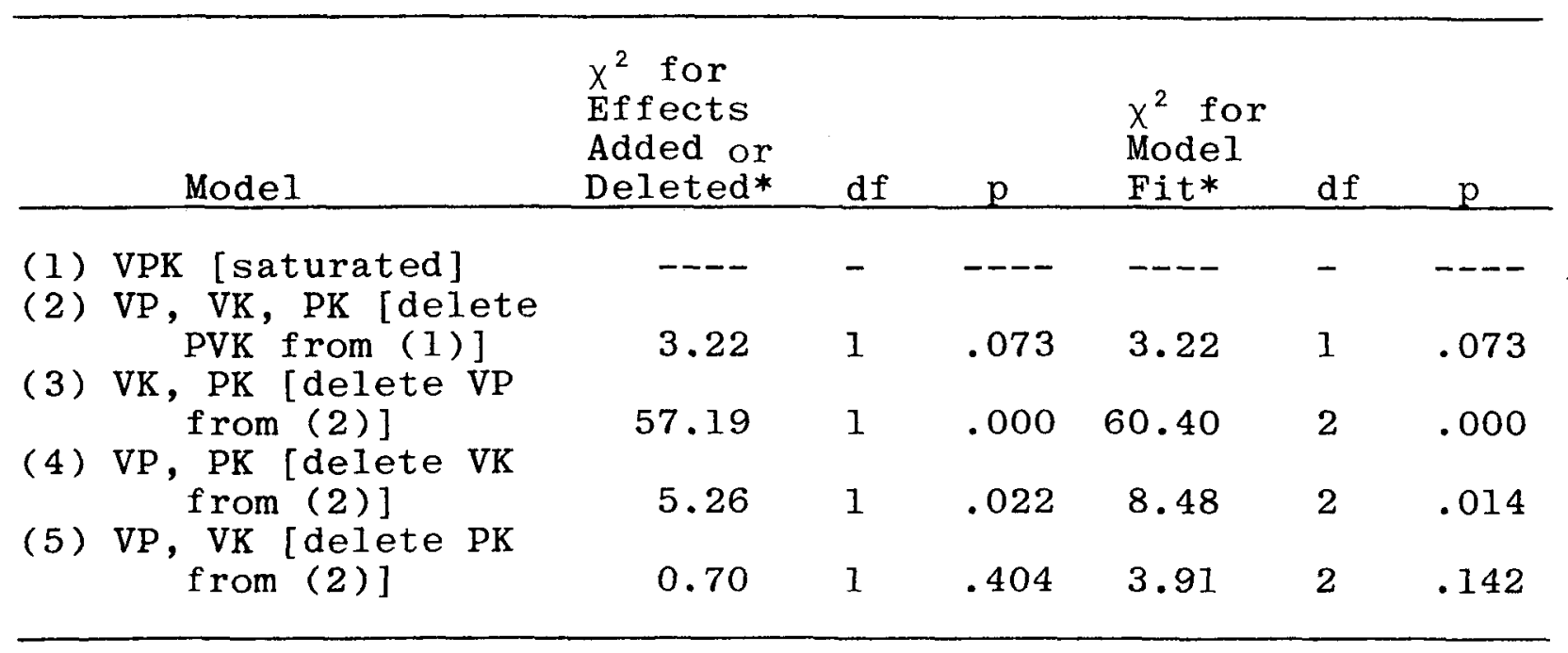

*Likelihood ratio $\chi^{2}$.

**Variable codes are as follows: (V) Non-alcohol-related moving violation within 18 months; (P) Violation within preceding 24 months; (K) Drinker type. 


\section{$\underline{\text { Accidents }}$}

\section{Crude Treatment Effects}

Table 24 shows the mean number of accidents within 18 months after referral to the project. Social drinkers averaged 0.29 accidents during the period while problem drinkers averaged 0.25 accidents, but that difference was not significant. There were also no differences between the means for the various treatments for either social drinkers or problem drinkers.

The findings in Table 25 are similar to those in Table 24. The percentages of clients who had accidents did not differ for the four treatments for either social drinkers or problem drinkers. Tables 24 and 25 also show that there was no difference between the accident rates of problem and social drinkers.

Figures 8 and 9 show the distributions of time-to-firstaccident for social and problem drinkers respectively. For social drinkers, the distributions all appear very similar, and a logrank test indicated no significant differences among them. For problem drinkers, the probation-only group generally had a higher accident rate than the other groups, but again the log-rank test was nonsignificant.

\section{Effects of Treatment and Prior Accident}

In addition to accidents during the 18 month followup period, data were available on accidents during the 24 months preceding referral to the project. Since prior accidents were likely to be a good predictor of subsequent accidents, the effects of prior accidents were analyzed in relation to those of treatment modality. In order to eliminate the problem of heteroscedasticity and the problem of empty cells, as well as to simplify the analysis, both prior and followup accidents were treated as dichotomous variables.

Table 26 shows cross-tabulations of followup accidents by prior accidents and treatment modality for social and for problem drinkers. It is obvious that clients who had prior accidents were more likely to have accidents during the followup period than were clients without prior accidents, but no other relationships are evident from mere inspection of the table.

Table 27 shows tests of models for the frequencies in Table 26. For each drinker type, the test of Model (4) is a test of differences in followup accident rates for the treatment modalities controlling for prior accidents. There were no treatment effects for either social or problem drinkers. The tests of Model

(2) show that there were no interactive effects of treatment and prior accidents on followup accidents.

For problem drinkers, the significance of the test of Mode1 (5) indicates that there was a relationship between treatment 
TABLE 24. MEAN NUMBER OF ACCIDENTS WITHIN 18 MONTHS FOLLOWING REFERRAL TO THE PROJECT, BY DRINKER TYPE AND TREATMENT

\begin{tabular}{lrc}
\hline Treatment & $\begin{array}{c}\text { Sample } \\
\text { Size }\end{array}$ & $\begin{array}{c}\text { Mean Number of } \\
\text { Accidents }\end{array}$ \\
\hline Social Drinkers & 1810 & 0.29 \\
Control & 438 & 0.25 \\
Probation-only & 445 & 0.30 \\
Rehabilitation-only & 461 & 0.31 \\
Probation + Rehabilitation & 466 & 0.29 \\
Problem Drinkers & & 0.25 \\
Control & 1051 & 0.21 \\
Probation-only & 261 & 0.28 \\
Rehabilitation-only & 263 & 0.23 \\
Probation + Rehabilitation & 264 & 0.27
\end{tabular}

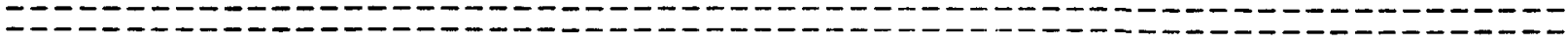

Significance Tests $\begin{gathered}\text { Statis- } \\ \text { tic* }\end{gathered}$ Value df

Social Drinkers

Overall test for treatment

differences

All other treatments vs. Con.

Pro.-only vis. Con.

Rehab.-only vs. Con.

Pro. + Rehab. vs. Con.

Pro. + Rehab. vs. Pro.

Pro. + Rehab. vs. Rehab.

$\begin{array}{rrrr}\frac{F}{t} & 1.019 & 3,1806 & .383 \\ \frac{t}{t} & -1.624 & 1806 & ---- \\ \frac{t}{t} & -1.382 & 1806 & ---- \\ \frac{t}{t} & -0.924 & 1806 & --- \\ \frac{t}{-} & 0.407 & 1806 & ---- \\ & 0.664 & 1806 & .392 \\ & & 1806 & .260\end{array}$

Problem Drinkers

Overall test for treatment

differences

All other treatments vs. Con.

pro.-only vs. Con.

Rehab.-only vs. Con.

Pro. + Rehab. vs. Con.

Pro. + Rehab. vs. Pro.

Pro. + Rehab. vs. Rehab.

\begin{tabular}{|c|c|c|c|}
\hline $\mathrm{F}$ & 1.029 & 3,1047 & .379 \\
\hline$t$ & -1.327 & 1047 & --- \\
\hline$t$ & -1.571 & 1047 & ---- \\
\hline$t$ & -0.451 & 1047 & ---- \\
\hline t & -1.233 & 1047 & $---m$ \\
\hline t & 0.339 & 1047 & .367 \\
\hline & -0.784 & 1047 & -- \\
\hline
\end{tabular}

Social Drinkers vs. Problem

Drinkers

t $\quad 1.503 \quad 2859 \quad .125$

*t tests are one-sided. For each drinker type, tests are based on a pooled estimate of variance for all four groups. A negative value of $\underline{t}$ indicates difference in direction opposite that hypothesized. 
TABLE 25. PERCENTAGE WITH AT LEAST ONE ACCIDENT WITHIN 18 MONTHS FOLLOWING REFERRAL TO THE PROJECT, BY DRINKER TYPE AND TREATMENT

\begin{tabular}{lrrr}
\hline Treatment & $\begin{array}{c}\text { Sample } \\
\text { Size }\end{array}$ & $\begin{array}{c}\text { Number w/ } \\
\text { Accidents }\end{array}$ & $\begin{array}{r}\text { Percentage w/ } \\
\text { Accidents }\end{array}$ \\
\hline Social Drinkers & 1810 & 418 & 23.1 \\
Control & 438 & 91 & 20.8 \\
Probation-only & 445 & 106 & 23.8 \\
Rehabilitation-only & 461 & 113 & 24.5 \\
Probation + Rehabilitation & 466 & 108 & 23.2 \\
& & & \\
Problem Drinkers & 1051 & 232 & 19.9 \\
Control & 261 & 52 & 25.9 \\
Probation-only & 263 & 68 & 20.5 \\
Rehabilitation-only & 264 & 54 & 22.1 \\
Probation + Rehabilitation & 263 & 58 &
\end{tabular}

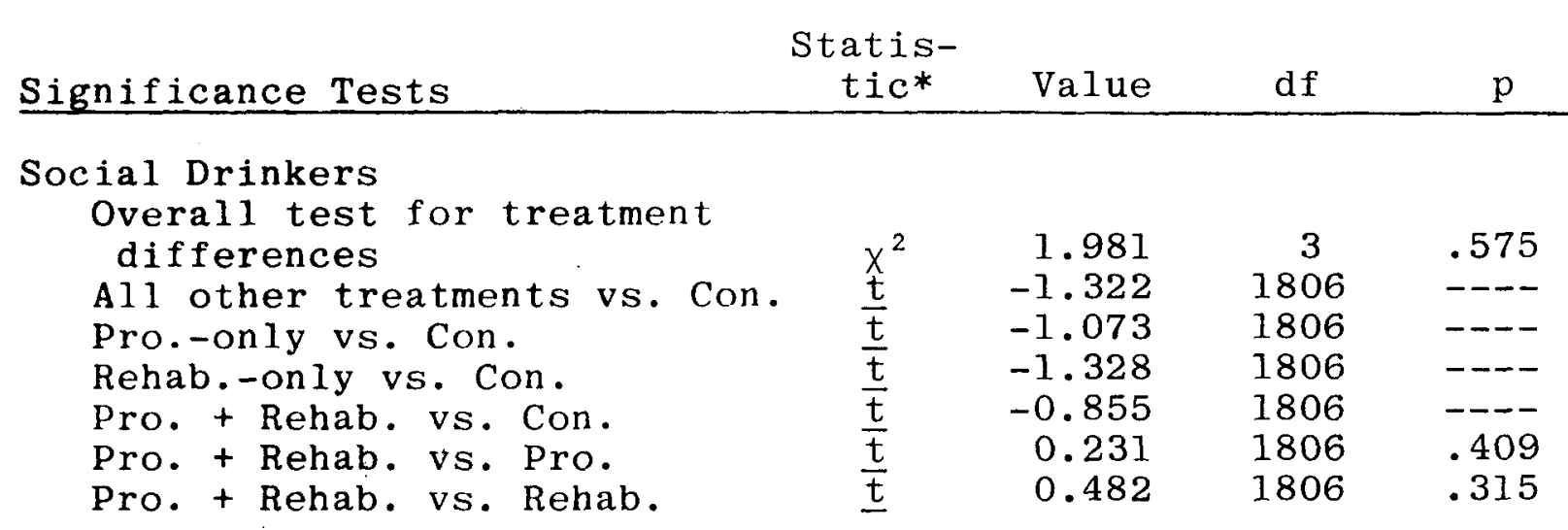

Problem Drinkers

Overall test lor lreatmenl

differences

All other treatments vs. Con

Pro.-only vis. Con.

Rehab.-only vs. Con.

Pro. + Rehab. vs. Con.

Pro. + Rehab. vs. Pro.

Pro. + Rehab. vs. Rehab.

$\begin{array}{lrcc}\chi^{2} & 3.291 & 3 & .349 \\ \frac{t}{t} & -0.967 & 1047 & ---- \\ \frac{t}{t} & -1.636 & 1047 & ---- \\ \frac{t}{t} & -0.147 & 1047 & ---- \\ \frac{t}{t} & 1.051 & 1047 & .147 \\ & -0.442 & 1047 & ----\end{array}$

Social Drinkers vs. Problem Drinkers

$\begin{array}{lll}\mathrm{t} & 0.532 \quad 2857 \quad .561\end{array}$

*t tests are one-sided. For each drinker type, tests are based on a pooled estimate of variance for all four groups. A negative value of $t$ indicates a difference in direction opposite that hypothesized. 


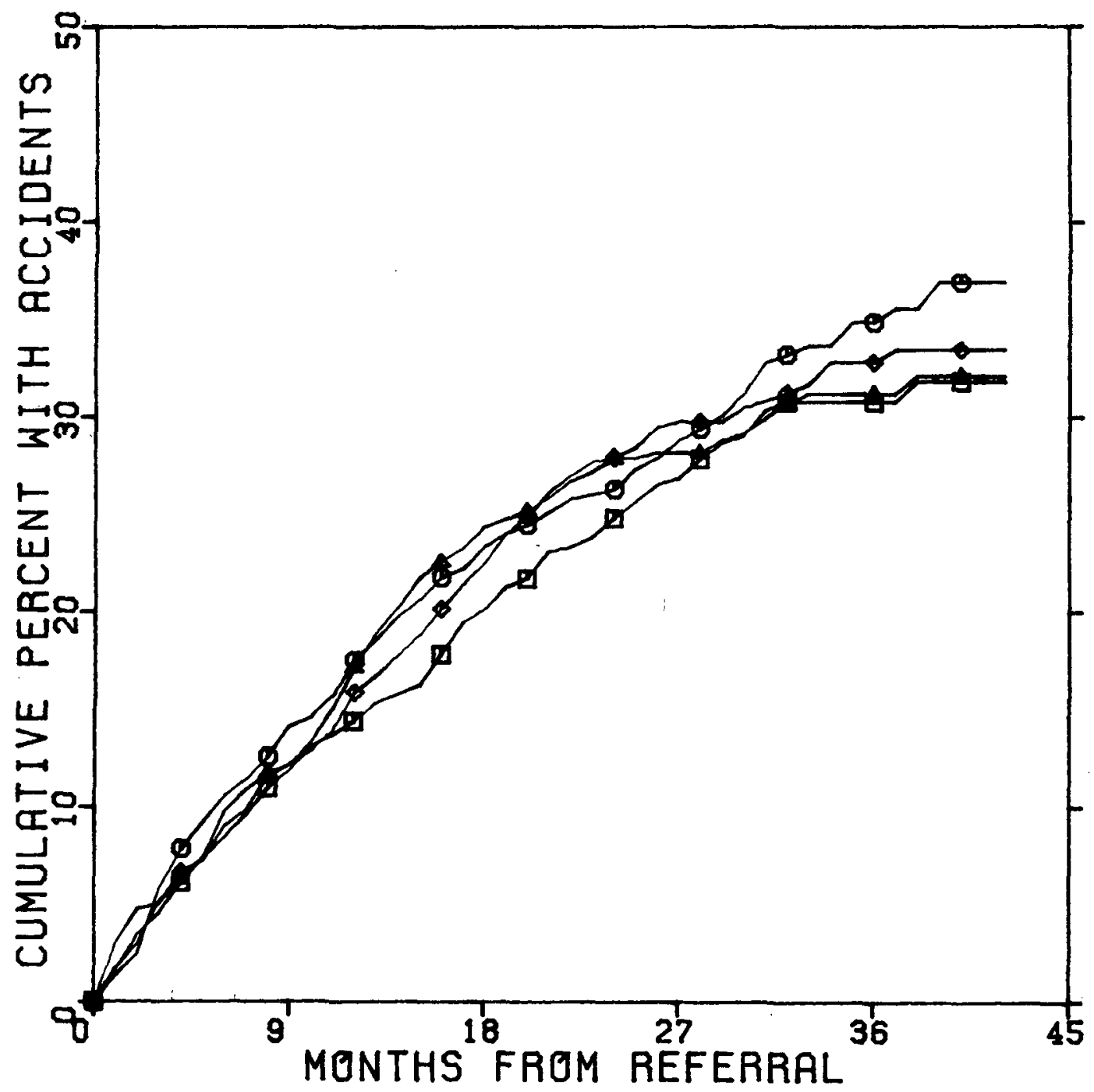

CONTROL

$\triangle$ REHAB-ONLY o PROBATION-ONLY

$\diamond$ PROBATN-REHAB

FIGURE 8. TIME FROM REFERRAL TO FIRST ACCIDENT FOR SOCIAL DRINKERS, BY TREATMENT 


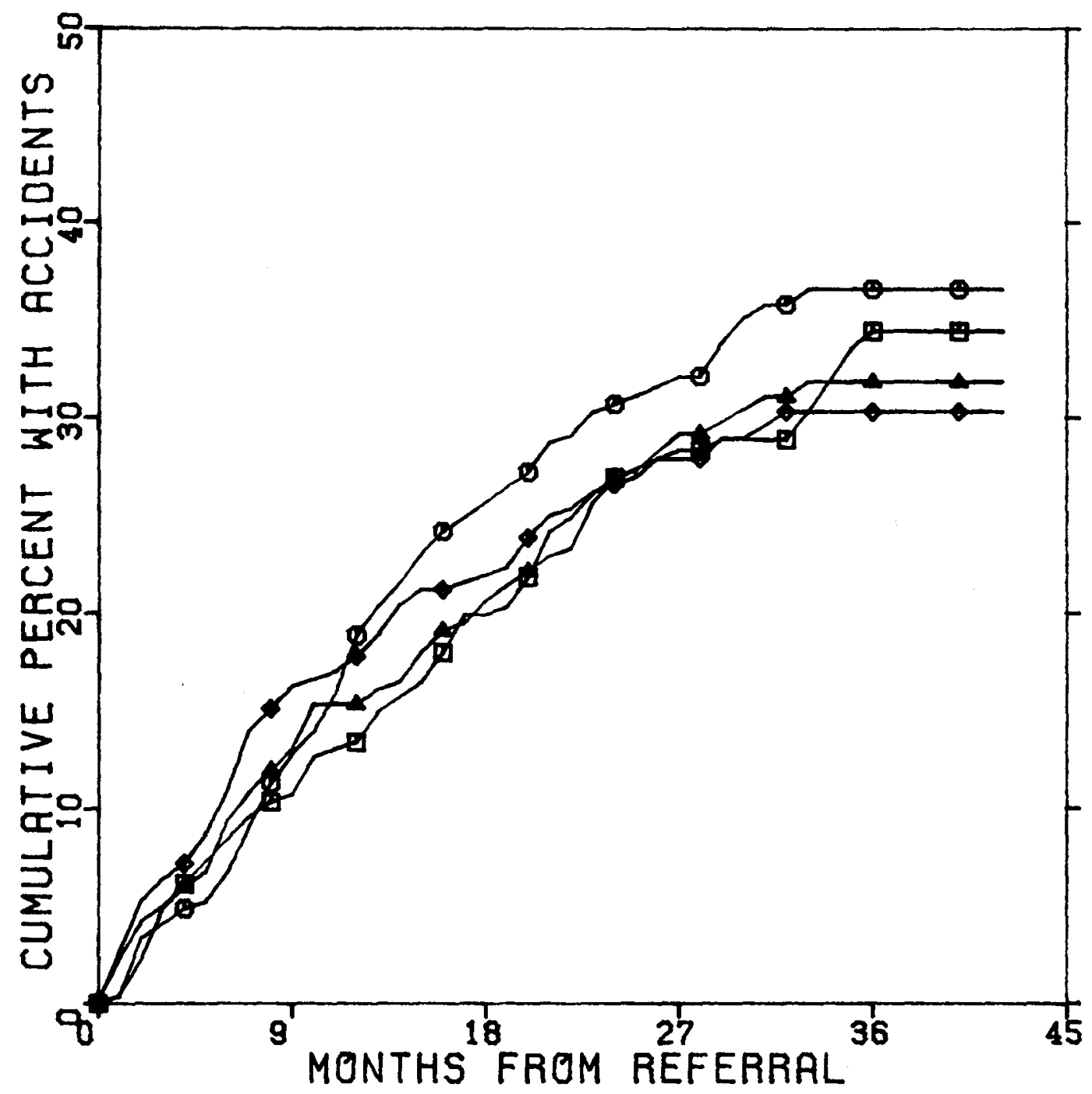

(T) CONTROL

$\triangle$ REHAB-ONLY

(1) PRUBATION-ONLY

ه PROBATN-REHAB

FIGURE 9. TIME FROM REFERRAL TO FIRST ACCIDENT FOR PROBLEM DRINKERS, BY TREATMENT 
modality and prior accidents. Table 26 shows that the control group had the smallest percentage of clients with prior accidents, while the rehabilitation-only group had the highest. However, the analysis took those differences into account.

TABLE 26. CROSS-TABULATIONS OF FOLLOWUP ACCIDENT BY PRIOR ACCIDENT AND TREATMENT MODALITY

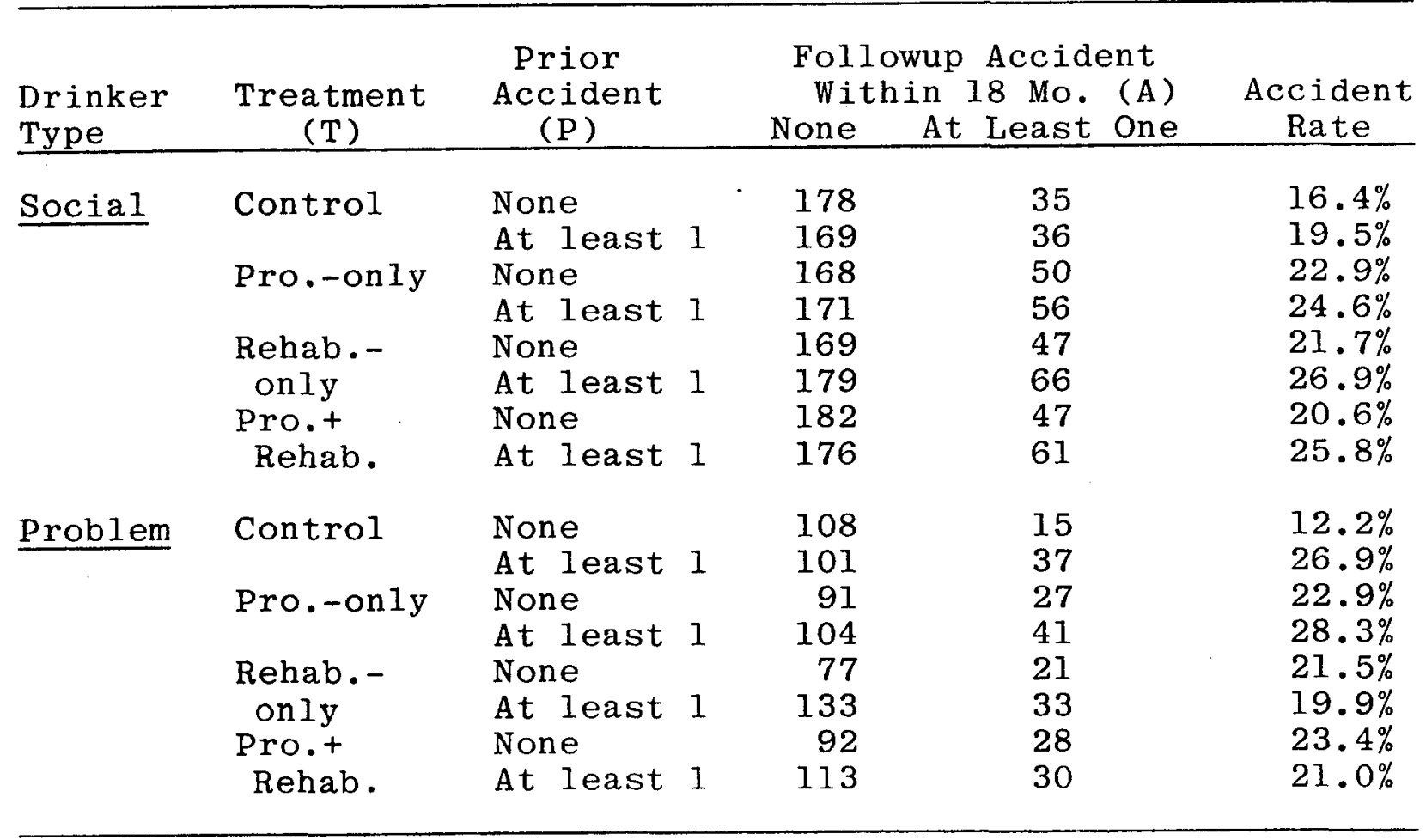

A cross-tabulation of followup accident by prior accident and drinker type is shown in Table 28. Controlling for prior accidents social drinkers actually had slightly higher followup accident rates, even though they had an overall lower accident rate due to a lower percentage of clients with prior accidents. Table 29, shows that there was a significant relationship between problem drinking and prior accidents, but none between problem drinking and followup accidents controlling for prior accidents.

\section{$\underline{\text { Summary }}$}

Three types of event subsequent to project referral were analyzed--rearrests for DWI, convictions for non-alcohol-related moving traffic violations, and traffic accidents. The analyses showed no differences between the rates of any of the events for the various treatment modalities, for either social or problem drinkers. That is, there was no evidence of reductions in DWI rearrest rates, rates of subsequent non-alcohol-related moving traffic violations, or accident rates due to probation supervision, 
rehabilitation, or the combination of probation supervision with rehabilitation.

There was no evidence of a reduction in DWI rearrests due to followup LAI administrations (which can be viewed as a treatment) or of an interactive effect of LAI and treatment modality on rearrests. There were no effects of treatment modality on rearrest when effects of and race were controlled for.

TABLE 27. TESTS OF LOG-LINEAR MODELS FOR FOLLOWUP ACCIDENT

\begin{tabular}{llllll} 
& $x^{2}$ for & & & \\
& & & & \\
Effect & $x^{2}$ for & \\
Added or & & & Model \\
Deleted* & df & $p$ & Fit* & df & $p$ \\
\hline
\end{tabular}

Social Drinkers

(1) $\mathrm{APT} * *$ [saturated]

(2) AP, AT, PT [delete APT from (1) ]

(3) AT, PT [delete AP from (2)]

(4) AP, PT [delete AT from (2)

(5) $\mathrm{AP}, \mathrm{AT}[$ delete $\mathrm{PT}$ from (2)]

$\begin{array}{llllll}--- & - & ---- & -\cdots & - & \ldots- \\ 1.68 & 3 & .642 & 1.68 & 3 & .642 \\ 6.66 & 1 & .010 & 8.34 & 4 & .080 \\ 1.93 & 3 & .586 & 3.61 & 6 & .729 \\ 0.56 & 3 & .905 & 2.24 & 6 & .896\end{array}$

Problem Drinkers

(1) APT [saturated]

(2) AP, AT, PT [delete APT from (1)]

(3) AT, PT [delete AP from (2)]

(4) AP, PT [delete AT from (2)]

(5) AP, AT [delete PT from (2)]

$\begin{array}{rrrrrr}--1 . & - & -\ldots & -\ldots & - & \ldots- \\ 7.65 & 3 & .054 & 7.65 & 3 & .054 \\ 2.42 & 1 & .119 & 10.08 & 4 & .039 \\ 3.30 & 3 & .347 & 10.95 & 6 & .090 \\ 6.55 & 3 & .088 & 14.21 & 6 & .027\end{array}$

*Likelihood ratio $x^{2}$.

**Variable codes are as follows:

(A) Accident within 18 month followup period

(P) Accident within 24 month prior period

(T) Treatment modality.

It was found that subsequent events of all three types were highly related to prior events of the same type. DWI rearrests were also related to problem drinking and to prior non-DWI 
convictions (indicated by nonqualification for diversion). However, accidents were unrelated to problem drinking, and social drinkers were actually more likely to have non-alcohol-related violations than were problem drinkers.

TABLE 28. CROSS-TABULATION OF FOLLOWUP ACCIDENT BY PRIOR ACCIDENT AND DRINKER TYPE

\begin{tabular}{llccc}
\hline $\begin{array}{l}\text { Drinker } \\
\text { Type (K) }\end{array}$ & $\begin{array}{c}\text { Prior } \\
\text { Accident }\end{array}$ & $\begin{array}{c}\text { Followup } \\
\text { No }\end{array}$ & $\begin{array}{c}\text { Accident } \\
\text { Yes }\end{array}$ & $\begin{array}{c}\text { Accident } \\
\text { Rate }\end{array}$ \\
\hline \multirow{2}{*}{ Social } & No prior & 697 & 179 & $20.5 \%$ \\
& Prior & 695 & 239 & $25.6 \%$ \\
Problem & No prior & 368 & 91 & $19.9 \%$ \\
& Pri,or & 451 & 141 & $23.9 \%$ \\
\hline
\end{tabular}

TABLE 29. TEST OF LOG-LINEAR MODELS FOR TABLE 28

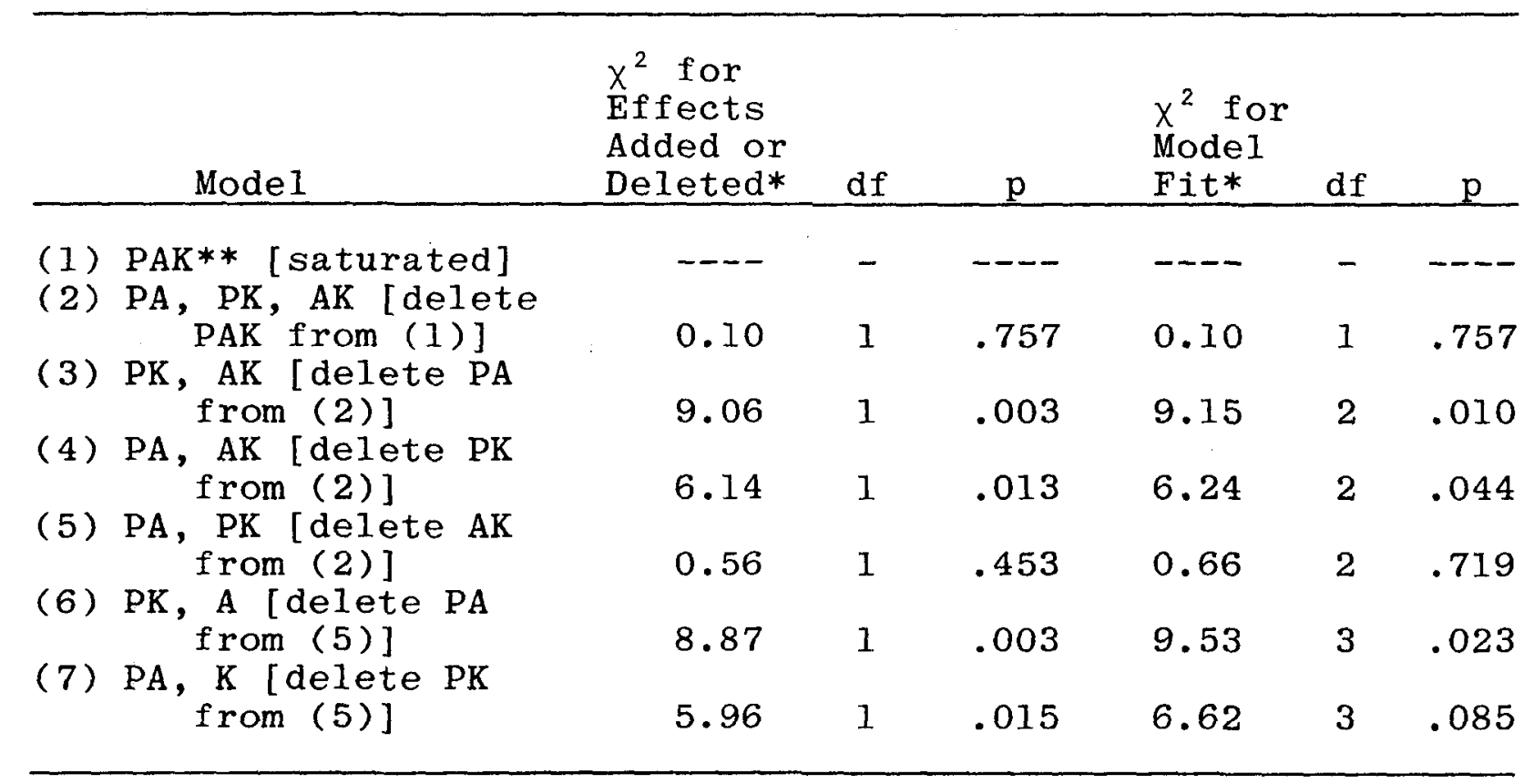

*Likelihood ratio $\chi^{2}$.

**Variable codes are as follows:

(P) Prior accident

(A) Followup accident

(K) Drinker type. 


\section{Life Activities Inventory}

Treatment effects on LAI scores were compared using a repeated measures analysis of variance (Dixon \& Brown, 1979; Winer, 1971). As with previous analyses, data for social and for problem drinkers were analyzed separately. Each of the six LAI scales (described above) was analyzed separately. Hypotheses of interest involved the nature of changes (if any) in the scores over time and the nature of differences (if any) in changes in the scores for various treatment modalities.

For each LAI scale and each drinker type the following null hypotheses were tested:

1. There were no differences between the four treatment modalities in the total scores for the three LAI applications (no treatment main effect). time.

2. There was no linear trend in the mean scale scores over

3. There were no differences in the linear trends for the four treatment modalities (no linear $x$ treatment interaction).

4. There was no quadratic trend in the mean scale scores over time.

5. There was no quadratic $x$ treatment interaction.

6. There were no changes in scale scores over time.

7. There was no trend by treatment interaction.

Since the treatments were presumed to effect changes in LAI scores, the hypotheses involving interactions ([3], [5], and [7]) are of primary interest for the evaluation.

\section{Social Drinkers}

Table 30 shows the means on the LAI scales for social drinkers assigned to the four treatment modalities, and Table 31 shows the results of $F$ tests for the various hypotheses described above. The tables indicate the following.

Scale 1 (Employment/Economic Stability): There were no differences between treatment groups, no changes in scale scores over time, and no interactions.

Scale 2 (Current Drinking Pattern): There was a significant interaction between treatment and linear trend. Table 30 shows that scores for the control groups and the rehabilitation-only groups decreased over time, indicating improvement (according 
TABLE 30. MEANS FOR SIX LAI SCALES, INITIAL, 6 MONTHS, AND 12 MONTHS, FOR SOCIAL DRINKERS

\begin{tabular}{|c|c|c|c|c|c|c|}
\hline Scale & Application & Control & $\begin{array}{l}\text { Pro.- } \\
\text { Only }\end{array}$ & $\begin{array}{c}\text { Rehab.- } \\
\text { On ly } \\
\end{array}$ & $\begin{array}{l}\text { Pro.t } \\
\text { Rehab. }\end{array}$ & $\begin{array}{c}\text { Marginal } \\
\text { Mean }\end{array}$ \\
\hline 1 & $\begin{array}{l}\text { Initial } \\
6 \text { Mo. } \\
12 \text { Mo. } \\
\text { Sample Size }\end{array}$ & $\begin{array}{c}551.17 \\
541.70 \\
535.70 \\
44 \\
\end{array}$ & $\begin{array}{c}538.52 \\
530.33 \\
533.18 \\
53 \\
\end{array}$ & $\begin{array}{c}523.37 \\
525.23 \\
542.11 \\
39 \\
\end{array}$ & $\begin{array}{c}546.39 \\
548.95 \\
555.68 \\
44 \\
\end{array}$ & $\begin{array}{c}540.25 \\
536.56 \\
541.23 \\
180 \\
\end{array}$ \\
\hline 2 & $\begin{array}{l}\text { Initial } \\
6 \text { Mo. } \\
12 \text { Mo. } \\
\text { Sample Size }\end{array}$ & $\begin{array}{c}496.24 \\
470.97 \\
476.92 \\
53 \\
\end{array}$ & $\begin{array}{l}481.96 \\
478.53 \\
471.68 \\
46 \\
\end{array}$ & $\begin{array}{l}511.58 \\
483.56 \\
467.80 \\
45 \\
\end{array}$ & $\begin{array}{c}461.00 \\
481.08 \\
484.17 \\
51 \\
\end{array}$ & $\begin{array}{r}487.19 \\
478.30 \\
475.47 \\
195 \\
\end{array}$ \\
\hline 3 & $\begin{array}{l}\text { Initial } \\
6 \mathrm{Mo} \text {. } \\
12 \mathrm{Mo} \text {. } \\
\text { Sample Size }\end{array}$ & $\begin{array}{r}522.10 \\
502.25 \\
513.58 \\
61 \\
\end{array}$ & $\begin{array}{c}495.31 \\
496.77 \\
505.57 \\
63 \\
\end{array}$ & $\begin{array}{c}508.81 \\
485.18 \\
510.91 \\
55 \\
\end{array}$ & $\begin{array}{c}509.96 \\
506.18 \\
494.95 \\
63 \\
\end{array}$ & $\begin{array}{l}508.95 \\
497.97 \\
506.04 \\
242 \\
\end{array}$ \\
\hline 4 & $\begin{array}{l}\text { Initial } \\
6 \text { Mo. } \\
12 \text { Mo. } \\
\text { Sample Size }\end{array}$ & $\begin{array}{c}526.53 \\
526.47 \\
507.44 \\
63 \\
\end{array}$ & $\begin{array}{c}522.31 \\
501.15 \\
505.18 \\
62 \\
\end{array}$ & $\begin{array}{c}502.82 \\
510.83 \\
508.76 \\
53 \\
\end{array}$ & $\begin{array}{c}503.41 \\
498.95 \\
495.71 \\
65 \\
\end{array}$ & $\begin{array}{c}514.10 \\
509.24 \\
504.01 \\
243 \\
\end{array}$ \\
\hline 5 & $\begin{array}{l}\text { Initial } \\
6 \text { Mo. } \\
12 \text { Mo. } \\
\text { Sample Size }\end{array}$ & $\begin{array}{c}475.82 \\
484.71 \\
462.47 \\
66 \\
\end{array}$ & $\begin{array}{c}457.83 \\
480.36 \\
486.26 \\
66 \\
\end{array}$ & $\begin{array}{c}475.13 \\
467.42 \\
457.04 \\
56 \\
\end{array}$ & $\begin{array}{c}459.99 \\
492.56 \\
466.56 \\
62 \\
\end{array}$ & $\begin{array}{l}466.99 \\
481.64 \\
468.55 \\
250 \\
\end{array}$ \\
\hline 6 & $\begin{array}{l}\text { Initial } \\
6 \mathrm{Mo} . \\
12 \mathrm{Mo} . \\
\text { Sample Size }\end{array}$ & $\begin{array}{l}483.86 \\
467.61 \\
482.55 \\
10\end{array}$ & $\begin{array}{l}462.03 \\
494.19 \\
487.11 \\
14\end{array}$ & $\begin{array}{r}492.98 \\
450.12 \\
487.68 \\
\frac{7}{4}\end{array}$ & $\begin{array}{c}531.60 \\
589.83 \\
539.33 \\
10\end{array}$ & $\begin{array}{c}489.61 \\
503.51 \\
498.83\end{array}$ \\
\hline
\end{tabular}


TABLE 31. TESTS OF HYPOTHESES FOR LAI SCORES, SOCIAL DRINKERS

\begin{tabular}{|c|c|c|c|c|}
\hline Scale & Effect & $\mathrm{F}$ & $\mathrm{df}$ & $p$ \\
\hline 1 & $\begin{array}{l}\text { Treatment Main } \\
\text { Linear Trend } \\
\text { Linear } x \text { Treatment } \\
\text { Quadratic Trend } \\
\text { Quadratic x Treatment } \\
\text { Trend } \\
\text { Trend x Treatment } \\
\end{array}$ & $\begin{array}{l}1.55 \\
0.12 \\
2.01 \\
1.04 \\
0.11 \\
0.54 \\
1.15 \\
\end{array}$ & $\begin{array}{l}3,176 \\
1,176 \\
3,176 \\
1,176 \\
3,176 \\
2,352 \\
6,352 \\
\end{array}$ & $\begin{array}{l}.202 \\
.731 \\
.114 \\
.310 \\
.956 \\
.585 \\
.335 \\
\end{array}$ \\
\hline 2 & $\begin{array}{l}\text { Treatment Main } \\
\text { Linear Trend } \\
\text { Linear x Treatment } \\
\text { Quadratic Trend } \\
\text { Quadratic x Treatment } \\
\text { Trend } \\
\text { Trend x Treatment }\end{array}$ & $\begin{array}{l}0.17 \\
2.19 \\
2.67 \\
0.25 \\
0.87 \\
1.46 \\
1.99\end{array}$ & $\begin{array}{l}3,191 \\
1,191 \\
3,191 \\
1,191 \\
3,191 \\
2,382 \\
6,382 \\
\end{array}$ & $\begin{array}{l}.919 \\
.140 \\
.049 \\
.615 \\
.457 \\
.234 \\
.067 \\
\end{array}$ \\
\hline 3 & $\begin{array}{l}\text { Treatment Main } \\
\text { Linear Trend } \\
\text { Linear } x \text { Treatment } \\
\text { Quadratic Trend } \\
\text { Quadratic } x \text { Treatment } \\
\text { Trend } \\
\text { Trend } x \text { Treatment } \\
\end{array}$ & $\begin{array}{l}0.42 \\
0.09 \\
0.38 \\
3.21 \\
1.23 \\
1.13 \\
0.67 \\
\end{array}$ & $\begin{array}{l}3,238 \\
1,238 \\
3,238 \\
1,238 \\
3,238 \\
2,476 \\
6,476 \\
\end{array}$ & $\begin{array}{l}.737 \\
.761 \\
.765 \\
.075 \\
.299 \\
.325 \\
.677 \\
\end{array}$ \\
\hline 4 & $\begin{array}{l}\text { Treatment Main } \\
\text { Linear Trend } \\
\text { Linear } x \text { Treatment } \\
\text { Quadratic Trend } \\
\text { Quadratic } x \text { Treatment } \\
\text { Trend } \\
\text { Trend } x \text { Treatment } \\
\end{array}$ & $\begin{array}{l}1.22 \\
5.55 \\
1.88 \\
0.01 \\
2.35 \\
3.07 \\
2.09 \\
\end{array}$ & $\begin{array}{l}3,239 \\
1,239 \\
3,239 \\
1,239 \\
3,239 \\
2,478 \\
6,478 \\
\end{array}$ & $\begin{array}{l}.302 \\
.019 \\
.133 \\
.916 \\
.073 \\
.048 \\
.053 \\
\end{array}$ \\
\hline 5 & $\begin{array}{l}\text { Treatment Main } \\
\text { Linear Trend } \\
\text { Linear x Treatment } \\
\text { Quadratic Trend } \\
\text { Quadratic x Treatment } \\
\text { Trend } \\
\text { Trend x Treatment } \\
\end{array}$ & $\begin{array}{l}0.11 \\
0.02 \\
2.20 \\
3.76 \\
0.70 \\
2.11 \\
1.36\end{array}$ & $\begin{array}{l}3,246 \\
1,246 \\
3,246 \\
1,246 \\
3,246 \\
2,492 \\
6,492 \\
\end{array}$ & $\begin{array}{l}.952 \\
.902 \\
.088 \\
.055 \\
.554 \\
.123 \\
.228 \\
\end{array}$ \\
\hline 6 & $\begin{array}{l}\text { Treatment Main } \\
\text { Linear Trend } \\
\text { Linear } x \text { Treatment } \\
\text { Quadratic Trend } \\
\text { Quadratic } x \text { Treatment } \\
\text { Trend } \\
\text { Trend } x \text { Treatment }\end{array}$ & $\begin{array}{l}2.62 \\
0.17 \\
0.20 \\
0.08 \\
1.54 \\
0.12 \\
0.96\end{array}$ & $\begin{array}{l}3,37 \\
1,37 \\
3,37 \\
1,37 \\
3,37 \\
2,74 \\
6,74\end{array}$ & $\begin{array}{l}.065 \\
.686 \\
.892 \\
.777 \\
.220 \\
.889 \\
.457\end{array}$ \\
\hline
\end{tabular}


to Ellingstad \& Struckman-Johnson, 1977); scores increased for the probation and probation-plus-rehabilitation groups.

Scale 3 (Family Status): There were no differences between treatment groups, no changes over time, and no interactions.

Scale 4 (Social Interaction/Involvement): There was a general decrease in scale scores over time. There were no differences between groups and no interactions.

Scale 5 (Current Physical Health Problems): There were no differences between groups, no changes in scale scores over time, and no interactions.

Scale 6 (Immoderate Drinking Behavior): There were no differences between groups, no changes over time, and no interactions.

\section{Problem Drinkers}

LAI scale means and $F$ tests for problem drinkers are shown in tables 32 and 33. The tables indicate the following:

Scale 1 (Employment/Economic Stability): There were no differences between treatment groups, no changes over time, and no interactions.

Scale 2 (Current Drinking Pattern): There were no differences between groups, no changes over time, and no interactions.

Scale 3 (Family Status): There were no differences between treatment groups, no changes over time, and no interactions.

Scale 4 (Social Interaction/Involvement): There were no differences between groups, no changes over time, and no interactions.

Scale 5 (Current Physical Health Problems): There were no differences between groups, no changes over time, and no interactions.

Scale 6 (Immoderate Drinking Behavior): There were no differences between groups, no changes over time, and no interactions.

\section{$\underline{\text { Summary }}$}

Of the 12 LAI analyses performed (six scales for two drinker types) only one showed a significant effect of a type that would indicate lifestyle changes (as measured by the LAI) resulting from treatment. Specifically, social drinkers not receiving probation supervision (i.e., control and rehabilitation-only groups) were found to have improved their "current drinking patterns." Social drinkers in probation-only and probation-plus-rehabilitation 
TABLE 32. MEANS FOR SIX LAI SCALES, INITIAL, 6 MONTHS, AND 12 MONTHS, FOR PROBLEM DRINKERS

\begin{tabular}{|c|c|c|c|c|c|c|}
\hline Scale & Application & Control & $\begin{array}{l}\text { Pro.- } \\
\text { Only }\end{array}$ & $\begin{array}{l}\text { Rehab.- } \\
\text { Only }\end{array}$ & $\begin{array}{l}\text { Pro.t } \\
\text { Rehab. }\end{array}$ & $\begin{array}{c}\text { Marginal } \\
\text { Mean }\end{array}$ \\
\hline 1 & $\begin{array}{l}\text { Initial } \\
6 \text { Mo. } \\
12 \text { Mo. } \\
\text { Sample Size }\end{array}$ & $\begin{array}{c}546.05 \\
537.42 \\
520.04 \\
40 \\
\end{array}$ & $\begin{array}{l}530.97 \\
520.83 \\
522.00 \\
42 \\
\end{array}$ & $\begin{array}{c}531.80 \\
515.31 \\
529.83 \\
37 \\
\end{array}$ & $\begin{array}{c}519.69 \\
538.16 \\
531.24 \\
39 \\
\end{array}$ & $\begin{array}{r}532.20 \\
528.02 \\
525.62 \\
158 \\
\end{array}$ \\
\hline 2 & $\begin{array}{l}\text { Initial } \\
6 \mathrm{Mo} \text {. } \\
12 \mathrm{Mo} \text {. } \\
\text { Sample Size }\end{array}$ & $\begin{array}{c}508.51 \\
481.42 \\
493.73 \\
32 \\
\end{array}$ & $\begin{array}{c}513.05 \\
490.83 \\
468.60 \\
39 \\
\end{array}$ & $\begin{array}{c}481.30 \\
460.67 \\
451.29 \\
42 \\
\end{array}$ & $\begin{array}{c}459.26 \\
467.14 \\
419.86 \\
40 \\
\end{array}$ & $\begin{array}{c}489.32 \\
474.39 \\
456.36 \\
153 \\
\end{array}$ \\
\hline 3 & $\begin{array}{l}\text { Initial } \\
6 \text { Mo. } \\
12 \text { Mo. } \\
\text { Sample Size }\end{array}$ & $\begin{array}{c}493.88 \\
505.95 \\
496.75 \\
52 \\
\end{array}$ & $\begin{array}{l}499.87 \\
482.20 \\
473.66 \\
61 \\
\end{array}$ & $\begin{array}{l}485.57 \\
491.90 \\
490.97 \\
55 \\
\end{array}$ & $\begin{array}{l}470.65 \\
469.18 \\
463.06 \\
49 \\
\end{array}$ & $\begin{array}{l}488.21 \\
487.41 \\
481.19 \\
217 \\
\end{array}$ \\
\hline 4 & $\begin{array}{l}\text { Initial } \\
6 \text { Mo. } \\
12 \text { Mo. } \\
\text { Sample Size }\end{array}$ & $\begin{array}{l}483.29 \\
486.31 \\
488.74 \\
49 \\
\end{array}$ & $\begin{array}{l}493.01 \\
495.10 \\
484.85 \\
51 \\
\end{array}$ & $\begin{array}{r}482.98 \\
490.25 \\
492.24 \\
50 \\
\end{array}$ & $\begin{array}{l}486.62 \\
490.76 \\
488.84 \\
45 \\
\end{array}$ & $\begin{array}{l}486.52 \\
490.64 \\
488.64 \\
195 \\
\end{array}$ \\
\hline 5 & $\begin{array}{l}\text { Initial } \\
6 \text { Mo. } \\
12 \text { Mo. } \\
\text { Sample Size }\end{array}$ & $\begin{array}{l}473.47 \\
494.84 \\
467.71 \\
48 \\
\end{array}$ & $\begin{array}{c}475.92 \\
486.16 \\
497.02 \\
55 \\
\end{array}$ & $\begin{array}{l}486.32 \\
469.77 \\
467.81 \\
57 \\
\end{array}$ & $\begin{array}{l}477.56 \\
487.49 \\
458.91 \\
49 \\
\end{array}$ & $\begin{array}{l}478.58 \\
484.00 \\
473.39 \\
209 \\
\end{array}$ \\
\hline 6 & $\begin{array}{l}\text { Initial } \\
6 \text { Mo. } \\
12 \text { Mo. } \\
\text { Sample Size }\end{array}$ & $\begin{array}{c}570.38 \\
513.29 \\
467.25 \\
14\end{array}$ & $\begin{array}{r}514.81 \\
481.36 \\
\frac{481.89}{12}\end{array}$ & $\begin{array}{l}545.53 \\
483.52 \\
\frac{499.31}{15}\end{array}$ & $\begin{array}{c}477.00 \\
487.71 \\
538.18 \\
9\end{array}$ & $\begin{array}{l}532.78 \\
492.09 \\
493.15 \\
50\end{array}$ \\
\hline
\end{tabular}


TABLE 33. TESTS FOR HYPOTHESES FOR LAI SCORES, PROBLEM DRINKERS

\begin{tabular}{|c|c|c|c|c|}
\hline Scale & Effect & $\mathrm{F}$ & $\mathrm{df}$ & $\mathrm{p}$ \\
\hline 1 & $\begin{array}{l}\text { Treatment Main } \\
\text { Linear Trend } \\
\text { Linear } x \text { Treatment } \\
\text { Quadratic Trend } \\
\text { Quadratic } x \text { Treatment } \\
\text { Trend } \\
\text { Trend } x \text { Treatment }\end{array}$ & $\begin{array}{l}0.19 \\
0.98 \\
1.49 \\
0.04 \\
1.52 \\
0.57 \\
1.50\end{array}$ & $\begin{array}{l}3,154 \\
1,154 \\
3,154 \\
1,154 \\
3,154 \\
2,308 \\
6,308 \\
\end{array}$ & $\begin{array}{l}.902 \\
.324 \\
.220 \\
.835 \\
.212 \\
.565 \\
.177 \\
\end{array}$ \\
\hline 2 & $\begin{array}{l}\text { Treatment Main } \\
\text { Linear Trend } \\
\text { Linear x Treatment } \\
\text { Quadratic Trend } \\
\text { Quadratic x Treatment } \\
\text { Trend } \\
\text { Trend } x \text { Treatment } \\
\end{array}$ & $\begin{array}{l}2.12 \\
7.16 \\
0.27 \\
0.00 \\
1.21 \\
4.19 \\
0.67 \\
\end{array}$ & $\begin{array}{l}3,149 \\
1,149 \\
3,149 \\
1,149 \\
3,149 \\
2,298 \\
6,298 \\
\end{array}$ & $\begin{array}{l}.101 \\
.008 \\
.846 \\
.950 \\
.309 \\
.017 \\
.675 \\
\end{array}$ \\
\hline 3 & $\begin{array}{l}\text { Treatment Main } \\
\text { Linear Trend } \\
\text { Linear } x \text { Treatment } \\
\text { Quadratic Trend } \\
\text { Quadratic } x \text { Treatment } \\
\text { Trend } \\
\text { Trend } x \text { Treatment } \\
\end{array}$ & $\begin{array}{l}0.88 \\
1.12 \\
1.53 \\
0.53 \\
0.60 \\
0.90 \\
1.17\end{array}$ & $\begin{array}{l}3,213 \\
1,213 \\
3,213 \\
1,213 \\
3,213 \\
2,426 \\
6,426 \\
\end{array}$ & $\begin{array}{l}.454 \\
.291 \\
.207 \\
.466 \\
.618 \\
.409 \\
.319 \\
\end{array}$ \\
\hline 4 & $\begin{array}{l}\text { Treatment Main } \\
\text { Linear Trend } \\
\text { Linear } x \text { Treatment } \\
\text { Quadratic Trend } \\
\text { Quadratic } x \text { Treatment } \\
\text { Trend } \\
\text { Trend } x \text { Treatment } \\
\end{array}$ & $\begin{array}{l}0.05 \\
0.26 \\
0.80 \\
0.77 \\
0.13 \\
0.50 \\
0.48 \\
\end{array}$ & $\begin{array}{l}3,191 \\
1,191 \\
3,191 \\
1,191 \\
3,191 \\
2,382 \\
6,382 \\
\end{array}$ & $\begin{array}{l}.985 \\
.609 \\
.497 \\
.381 \\
.945 \\
.607 \\
.820 \\
\end{array}$ \\
\hline 5 & $\begin{array}{l}\text { Treatment Main } \\
\text { Linear Trend } \\
\text { Linear } x \text { Treatment } \\
\text { Quadratic Trend } \\
\text { Quadratic x Treatment } \\
\text { Trend } \\
\text { Trend } \times \text { Treatment } \\
\end{array}$ & $\begin{array}{l}0.23 \\
0.40 \\
1.24 \\
1.95 \\
1.40 \\
1.07 \\
1.37\end{array}$ & $\begin{array}{l}3,205 \\
1,205 \\
3,205 \\
1,205 \\
3,205 \\
2,410 \\
6,410 \\
\end{array}$ & $\begin{array}{l}.873 \\
.526 \\
.295 \\
.164 \\
.244 \\
.345 \\
.251 \\
\end{array}$ \\
\hline 6 & $\begin{array}{l}\text { Treatment Main } \\
\text { Linear Trend } \\
\text { Linear } x \text { Treatment } \\
\text { Quadratic Trend } \\
\text { Quadratic x Treatment } \\
\text { Trend } \\
\text { Trend } x \text { Treatment }\end{array}$ & $\begin{array}{l}0.31 \\
1.97 \\
2.22 \\
4.02 \\
0.56 \\
2.43 \\
1.84\end{array}$ & $\begin{array}{l}3,46 \\
1,46 \\
3,46 \\
1,46 \\
3,46 \\
2,92 \\
6,92\end{array}$ & $\begin{array}{l}.821 \\
.168 \\
.099 \\
.051 \\
.642 \\
.094 \\
.100\end{array}$ \\
\hline
\end{tabular}


showed deterioration (as measured by the LAI scale). However, given the multiplicity of the tests performed, the single significant test can easily be attributed to chance. It must be concluded that there were no Iifestyle changes (as measured by the LAI scales) resulting from the treatments.

However, the evaluation staff wishes to make clear that it does not necessarily consider the above findings (with regard to the LAI) to be indicative of negative treatment results, or of anything else. The evaluation staff is unaware of any demonstrations that the LAI is a valid instrument for the purposes for which it was used. Further, doubts as to its validity are raised by tables 8,9 , and 10 and by findings reported in Appendix E. The reader is also referred to Appendix $F$. 


\section{ADDITIONAL COMMENTS AND CONCLUSION}

In the preceding sections it was shown that the various treatment modalities to which the project clients were assigned produced no reduction in recidivism, when compared to the control groups, for either problem or non-problem drinkers. In this section several matters concerning the validity of the findings will be discussed.

There are several factors which might affect the external validity or generalizability (Campbell \& Stanley, 1963) of the study. The first is the nature of the treatment modalities used. Since the rehabilitation treatments were similar to treatments for drunk drivers used in many other localities (including ASAPS), the findings concerning the rehabilitative treatments can be generalized to rehabilitative efforts in many other sites. Further, the supervised probation program was designed to correspond to other lower-court probation programs, so findings concerning the effectiveness of probation supervision should also be generalizable.

The second factor is the nature of the offenders involved in the program. Only DWI first offenders were supposed to be referred to the Project, whereas first-and multiple-offenders might be mixed in other localities. However, it is reasonable to assume that first offenders are the most 1 ikely to be affected by treatments of the types studied, so it is not unreasonable to draw conclusions based on only first offenders.

Two other factors also need to be discussed. Although most of their cases were entirely routine, offenders experienced an average delay of more than five months between arrest and referral to the Project (see Appendix A). This delay is thought to be much longer than that experienced in other localities. Many criminologists argue (without hard evidence) that celerity is a major factor in determining the effectiveness of punishment. Further, to the extent that DWI results from problem drinking it is important to place offenders in treatment as soon as possible, to prevent additional offense (assuming the treatments are effective in reducing alcohol abuse). Given these considerations, the lengthy court delays might have had a major impact on the overall recidivism of the Project clients. Unfortunately, the inpact of the delays on recidivism cannot be easily determined, since the length of delay was confounded with the offender's characteristics; in general, offenders with higher rearrest risks experienced longer court delays than did lower-risk offenders. However, the delays should not have affected the internal validity of the experiment, since the delays were distributed randomly among the treatment groups.

The final factor concerns the nature of the control groups. All of the clients were referred to the Project as a condition of diversion or of probation. Diversion clients were subject to a 
jail sentence of 11 months and 29 days if they did not complete the 11-29 diversion period satisfactorily (that is, if their diversion was revoked). Probation clients (i.e., non-diversion clients, not to be confused with clients assigned to the supervised probation treatment modality) were subject to jail for the remainder of their 11-29 probation periods if their probation was revoked. All of the project clients were thus under the threat of a jail sentence for any subsequent offense. And, in general, the threat was not empty: recidivists usually were jailed for at least a short period ( 30 or 60 days), following court delays comparable to those described in Appendix A for initial arrests.

Thus, each of the treatment modalities evaluated included the suspended jail sentence in addition to any rehabilitative or supervisory aspects. The control groups were also subject to the jail threat and as such were "suspended jail sentence" groups.

There were three advantages to having this type of control group. First, the suspended jail threat was comparable to a sanction commonly used for DWI offenders. Even when not given a formal suspended sentence, offenders are traditionally threatened with jail should they be arrested again. (That threat is often made repeatedly.) Thus, the control group experienced a very traditional form of sanction.

The suspended jail threat was also necessary to ensure the internal validity of the experiment. Unlike some similar projects, participation in the treatments was coerced rather than voluntary. Failure to attend the DWI School, therapy sessions, or probation meetings could lead to revocation of probation or diversion status and to jail. For this reason participation was close to 100 percent; clients could not drop out of the study. This fact, coupled with the random assignment of clients to treatments, prevented the problem of self-selection of subjects which often plagues research projects of this type. The present study is probably one of the soundest field experiments ever performed with the criminal justice system.

Although the jail threat was clearly a positive factor affecting the internal validity of the study, it may or may not have enhanced the external validity. The project evaluation staff regards the results as more generalizable because of the jail threat since the suspended jail threat was a more realistic sanction to which to compare additional treatments than would have been the complete absence of any sanction.

The existence of the jail threat also ensured the validity of conclusions drawn about the supervisory aspect of the DWI probation program. Referral of an offender to a probation program is generally not done without the additional proviso that a more severe sanction will be applied if the conditions of the probation are not satisfied. The design used in the present study employed a threat-only group, so that any benefit found for supervised probation could be attributed to the supervision of the clients rather than to the threat of the more severe sanction. 


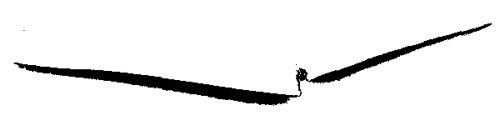

However, it has been argued by some NHTSA staff involved with the project that the jail threat somehow reduced the validity of the experimental results. It is not clear why that would be so. The suspended jail threat was not an extraordinary sanction for the offense, one unlikely to be used in other localities in combination with rehabilitation or probation, so the results found for the project treatment modalities should still be readily generalizable to treatments in other localities.

The external validity of the experiment would be seriously threatened only if the threat of jail interacted with the various treatment modalities in affecting recidivism, fouling up the comparisons of the recidivism rates of the treatments. It has been hypothesized by some that such an effect did indeed occur, that the impact of the threat of jail experienced by all of the clients was such as to mask differences in the effectiveness of the treatment modalities. This hypothesishas been advanced to account for the negative findings reported above, in an attempt to escape the otherwise hard to escape conclusion that the supervised probation and rehabilitation programs did not have any effect.

The reasoning behind the hypothesis is unclear. It might be suggested that the effect of the threatened jail sentence was extremely strong, such that the effects of the other treatment efforts were miniscule in comparison. However, as has been discussed above, the informal or formal threat of jail is a traditional form of sanction for DWI, and it was partly because of a lack of demonstrated effectiveness of such sanctions that the present project was funded. Otherwise it might be argued that the jail threat interacted with the treatments, having a deterrent effect on the control groups but none on the other groups, while the probation and rehabilitation programs had comparable effects on the groups that received those treatments. There is no way to refute that hypothesis.

There is some rather weak data available which can be brought to bear on the hypothesis that the threat of jail imposed on the Project clients reduced their recidivism. Prior to the project, the threat of jail was not imposed as systematically as during the project, since DWI offenders were not routinely placed on probation nor on diversion. Hence, given the above hypothesis, it should be expected that rearrest rates were higher before the Project than during the Project.

Figure 10 shows the cumulative rearrest rates of the project offenders and a baseline sample of offenders arrested in 1973, 1974 and 1975. Approximately one fifth of the persons arrested at least once for DWI during the 1973-1975 period are included in the baseline sample. The rearrest rates for the baseline sample are clearly much higher than those of the clients. However, it must be emphasized that the Project clients were first offenders at DWI. No such assumption can be made about the offenders in the baseline sample. Therefore, comparisons of the rearrest rates for the two groups are very questionable. 


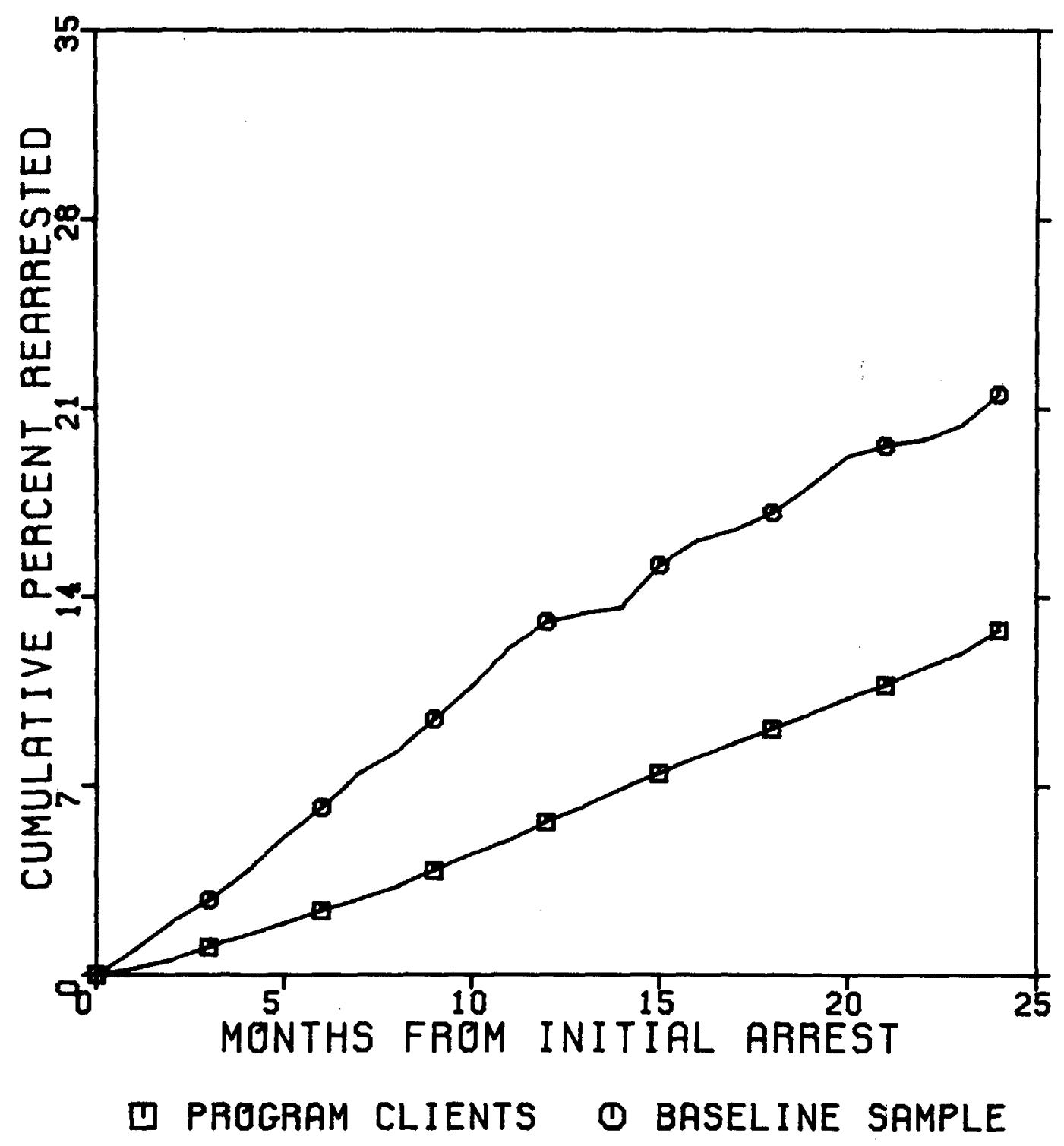

FIGURE 10. TIME FRÓM INITIAL ARREST TO FIRST REARREST, FOR PROGRAM AND BASELINE SAMPLES 
The importance of distinguishing between first- and multipleoffenders is shown in Figures 11 and 12. Figure 11 compares the times from the first observed arrest to the second observed arrest, the second observed arrest to the third and the third to the fourth for the baseline sample. Clearly, the more observed prior offenses a person had, the more likely the offender was to be arrested for an additional DWI offense. Figure 12 shows comparable results for the Project clients: the moretimes an individual was rearrested, the more likely he or she was to be arrested an additional time. The results are summarized in Table 34. These findings invalidate any comparison of the Project rearrest rate to the baseline sample rearrest rate, since the baseline sample contained an unknown number of multiple offenders.

The evaluation staff rejects any challenge of the design of the study, and stands by its substantive conclusion that the probation supervision and the rehabilitative treatments did not reduce the recidivism of the Project clients. Additional inquiry into the results should focus on two substantive topics: the nature of the Project clientele and the appropriateness of the treatment modalities for that clientele. The rehabilitation programs, especially the group therapy (assertiveness training) appear to have been designed for a middle-class, fairly well-educated clientele. Tables B1 and B2 (Appendix B) show that more than 50 percent of the problem drinkers and more than 30 percent of the social drinkers had less than a high school education; less than 20 percent of the problem drinkers and 30 percent of the social drinkers had an education beyond high school. Thus, the appropriateness of the rehabilitation programs must be questioned, especially for the problem drinkers. Also, it is not clear why assertiveness training would have been prescribed for problem drinkers. Its contents and rationale appear to be more appropriate for social drinkers.

Finally, it must be reiterated that the Project clientele included a number of individuals who were arrested during the followup period on non-DWI charges. There appears to be an association between DWI and other offenses which has not received attention. The appropriateness of treatment modalities such as those evaluated in this study for individuals who commit a variety of offenses including DWI must be questioned. 


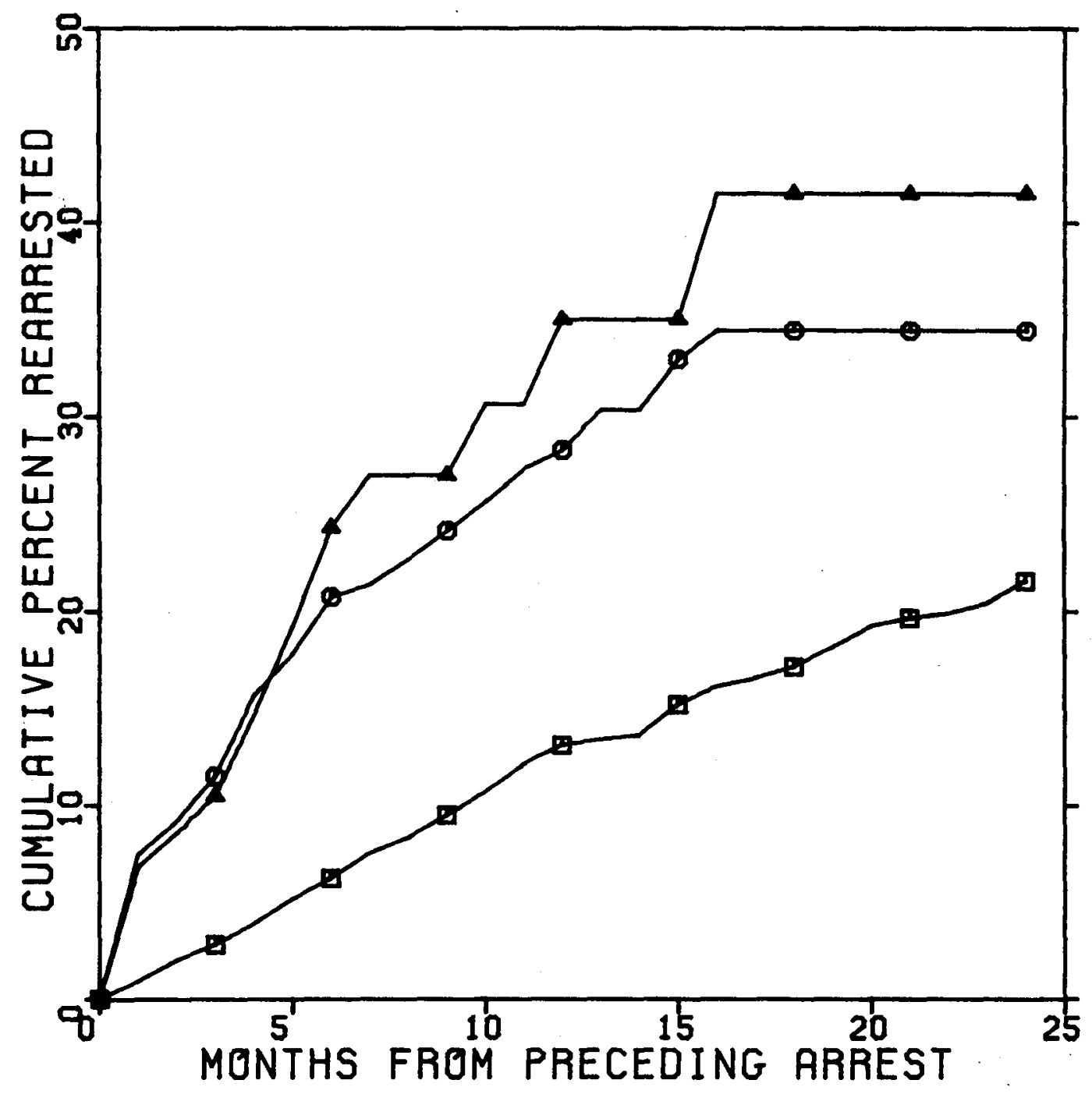

(u FIRST REARREST O SECOND REARREST

$\triangle$ THIRD REARREST

FIGURE 1 1. TIME FROM ARREST

TO SUBSEQUENT ARREST, FOR

BASELINE SAMPLE 


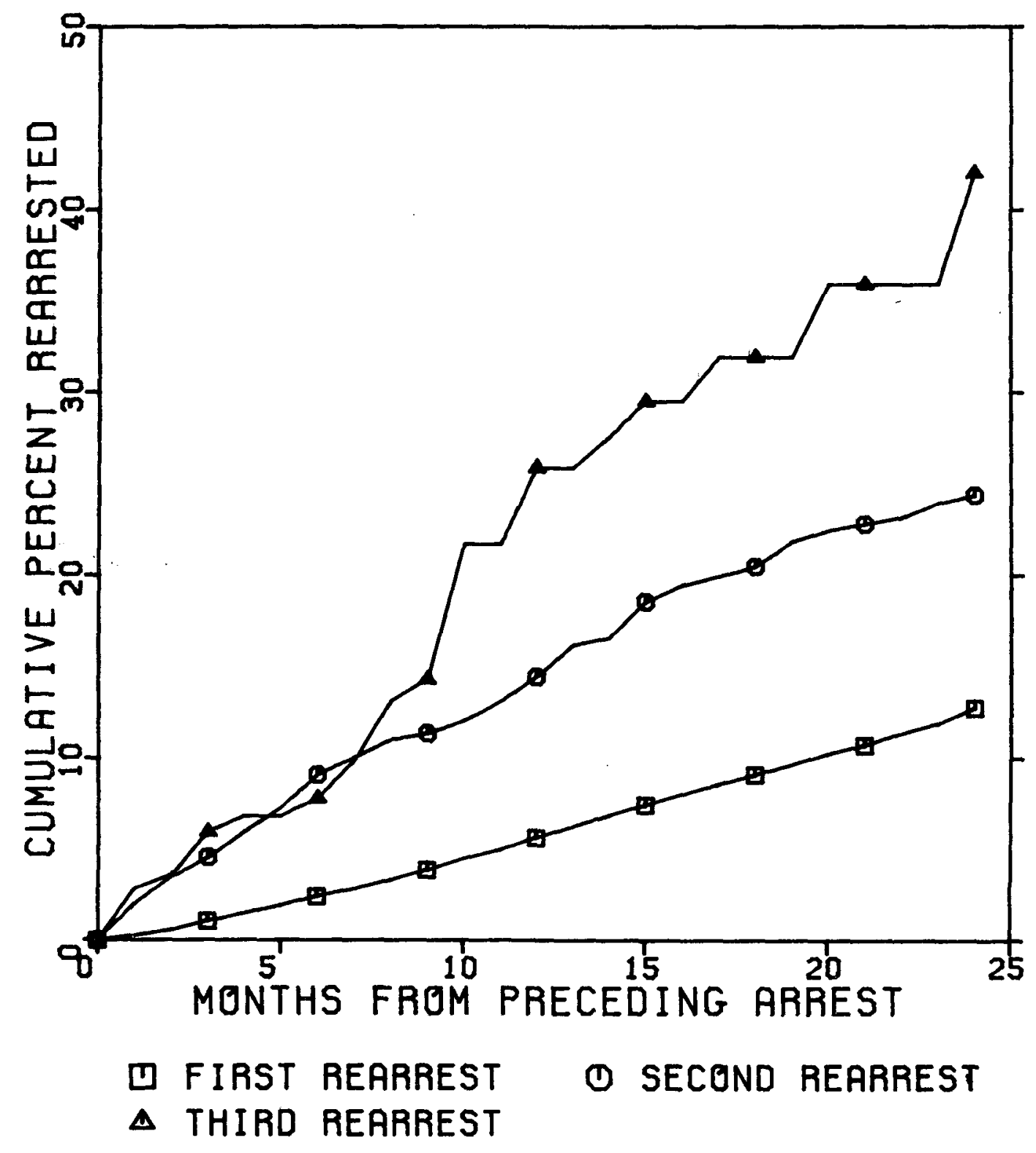

FIGURE 12. TIME FROM ARREST

TO SUBSEQUENT ARREST, FOR ALL PROGRAM CLIENTS 
Table 34. TWO YEAR DWI REARREST RATES FOR PROGRAM CLIENTS AND BASELINE SAMPLE.

\begin{tabular}{cccc}
\hline & $\begin{array}{c}\text { 2 Year } \\
\text { Rearrest } \\
\text { Rate* }\end{array}$ & $\begin{array}{c}\text { Standard } \\
\text { Error }\end{array}$ & $\begin{array}{c}\text { Sample } \\
\text { Size }\end{array}$ \\
\hline Program Clients** & & & \\
First Rearrest & $13.3 \%$ & $0.52 \%$ & 4143 \\
Second Rearrest & $24.4 \%$ & $1.95 \%$ & 771 \\
Third Rearrest & $42.0 \%$ & $8.22 \%$ & 147 \\
Baseline Sample & & & 1924 \\
First Rearrest & $21.6 \%$ & $1.43 \%$ & 248 \\
Second Rearrest & $34.4 \%$ & $4.10 \%$ & 59 \\
Third Rearrest & $41.5 \%$ & $9.40 \%$ & \\
& & & \\
\hline
\end{tabular}

* Life table estimates, based on date of preceding arrest.

** Program clients are presumed to have entered the program after their first DWI offense; hence, the first rearrest is the second offense, etc. Baseline offenders' first rearrest is the second offense between 1973 and 1975; the first arrest between 1973 and 1975 may not have been the first offense. See text for more explanation. 


\section{References}

Bishop, Y.M.M. "Fully Contigency Tables, Logits, and Split Contingency Tables," Biometrics 25, 1969, pp. 383-399.

Bishop, Y.M.M., Fienberg, S.E. \& Holland, P.D. Discrete Multivariate Analysis. Cambridge, Mass.: MIT Press, 1975.

Campbell, D.T. \& Stanley, J.D. Experimental and Quasi-Experimental Designs for Research. Chicago: Rand-McNally, 1966

Dixon, W.J. \& Brown, M.B. BMDP-79: Biomedical Computer Programs, P-Series. Berkeley, California: University of California Press, $197 \overline{9}$.

Ellingstad, V.S. LAI/CSQ Scoring Manual. Washington, D.C.: National Highway Traffic Safety Administration, 1977.

Ellingstad, V.S. \& Struckman-Johnson, D. L. Interiam Analysis of STR Performance and Effectiveness. Washington, D.C.: NHTSA, 1977.

Hul1, C.H. \& Nie, N.H. SPSS Update: New Procedures and Facilities for Releases 7 and 8. New York: McGraw-Hill, 1979.

Nie, N.H. Hull, C.H., Jenkins, J.G., Steinbrenner, K., \& Bent, D.H. SPSS: Statistical Package for the Social Sciences, second edition. New York: McGraw-Hi11, 1975.

Nunally, J.C. Psychometric Theory, second edition. New York: McGraw-Hill, 1978.

Winer, B.J. Statistical Principles in Experimental Design, second edition. New York: McGraw-Hill, 1971. 


\section{APPENDIX A}

\section{COURT DISPOSITION (REFERRAL) TIMES}

The clients in the Project were arrested in Memphis and processed in Division VIII of the Memphis City Court under Judge . Love. By agreement with the court, only DWI first-offenders were to be referred to the Project. Most of those offenders had no previous convictions of any kind, and therefore qualified for the diversion program.

Under the diversion program, the offenders were not convicted of DWI. They were placed under the jurisdiction of the DWI Probation Department for 11 months and 29 days and their cases were dismissed at the end of that period if they were not rearrested within the 11/29 period and they successfully completed the "Driver Improvement Program" (any one of four treatment modalities assigned at random by the probation department).

For practical purposes, referral to the Driver Improvement Program ( $i . e .$, the Demonstration Project) can be thought of as disposition of the cases. Technically, however, most cases were not disposed of until after the 11/29 period. For that reason, the term "program referral" will be used instead of "disposition."

Table Al shows the median time (in days) clients' cases were in the court system prior to referral to the project. The median for all clients was 149.8 days (approximately 5 months), but the period of delay differed significantly for various types of clients. Specifically, delays were associated with classification as problem drinker and with nonqualification for diversion. Social drinkers on diversion had cases disposed of in an average (median) of 131 days, while problem drinkers on diversion took 156 days. Offenders who did not qualify for diversion were in the court system much longer: nondiversion social drinkers' cases took an average of 207 days, while nondiversion problem drinkers' cases took 257 days.

The distributions of time in the court system for the four types of client are shown in Figure Al. A high line on the graph indicates that the cases were dealt with by the court relatively quickly, while a low line indicates that the court acted more slowly. As indicated by the log-rank tests, all four distributions are quite distinct from each other. It can clearly be seen that diversion clients were referred much more quickly than nondiversion clients and that social drinkers were referred more quickly than problem drinkers. It can also be seen that even 20 months after arrest, some clients' cases were still before the court.

The lengthy referral times whown in Figure Al can be explained to some extent by these factors: 
TABLE AI. MEDIAN TIME FROM ARREST TO REFERRAL TO THE PROJECT, BY DRINKER TYPE AND DIVERSION STATUS

\begin{tabular}{ccc}
\hline Drinker Type & $\begin{array}{c}\text { Median Days } \\
\text { to Referral }\end{array}$ & $\begin{array}{c}\text { Sample } \\
\text { Size }\end{array}$ \\
\hline Social Drinkers & & \\
Diversion & 131.0 & 2241 \\
Nondiversion & 206.9 & 266 \\
Problem Drinkers & & 1275 \\
Diversion & 155.8 & 358 \\
Nondiversion & 256.9 & 4140 \\
All Clients & 149.8 & \\
\hline
\end{tabular}

TABLE. A2, LOG-RANK TESTS FOR EQUALITY OF THE DISTRIBUTIONS OF TIME FROM ARREST TO REFERRAL, FOR DRINKER TYPE AND DIVERSION STATUS*

\begin{tabular}{|c|c|c|c|}
\hline & $x^{2}$ & $\mathrm{df}$ & $p$ \\
\hline $\begin{array}{l}\text { Overall Comparison of Four } \\
\text { Groups }\end{array}$ & 265.803 & 3 & .000 \\
\hline $\begin{array}{l}\text { Social Drinkers/Diversion } \\
\text { vs. Problem Drinkers } \\
\text { Diversion }\end{array}$ & 191.11 & 1 & .000 \\
\hline $\begin{array}{l}\text { Problem Drinkers/Diversion } \\
\text { vs. Social Drinkers/ } \\
\text { Nondiversion }\end{array}$ & 34.00 & 1 & .000 \\
\hline $\begin{array}{l}\text { Social Drinkers/Nondiversion } \\
\text { vs. Problem Drinkers/ } \\
\text { Nondiversion }\end{array}$ & 6.791 & 1 & .009 \\
\hline
\end{tabular}

*Two groups comparisons are of groups with most similar distributions.

1. Some clients ( 82 , or approximately $1.9 \%$, as far as evaluation staff can determine) were rearrested between their initial arrest and program referral. This caused delays and generally resulted in disqualification for diversion. 


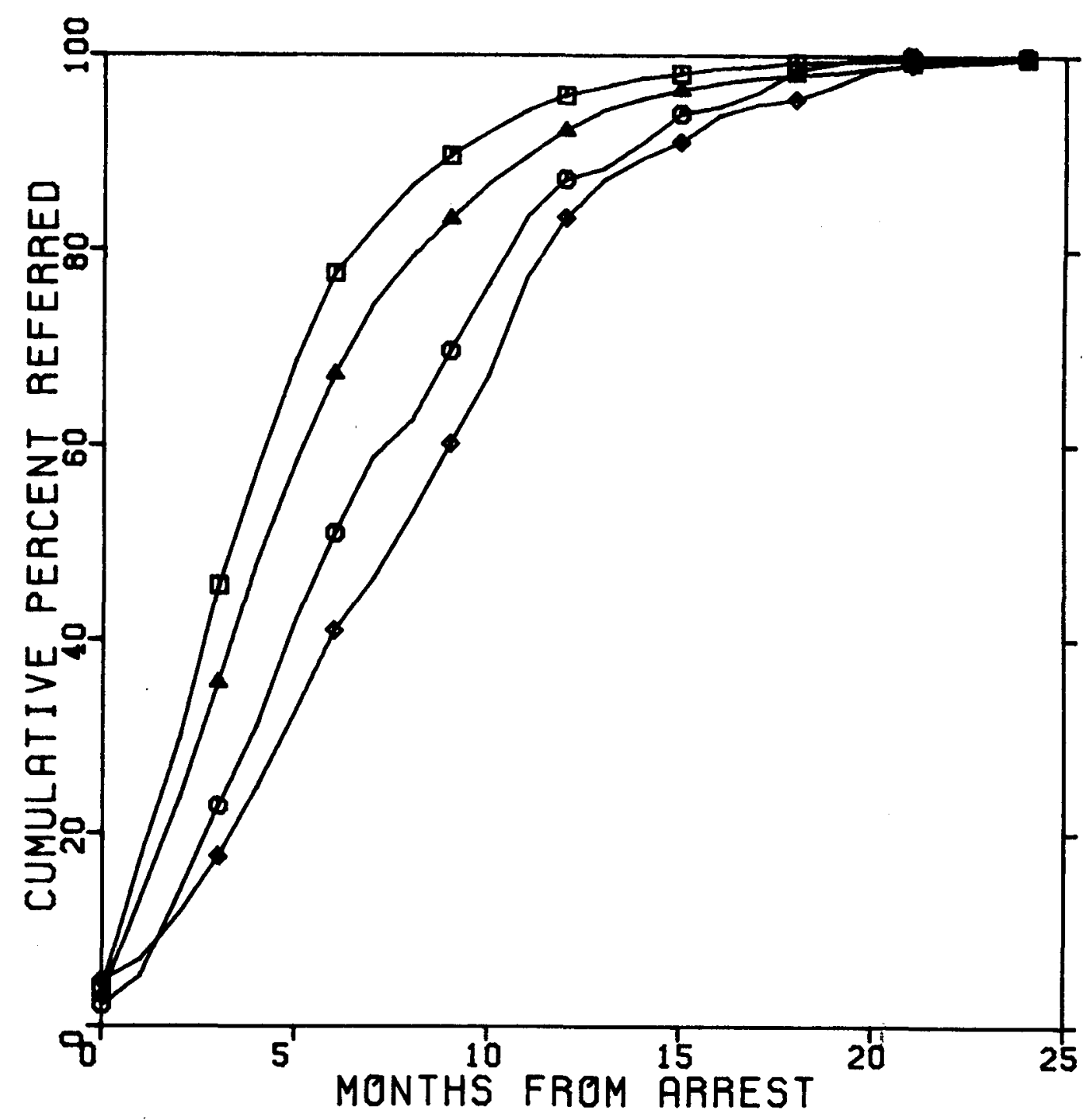

$\begin{array}{ll}\square \text { SOCIAL-DIVERSN } & \text { O SOCIAL-NONDIV } \\ \triangle \text { PROBLM-DIVERSN } & \diamond \text { PROBLM-NONDIV }\end{array}$

FIGURE A1. TIME FROM ARREST TO REFERRAL, BY DRINKER TYPE AND DIVERSION STATUS 
2. Individuals with previous arrest histories, who had more experience with the criminal justice system, were more likely to avoid case disposition with delaying tactics. Those persons were also likely to be unqualified for diversion.

3. Judge Love had a policy of requiring that every individual appearing in his court be represented by a private attorney. Cases were delayed if offenders appeared without attorneys.

4. Judge Love also had a policy of cooperating with defense attorneys, and usually granted continuances when requested. Attorneys often asked and received continuances until clients had paid their fees. Since social- and problem-drinking status was not determined until after Project referral, the differing delays for those two groups might simply be due to their differing demographic compositions (see Appendix C), such that social drinkers were better able to pay their attorneys.

The great majority of cases heard in Judge Love's court were of a very routine nature, and there were no legitimate reasons for the lengthy delays. Many criminologists have suggested that legal sanctions are most effective if applied to offenders immediately after commission of their offenses. It is possible that the apparent lack of effectiveness of the treatments evaluated in this report was due to the long delays prior to treatment referral. 
APPENDIX B

EFFECTIVENESS OF THE RANDOMIZATION PROCEDURE

At the first meeting between a Project client and the probation staff the client was assigned at random to one of the four treatment modalities. The purpose of the randomization procedure, as with randomization in general, was to distribute equally among all of the treatment groups any client attribute that might be related to subsequent performance (particularly, DWI recidivism). In this appendix the results of the assignment procedure will be examined so that, if necessary, statistical adjustments in the rearrest rates for the treatments can be made to ensure that the project's results do not merely reflect unequal distribution of client characteristics.

Data were collected on a number of variables potentially related to client recidivism, including demographic characteristics and variables such as prior DWI arrest and diversion eligibility. Those variables were the following:

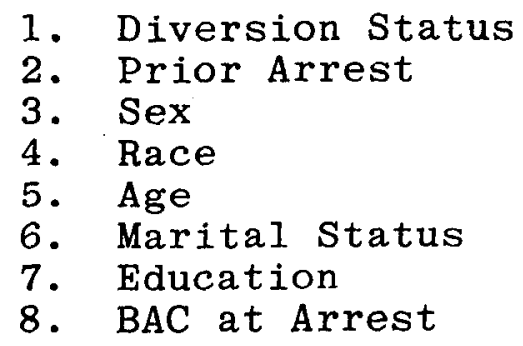

All comparisons of the client characteristics were performed separately for social and problem drinkers.

Tables B1 and B2 show univariate comparisons of the four treatment groups with respect to the client characteristics. It can be seen that the assignment procedure was very. successful in producing groups of approximately equal size, even though no mechanism other than chance was employed. For social drinkers, each of the treatment groups contained between $24.5 \%$ and $25.3 \%$ of the total sample; the problem drinker groups all contained between $24.4 \%$ and $25.8 \%$ of the sample.

Table Bl shows that when considered separately there were no characteristics on which social drinkers in the various treatments differed significantly. The only characteristic on which the test approached significance was race. The probation-plusrehabilitation groups had the highest percentage black (47.6) while the probation-only groups had the lowest (40.1).

Table B2 shows only one characteristic on which the problem drinker treatment groups differed significantly, sex. The 
percentage of women in the probation-plus-rehabilitation group (11.5) was way out of line with the percentage for the other groups.

Because for each drinker type there was at most one characteristic on which the treatment groups differed.It was unnecessary to perform multivariate tests to determine if differences on some characteristics might be consequences of differences on other characteristics. However, it was desirable to make more general tests of equality of the distributions of the characteristics of the clients in the various treatment groups. This was done using multidimensional contingency table methods to compare the groups on. several characteristics at a time. (See Table B3.)

Two groups of variables were considered separately. The first consisted of sex, race, and age. The goodness of fit tests for Model (1) (for social and for problem drinkers) amount to comparisons of the three-way distributions of sex, race, and age for the various treatment groups. The tests show that overall, the group did not differ with respect to those three characteristics. A second group of characteristics consisting of diversion status, LAI assignment, and prior arrest was also compared, and again no differences were found.

In summary, the random-assignment procedure was not successful at equating the problem drinker groups with respect to sex, and was only marginally successful at equating the social drinker groups with respect to race. Given the multiplicity of the statistical tests involved it is not unreasonable to attribute those discrepancies to chance. That interpretation is supported by the fact that the multivariate tests for equality of the distributions of the client characteristics indicated no differences between treatment groups for either social or problem drinkers. However, because of these findings, sex and race were entered into the analyses of treatment effects on DWI rearrest as control variables. 
TABLE B1. CHARACTERISTICS OF SOCIAL DRINKERS IN VARIOUS TREATMENT GROUPS

\begin{tabular}{|c|c|c|c|c|c|c|c|}
\hline \multirow[b]{2}{*}{ Characteristic } & \multirow[b]{2}{*}{ Con. } & \multicolumn{3}{|c|}{ reatment Assignment } & \multicolumn{3}{|c|}{$\frac{\text { Significance }}{\text { Test }}$} \\
\hline & & $\begin{array}{l}\text { Pro.- } \\
\text { only }\end{array}$ & $\begin{array}{l}\text { Rehab.- } \\
\text { only }\end{array}$ & $\begin{array}{l}\text { Pro.t } \\
\text { Rehab. }\end{array}$ & $x^{2}$ & $\mathrm{df}$ & $\mathrm{p}$ \\
\hline Sex & & & & & & & \\
\hline $\begin{array}{l}\text { Female } \\
\text { Male }\end{array}$ & $\begin{array}{l}12.7 \% \\
87.3 \%\end{array}$ & $\begin{array}{l}10.0 \% \\
90.0 \%\end{array}$ & $\begin{array}{l}11.0 \% \\
89.0 \%\end{array}$ & $\begin{array}{l}11.5 \% \\
88.5 \%\end{array}$ & 2.48 & 1 & .479 \\
\hline Race & & & & & & & \\
\hline $\begin{array}{l}\text { Black } \\
\text { White }\end{array}$ & $\begin{array}{l}44.7 \% \\
55.3 \%\end{array}$ & $\begin{array}{l}40.1 \% \\
59.9 \%\end{array}$ & $\begin{array}{l}44.3 \% \\
55.5 \%\end{array}$ & $\begin{array}{l}47.6 \% \\
53.5 \%\end{array}$ & 7.21 & 1 & .066 \\
\hline Age & & & & & & & \\
\hline $\begin{array}{l}24 \& \text { Under } \\
25-34 \\
35-44 \\
45-54 \\
55 \& \text { Over }\end{array}$ & $\begin{array}{l}25.6 \% \\
34.3 \% \\
16.0 \% \\
12.9 \% \\
11.3 \%\end{array}$ & $\begin{array}{l}26.7 \% \\
33.2 \% \\
19.1 \% \\
10.7 \% \\
10.3 \%\end{array}$ & $\begin{array}{l}24.1 \% \\
33.3 \% \\
19.8 \% \\
12.3 \% \\
10.5 \%\end{array}$ & $\begin{array}{l}27.6 \% \\
30.0 \% \\
18.5 \% \\
13.0 \% \\
10.9 \%\end{array}$ & 8.40 & 12 & .753 \\
\hline Marita1 Status & & & & & & & \\
\hline $\begin{array}{l}\text { Single } \\
\text { Married } \\
\text { Divorced, Sep- } \\
\text { arated, } \\
\text { Widowed }\end{array}$ & $\begin{array}{l}32.0 \% \\
44.2 \% \\
23.8 \%\end{array}$ & $\begin{array}{l}33.5 \% \\
43.3 \% \\
23.2 \%\end{array}$ & $\begin{array}{l}31.6 \% \\
44.3 \% \\
24.1 \%\end{array}$ & $\begin{array}{l}35.4 \% \\
43.0 \% \\
21.7 \%\end{array}$ & 2.87 & 9 & .825 \\
\hline Education & & & & & & & \\
\hline $\begin{array}{l}\text { Less than HS } \\
\text { HS Grad. } \\
\text { More than HS }\end{array}$ & $\begin{array}{l}32.6 \% \\
37.0 \% \\
30.3 \%\end{array}$ & $\begin{array}{l}30.8 \% \\
41.4 \% \\
27.8 \%\end{array}$ & $\begin{array}{l}34.4 \% \\
36.7 \% \\
28.9 \%\end{array}$ & $\begin{array}{l}35.4 \% \\
35.4 \% \\
29.2 \%\end{array}$ & 6.47 & 6 & .372 \\
\hline$\underline{B A C}$ & & & & & & & \\
\hline $\begin{array}{l}\text { Less than .15 } \\
.16-.19 \\
.20 \text { \& Over } \\
\text { Refused Test }\end{array}$ & $\begin{array}{r}44.3 \% \\
28.7 \% \\
18.3 \% \\
8.6 \%\end{array}$ & $\begin{array}{l}41.1 \% \\
29.1 \% \\
19.6 \% \\
10.3 \%\end{array}$ & $\begin{array}{r}45.2 \% \\
23.9 \% \\
21.9 \% \\
9.1 \%\end{array}$ & $\begin{array}{l}41.7 \% \\
28.1 \% \\
19.4 \% \\
11.8 \%\end{array}$ & 11.28 & 12 & .506 \\
\hline$\frac{\text { Diversion Status }}{\text { Nondiversion }}$ & $11.6 \%$ & $10.1 \%$ & $11.6 \%$ & $9.3 \%$ & 2.58 & 3 & .462 \\
\hline $\begin{array}{l}\text { Prior Arrest } \\
\frac{\text { With Prior }}{\text { Sample }} \\
\text { Size }\end{array}$ & $\begin{aligned} 2.8 \% \\
---- \\
613\end{aligned}$ & $\begin{array}{r}2.5 \% \\
----\end{array}$ & $\begin{array}{l}1.9 \% \\
-\quad---\end{array}$ & $\begin{array}{l}2.1 \% \\
--- \\
633\end{array}$ & $\begin{array}{r}1.35 \\
-\quad-\quad-\end{array}$ & $\begin{array}{l}3 \\
-\quad-\end{array}$ & $\begin{array}{l}.717 \\
---\end{array}$ \\
\hline
\end{tabular}

Con. = Control

Pro.-only = Probation-only

Rehab.-only = Rehabilitation-only

Pro.+Rehab. = Probation-plus-Rehabilitation 
TABLE B2. CHARACTERISTICS OF PROBLEM DRINKERS IN THE VARIOUS TREATMENT GROUPS

\begin{tabular}{|c|c|c|c|c|c|c|c|}
\hline \multirow[b]{2}{*}{ Characteristic } & \multirow[b]{2}{*}{ Con. } & \multicolumn{3}{|c|}{ reatment Assignment } & \multicolumn{3}{|c|}{$\frac{\text { Significance }}{\text { Test }}$} \\
\hline & & $\begin{array}{l}\text { Pro.- } \\
\text { only }\end{array}$ & $\begin{array}{l}\text { Rehab.- } \\
\text { on 1y }\end{array}$ & $\begin{array}{l}\text { Pro.t } \\
\text { Rehab. }\end{array}$ & $x^{2}$ & $\mathrm{df}$ & $\mathrm{p}$ \\
\hline $\begin{array}{l}\frac{\text { Sex }}{\text { Female }} \\
\text { Male }\end{array}$ & $\begin{array}{r}7.6 \% \\
92.4 \%\end{array}$ & $\begin{array}{r}6.6 \% \\
93.4 \%\end{array}$ & $\begin{array}{r}4.8 \% \\
95.2 \%\end{array}$ & $\begin{array}{l}11.5 \% \\
88.5 \%\end{array}$ & 14.03 & 1 & .003 \\
\hline 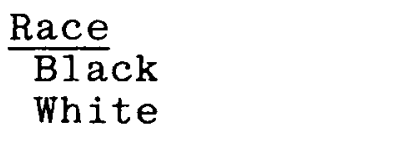 & $\begin{array}{l}49.9 \% \\
50.1 \%\end{array}$ & $\begin{array}{l}49.7 \% \\
50.3 \%\end{array}$ & $\begin{array}{l}46.4 \% \\
53.6 \%\end{array}$ & $\begin{array}{l}51.2 \% \\
48.8 \%\end{array}$ & 2.07 & 1. & .559 \\
\hline $\begin{array}{l}\frac{\text { Age }}{24} \& \text { Under } \\
25-34 \\
35-44 \\
45-54 \\
55 \& \text { Over }\end{array}$ & $\begin{array}{l}18.4 \% \\
28.9 \% \\
23.2 \% \\
18.9 \% \\
10.7 \%\end{array}$ & $\begin{array}{l}15.9 \% \\
25.0 \% \\
22.2 \% \\
22.0 \% \\
14.9 \%\end{array}$ & $\begin{array}{l}14.8 \% \\
28.3 \% \\
21.6 \% \\
22.1 \% \\
13.3 \%\end{array}$ & $\begin{array}{l}18.1 \% \\
32.6 \% \\
19.4 \% \\
18.6 \% \\
11.3 \%\end{array}$ & 13.43 & 12 & .339 \\
\hline $\begin{array}{l}\text { Marital Status } \\
\text { Single } \\
\text { Married } \\
\text { Divorced, Sep- } \\
\text { arated, } \\
\text { Widowed }\end{array}$ & $\begin{array}{l}27.7 \% \\
38.7 \% \\
33.7 \%\end{array}$ & $\begin{array}{l}22.0 \% \\
44.9 \% \\
35.1 \%\end{array}$ & $\begin{array}{l}22.8 \% \\
44.9 \% \\
32.3 \%\end{array}$ & $\begin{array}{l}23.3 \% \\
42.9 \% \\
33.8 \%\end{array}$ & 6.04 & 6 & .418 \\
\hline $\begin{array}{l}\text { Education } \\
\text { Less than HS } \\
\text { HS Grad. } \\
\text { More than HS }\end{array}$ & $\begin{array}{l}52.7 \% \\
32.7 \% \\
14.6 \%\end{array}$ & $\begin{array}{l}56.8 \% \\
30.1 \% \\
13.1 \%\end{array}$ & $\begin{array}{l}52.6 \% \\
27.8 \% \\
19.5 \%\end{array}$ & $\begin{array}{l}50.7 \% \\
32.8 \% \\
16.4 \%\end{array}$ & 9.21 & 6 & .162 \\
\hline $\begin{array}{l}\frac{\mathrm{BAC}}{\text { Less than } .15} \\
.16-.19 \\
.20 \text { \& Over } \\
\text { Refused Test }\end{array}$ & $\begin{array}{r}9.3 \% \\
34.1 \% \\
41.3 \% \\
15.3 \%\end{array}$ & $\begin{array}{l}11.4 \% \\
27.5 \% \\
46.7 \% \\
14.4 \%\end{array}$ & $\begin{array}{l}10.5 \% \\
28.8 \% \\
47.1 \% \\
13.5 \%\end{array}$ & $\begin{array}{l}11.2 \% \\
27.9 \% \\
44.9 \% \\
15.9 \%\end{array}$ & 9.30 & 12 & .677 \\
\hline$\frac{\text { Diversion Status }}{\text { Nondiversion }}$ & $27.1 \%$ & $21.7 \%$ & $21.3 \%$ & $21.1 \%$ & 1.41 & 3 & .703 \\
\hline $\begin{array}{l}\text { Prior Arrest } \\
\text { With Prior } \\
\overline{\text { Sample }} \\
\text { Size }\end{array}$ & $\begin{array}{c}5.3 \% \\
---- \\
419\end{array}$ & $\begin{array}{c}4.5 \% \\
---- \\
396\end{array}$ & $\begin{array}{c}5.6 \% \\
-\quad-- \\
408\end{array}$ & $\begin{array}{l}4.8 \% \\
--- \\
399\end{array}$ & $\begin{array}{r}0.61 \\
-\quad-\quad-\end{array}$ & $\begin{array}{l}3 \\
--\end{array}$ & $\begin{array}{l}.895 \\
-\quad--\end{array}$ \\
\hline
\end{tabular}

Con. = Control

Pro.-only = Probation-only

Rehab.-only = Rehabilitation-only

Pro.+Rehab. = Probation-plus-Rehabilitation 
TABLE B3. MULTIVARIATE COMPARISONS OF CLIENT CHARACTERISTICS FOR TREATMENT GROUPS

\begin{tabular}{lccc}
\hline Model & $x^{2}$ for Model Fit* & df & p \\
\hline SQA, T** (Social Drinkers) & 51.58 & 57 & .678 \\
SQA, T, (Problem Drinkers) & 59.65 & 57 & .379 \\
DLP, T (Social Drinkers) & 17.17 & 21 & .666 \\
DLP, T (Problem Drinkers) & 16.44 & 21 & .746 \\
\hline
\end{tabular}

*Likelihood ratio $x^{2}$.

**Variable codes are as follows:

(T) Treatment modality

(S) Sex

(Q) Race

(A) Age

(D) Diversion Status

(L) LAI Administration

(P) Prior Arrest. 
During the intake session each client was classified as either a problem drinker or a nonproblem (or social) drinker on the basis of criteria described in the text of this report. It was implicit in the design of the project that the problem-drinker group was a higher risk group and hence required a higher level of intervention than the social-drinker group. The validity of the assumption that the clients classified as problem drinkers were a higher risk group has been shown by the significantly higher DWI rearrest rate of that group. In this appendix the characteristics of the two groups of clients will be analyzed, in the hope detailed examination of the characteristics of DWI offenders may eventually shed some light on the drinking and driving problem.

Table Cl shows the characteristics of social and problem drinkers. It can be seen that the social-drinker group had a higher percentage of females and a lower percentage of blacks than the problem-drinker group. Social drinkers were younger than problem drinkers, were better educated, and were more likely to be single or married (as opposed to divorced, separated, or widowed). Also, social drinkers were more likely to be on diversion and less likely to have prior arrests.

Because of interrelationships between the various client characteristics it is possible that some of the relationships described above are spurious. For example, problem drinkers might be more 1ikely to be divorced, separated, or widowed simply because they are older. Therefore it is necessary to perform multivariate tests of the differences between the two groups.

The client characteristics that were used in the analysis were sex, race, age, marital status, and education. Prior arrest and diversion status were not used. Data on client income were also available but were not considered to be very reliable.

A six-way contingency table was constructed and models that were saturated with respect to the client characteristics were considered. First models containing relationships of sex, race, and age with problem-drinker status were tested. It can be seen in Table C2 that, given sex and age, race was not related to problem drinking but marital status and education were. The tests of models (9) and (10) show that the three-way terms involving sex, age, and problem drinking also added significantly to the overall fit to the data.

The log-linear parameters for Model (11) were estimated and the following equation for the logic of the probability of classification as a problem drinker was constructed: 
TABLE C1. UNIVARIATE COMPARISON OF CHARACTERISTICS OF SOCIAL AND PROBLEM DRINKERS

\begin{tabular}{|c|c|c|c|c|c|}
\hline \multirow[b]{2}{*}{ Characteristic } & \multicolumn{2}{|c|}{ Drinker Type } & \multirow[b]{2}{*}{$x^{2}$} & \multirow[b]{2}{*}{$\mathrm{df}$} & \multirow[b]{2}{*}{$\mathrm{p}$} \\
\hline & Social & Prob. & & & \\
\hline \multicolumn{6}{|l|}{$\underline{\operatorname{Sex}}$} \\
\hline $\begin{array}{l}\text { Female } \\
\text { Male }\end{array}$ & $\begin{array}{l}11.3 \% \\
88.7 \%\end{array}$ & $\begin{array}{r}7.6 \% \\
92.4 \%\end{array}$ & 14.37 & 1 & .000 \\
\hline \multicolumn{6}{|l|}{ Race } \\
\hline $\begin{array}{l}\text { Black } \\
\text { White }\end{array}$ & $\begin{array}{l}44.2 \% \\
55.8 \%\end{array}$ & $\begin{array}{l}49.3 \% \\
50.7 \%\end{array}$ & 10.29 & 1 & .001 \\
\hline \multicolumn{6}{|l|}{$\underline{\text { Age }}$} \\
\hline $\begin{array}{l}\text { Less than } 25 \\
25-34 \\
35-44 \\
45-54 \\
55 \& \text { over }\end{array}$ & $\begin{array}{l}26.0 \% \\
32.7 \% \\
18.4 \% \\
12.2 \% \\
10.7 \%\end{array}$ & $\begin{array}{l}16.8 \% \\
28.7 \% \\
21.6 \% \\
20.3 \% \\
12.5 \%\end{array}$ & 92.25 & 4 & .000 \\
\hline \multicolumn{6}{|l|}{ Education } \\
\hline $\begin{array}{l}\text { Less than high school } \\
\text { High school } \\
\text { More than high school }\end{array}$ & $\begin{array}{l}33.3 \% \\
37.6 \% \\
29.1 \%\end{array}$ & $\begin{array}{l}53.2 \% \\
30.9 \% \\
15.9 \%\end{array}$ & 178.68 & 2 & .000 \\
\hline $\begin{array}{l}\text { Marital Status } \\
\text { Single } \\
\text { Married } \\
\text { Divorced, separated, or widowed }\end{array}$ & $\begin{array}{l}33.1 \% \\
43.7 \% \\
23.2 \%\end{array}$ & $\begin{array}{l}24.0 \% \\
42.8 \% \\
33.2 \%\end{array}$ & 64.66 & 2 & .000 \\
\hline \multicolumn{6}{|l|}{ Diversion Status } \\
\hline $\begin{array}{l}\text { Nondiversion } \\
\text { Diversion }\end{array}$ & $\begin{array}{l}10.7 \% \\
89.3 \%\end{array}$ & $\begin{array}{l}22.1 \% \\
77.9 \%\end{array}$ & 99.01 & 1 & .000 \\
\hline \multicolumn{6}{|l|}{ Prior Arrest } \\
\hline $\begin{array}{l}\text { With prior } \\
\text { With no prior }\end{array}$ & $\begin{array}{r}2.3 \% \\
97.7 \%\end{array}$ & $\begin{array}{r}5.1 \% \\
94.9 \%\end{array}$ & 22.75 & 1 & .000 \\
\hline Sample Size & 2506 & 1622 & --- & - & - \\
\hline
\end{tabular}


TABLE C2. TESTS OF LOG-LINEAR MODELS FOR PREDICTING PROBLEM DRINKING

\begin{tabular}{|c|c|c|c|c|c|c|c|}
\hline & Model & $\begin{array}{l}\chi^{2} \text { for } \\
\text { Effects } \\
\text { Added or } \\
\text { Deleted* }\end{array}$ & $\mathrm{df}$ & $p$ & $\begin{array}{l}x^{2} \\
\text { for } \\
\text { Model } \\
\text { Fit* } \\
\end{array}$ & $\mathrm{df}$ & $p$ \\
\hline (1) & $\mathrm{SQAME}, \mathrm{K}^{* *}$ & --- & -- & ---- & 420.35 & 179 & .000 \\
\hline (2) & $\mathrm{SQAME}, \mathrm{KS}, \mathrm{KQ}, \mathrm{KA}$ & 103.53 & 6 & .000 & 316.82 & 173 & .000 \\
\hline (3) & $\begin{array}{l}\text { SQAME, KS, KQ } \\
\text { [delete KA from } \\
\text { (2)] }\end{array}$ & 86.44 & 4 & .000 & 403.26 & 177 & .000 \\
\hline (4) & $\begin{array}{l}\text { SQAME, KS, KA } \\
\text { [delete KQ from } \\
\text { (2)] }\end{array}$ & 1.67 & 1 & .196 & 318.49 & 174 & .000 \\
\hline (5) & $\begin{array}{l}\text { SQAME, KA, KQ } \\
\text { [delete KS from } \\
\text { (2)] }\end{array}$ & 8.45 & 1 & .004 & 325.27 & 174 & .000 \\
\hline (6) & 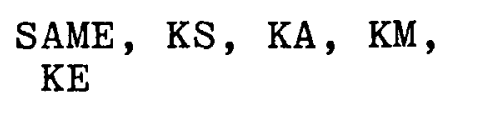 & --- & -- & $\cdots$ & 89.71 & 80 & .214 \\
\hline (7) & $\begin{array}{l}\text { SAME, KS, KA, KM } \\
\text { [delete KE from } \\
\text { (6)] }\end{array}$ & 120.19 & 2 & .000 & 209.90 & 82 & .000 \\
\hline (8) & $\begin{array}{l}\text { SAME, KS, KA, KE } \\
\text { [delete KM from } \\
\text { (6)] }\end{array}$ & 28.52 & 2 & .000 & 118.24 & 82 & .006 \\
\hline (9) & $\begin{array}{l}\text { SAME, KSA, KE, KM } \\
\text { [add KSA to (6)] }\end{array}$ & 18.85 & 4 & .000 & 70.87 & 76 & .645 \\
\hline$(10)$ & $\begin{array}{l}\text { SAME, KSA, KSE, } \\
\text { KM [add KSE to } \\
\text { (9.)] }\end{array}$ & 8.04 & 2 & .018 & 62.82 & 74 & .820 \\
\hline (11) & $\begin{array}{l}\text { SAE, SAM, ME, KSA } \\
\text { KSE, KM [delete } \\
\text { unneeded terms } \\
\text { from (10)] }\end{array}$ & 39.74 & 36 & .400 & 102.56 & 110 & .680 \\
\hline
\end{tabular}

*Likelihood ratio $x^{2}$.

**Variable codes are as follows: (K) Problem-drinker classification; (S) Sex; (Q) Race; (A) Age; (M) Marital status; and (E) Education. 


$$
\begin{aligned}
& \log \left[\frac{\mathrm{P}(\text { problem })}{\mathrm{P}(\mathrm{social})}\right]=-.680+.258 \mathrm{I}_{1}+\left(-.080 \mathrm{I}_{2}+.064 \mathrm{I}_{3}+.176 \mathrm{I}_{4}\right. \\
& \left.+.194 \mathrm{I}_{5}-.354 \mathrm{I}_{6}\right)+\left(-.068 \mathrm{I}_{7}-.180 \mathrm{I}_{8}+\right. \\
& \left..248 \mathrm{I}_{9}\right)+\left(.312 \mathrm{I}_{10}+.032 \mathrm{I}_{11}-.344 \mathrm{I}_{12}\right)+ \\
& \left(376 \mathrm{I}_{13}+.138 \mathrm{I}_{14}+.070 \mathrm{I}_{15}-.204 \mathrm{I}_{16}-\right. \\
& \left..342 \mathrm{I}_{17}\right)+\left(-.216 \mathrm{I}_{18}+.082 \mathrm{I}_{19}+.136 \mathrm{I}_{20}\right) \\
& \text { where } I_{1} \quad-i \text { if male } \\
& I_{2}=\begin{array}{ll}
1 & \text { if age less than } 24 \\
0 & \text { otherwise }
\end{array} \\
& \mathrm{I}_{3}=\quad \begin{array}{l}
\text { if age from } 25-34 \\
0 \text { otherwise }
\end{array} \\
& I_{4}=\quad \begin{array}{l}
\text { If age from } 35-44 \\
0 \text { otherwise }
\end{array} \\
& I_{5}=\begin{array}{l}
1 \text { if age from } 45-54 \\
0 \text { otherwise }
\end{array} \\
& I_{6}=\quad \begin{array}{l}
1 \\
0 \text { if age greater than } 54
\end{array} \\
& \mathrm{I}_{7}=\begin{array}{l}
1 \text { if single } \\
0
\end{array} \\
& I_{8}=\quad \begin{array}{l}
1 \text { if married } \\
0 \text { if not }
\end{array} \\
& I_{9}=1 \text { if divorced, separated, } \\
& 0 \text { if not } \\
& I_{10}=\begin{array}{l}
1 \text { if less than HS ed. } \\
0 \text { otherwise }
\end{array} \\
& I_{I 1}=\quad \begin{array}{l}
\text { if HS grad. only } \\
0 \text { otherwise }
\end{array} \\
& \mathrm{I}_{12}=\quad \begin{array}{l}
\text { if more than HS ed. } \\
0 \text { otherwise }
\end{array} \\
& \mathrm{I}_{13}=\quad 1 \text { if female, less than } \\
& -1 \text { if male, less than } \\
& 25 \text { years } \\
& \begin{array}{c}
\mathrm{I}_{14}=\quad 1 \text { if female, 25- } \\
\quad 34 \text { years } \\
-1 \text { if male, 25- } \\
34 \text { years }
\end{array} \\
& I_{15}=\quad 1 \text { if female, 35- } \\
& \text {-1 if male, 35- } \\
& 44 \text { years } \\
& I_{16}=1 \text { jif female, 45- } \\
& 54 \text { years } \\
& \text {-1 if male, 45- } \\
& 54 \text { years } \\
& I_{17}=\quad I_{54} \text { if female, over } \\
& -1 \text { if male, over } \\
& 54 \text { years } \\
& \mathrm{I}_{18}=\quad 1 \text { if female, less } \\
& -1 \text { if male, less } \\
& \text { than HS } \\
& \mathrm{I}_{19}=\quad \begin{array}{r}
\text { If female, HS } \\
-1 \text { if male, HS }
\end{array} \\
& I_{20}=\quad L \text { if female, more } \\
& \text { than HS } \\
& \text { - it if male, more } \\
& \text { than HS }
\end{aligned}
$$


The equation can be interpreted qualitatively as showing the following:

1. Males were more likely than females to be classified as problem drinkers.

2. There was a curvilinear relationship between age and problem drinking: The oldest and youngest age groups were less likely than the others to be classified as problem drinkers.

3. Divorced, separated, and widowed clients were more likely than others to be classified as problem drinkers.

4. Less-educated clients were more likely to be classified as problem drinkers

5. Among younger clients, women were more likely than men to be classed as problem drinkers; but among older clients, men were more likely to be classified as problem drinkers. (Or, women problem drinkers were younger than men problem drinkers.)

6. Among poorly educated clients, men were more likely than women to be classed as problem drinkers, while among bettereducated clients, women were more likely than men to be classed as problem drinkers. (Or, male problem drinkers were not as well educated as women problem drinkers.) 
APPENDIX D

MODEL FOR DWI REARREST

Analyses in the text of this report showed no evidence of any effects on recidivism due to either treatment modality or LAI administration. However, effects of certain other variables were shown. In this section an attempt will be made to construct a model for predicting DWI rearrest, using any data available to the evaluation staff. Contingency table methods (specifically, log-linear models) were chosen as most appropriate for the analysis.

In general there is no "best" procedure for selection of appropriate log-linear model for a particular contingency table. Not only are various statistical criteria available, but the statistical criteria may be satisfied by alternative models. Therefore it is necessary to tailor a model-selection procedure to the goals of the particular analysis. (The methods used are described in Bishop, Fienberg \& Holland, 1975.)

One goal was to obtain a "simple" model. Simplicity meant that lower-order terms were tested before higher-order terms, and higher-order terms were tested only if all subsumed lowerorder terms were statistically significant. It was especially desirable to obtain a model that was as simple as possible with respect to relationships between rearrest and the predictors. Therefore, the predictors were initially allowed to explain as much of the contingency table as possible: only models that were saturated with respect to the predictors were considered when relationships involving rearrest were tested. After all significant relationships involving rearrest were found, the saturated predictor term was replaced by lower-order terms found through the forward stepwise procedure described above.

New terms were added to the model only if the terms added significantly to the fit of the model. Overall fit of the model to the data was a necessary but not sufficient criterion of model acceptability. Terms were added roughly in order of their significance, but explanatory variables such as prior arrest and problem drinking were used before other variables.

Preliminary analyses were performed which determined the following: given drinker type, diversion status and prior arrest, there was no relationship between $B A C$ and rearrest. Given sex and race there were no effects of education or age. This left six variables of interest as predictors: $\operatorname{sex}(S)$, race (Q), marital status (M), drinker type (K), prior arrest (P), and diversion status (D). Drinker type was used as an ordinary predictor. It was used as a conditioning variable in previous analyses because the treatment modalities for the two drinker types were different and their effects could not be compared across 
drinker types. However, it is no longer necessary to consider the possibility of treatment effects, since there obviously were none.

Table D1 shows that the first model, which contained no relationships involving rearrest, did not provide an adequate fit to the data. All of the predictors except sex had significant effects on rearrest, even when added to the model successively, as shown by models (9) through (15). Other analyses showed that no three-way terms involving rearrest $(R)$ added significantly to the fit of the model. Model (16) is the final model obtained by replacing the saturated predictor term with lower-order terms shown to be significant through a forward stepwise procedure.

Log-linear parameters for the final model were computed and were used to construct the following equation for predicting the log of the odds of rearrest:

$$
\begin{aligned}
\log \left[\frac{\mathrm{P}(\text { rearrest })}{\mathrm{P}(\text { no rearrest })}\right]= & -1.212+.402 \mathrm{I}_{1}+.120 \mathrm{I}_{2}+.116 \mathrm{I}_{3} \\
& +.222 \mathrm{I}_{4}-.060 \mathrm{I}_{5}-.162 \mathrm{I}_{6}+.218 \mathrm{I}_{7}
\end{aligned}
$$

where $I_{1}=1$ if prior arrest

-1 if no prior arrest

$I_{2}=\begin{aligned} 1 & \text { if nondiversion } \\ -1 & \text { if diversion }\end{aligned}$

$I_{3}=\begin{aligned} 1 & \text { if black } \\ -1 & \text { if white }\end{aligned}$

$\begin{array}{ll}I_{4}= & 1 \text { if } \text { single } \\ 0 \text { if not }\end{array}$

$I_{5}=\quad \begin{array}{ll}1 & \text { if married } \\ 0 & \text { if not }\end{array}$

$I_{6}=\begin{aligned} & 1 \text { if divorced, separated, or widowed } \\ & 0 \text { if not }\end{aligned}$

$I_{7}=\quad 1$ if problem drinker

The equation will only be discussed qualitatively in terms of probabilities of DWI rearrest. It shows that the best predictor of rearrest is prior arrest: individuals with prior arrests had a much higher probabilitty of rearrest. Further, clients not on diversion, blacks, and problem drinkers also had higher probabilities of rearrest. Single clients were also more likely to be rearrested. All of the effects hold given the effects of the other variables. As noted above, there were no separate effects of sex, age, or education. 
TABLE D1. TESTS OF LOG-LINEAR MODELS FOR PREDICTING REARREST

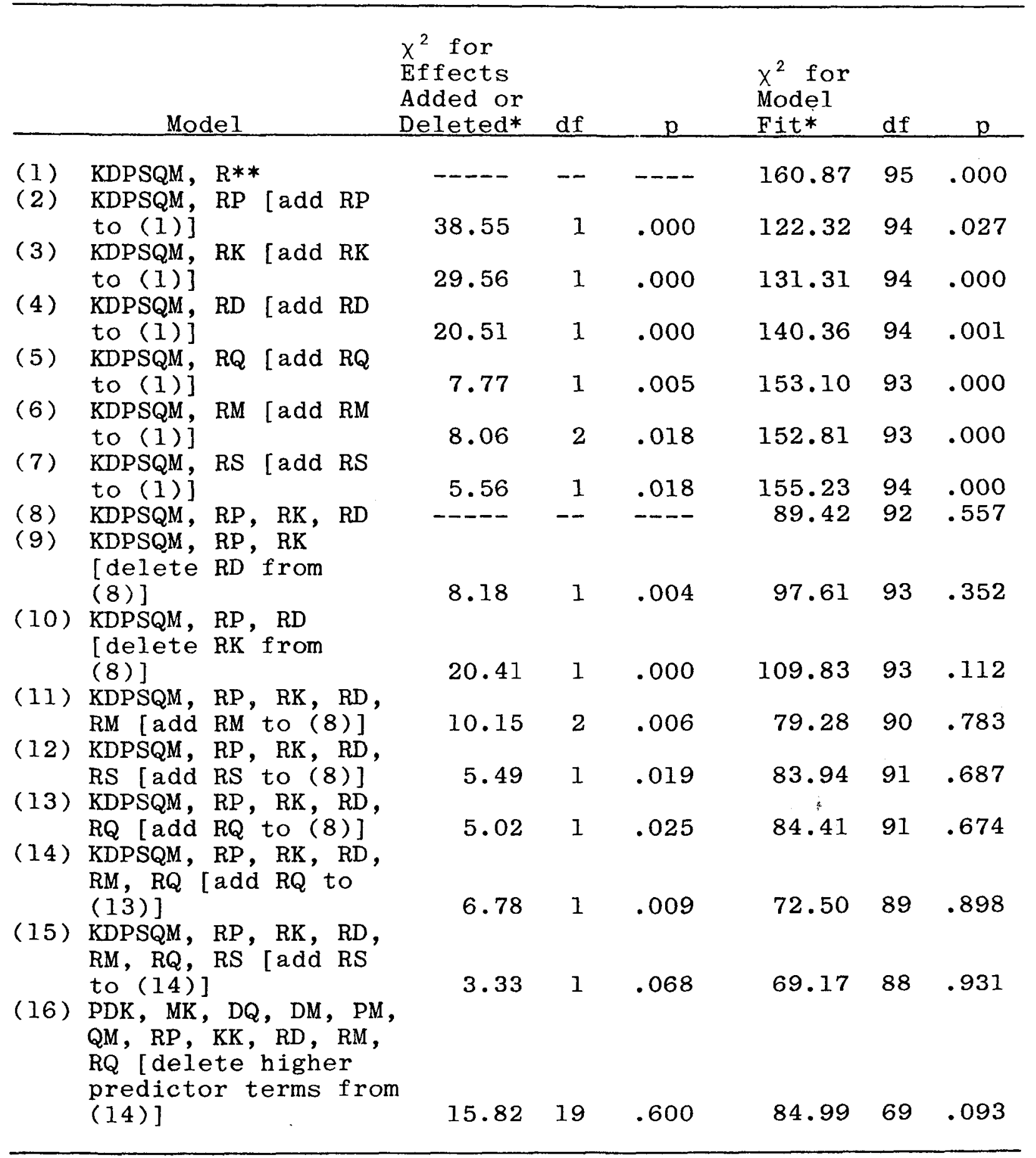

*Likelihood ratio $x^{2}$.

**Variable codes are as follows:

(R) DWI rearrest within 24 months; (K) Drinker type;

(D) Diversion status, (P) Prior DWI arrest; (S) Sex;

(Q) Race; (M) Marital status. 


\section{APPENDIX E}

\section{RELATIONSHIPS BETWEEN DEPENDENT VARIABLES}

Four criterion variables were used for evaluation of the effectiveness of the treatment modalities--rearrest for DWI, convictions for non-alcohol-related moving traffic violations, traffic accidents, and changes in LAI scale scores. In this appendix the relationships between those variables will be examined.

DWI Rearrest, Non-Alcohol-Related

Violations, and Accidents

Table El shows a cross-tabulation of DWI rearrest, non-alcoholrelated violation, and accident. Clients with at least one followup accident were almost three times as likely as those without accidents to have been rearrested for DWI (it is posisible that some of the accidents were associated with DWI arrests). Among clients with no accidents, those with non-alcohol-related moving violations were almost twice as likely to be rearrested for DWI, while among clients with accidents, those with no non-alcoholrelated violations were more likely to be rearrested. (The latter finding might have been due to the fact that either a DWI or a non-alcohol-related violation was likely to be associated with an accident, but if a DWI occurred then a non-alcohol-related violation was not recorded; this would result in a negative relationship between DWI and non-alcohol-related violation in the event of an accident.)

TABLE EI. CROSS-TABULATIONS OF DWI REARREST WITHIN 24 MONTHS, NON-ALCOHOL-RELATED MOVING VIOLATION WITHIN 18 MONTHS, AND ACCIDENT WITHIN 18 MONTHS

\begin{tabular}{|c|c|c|c|c|}
\hline Accident (A) & $\begin{array}{c}\text { Non-Alcohol-Related } \\
\text { Violation (V) }\end{array}$ & $\begin{array}{c}\text { DWI } \\
\text { None } \\
\end{array}$ & $\begin{array}{l}\text { At Least } \\
\text { One (R) }\end{array}$ & $\begin{array}{c}\text { Rearrest } \\
\text { Rate }\end{array}$ \\
\hline None & $\begin{array}{l}\text { None } \\
\text { At least one }\end{array}$ & $\begin{array}{r}1541 \\
438\end{array}$ & $\begin{array}{r}149 \\
83\end{array}$ & $\begin{array}{r}8.2 \% \\
15.7 \%\end{array}$ \\
\hline $\begin{array}{l}\text { At least } \\
\text { one }\end{array}$ & $\begin{array}{l}\text { None } \\
\text { At least one }\end{array}$ & $\begin{array}{l}216 \\
240\end{array}$ & $\begin{array}{r}112 \\
82\end{array}$ & $\begin{array}{l}34.1 \% \\
24.9 \%\end{array}$ \\
\hline
\end{tabular}

Table E2 shows tests of log-linear models for the crosstabulations. The three-way interaction was statistically significant, and reduced the DWI/non-alcohol-related violation 
relationship to nonsignificance. Accidents were significantly related to both DWI rearrests and non-alcohol-related violations.

TABLE E2. LOG-LINEAR MODELS FOR TABLE EI

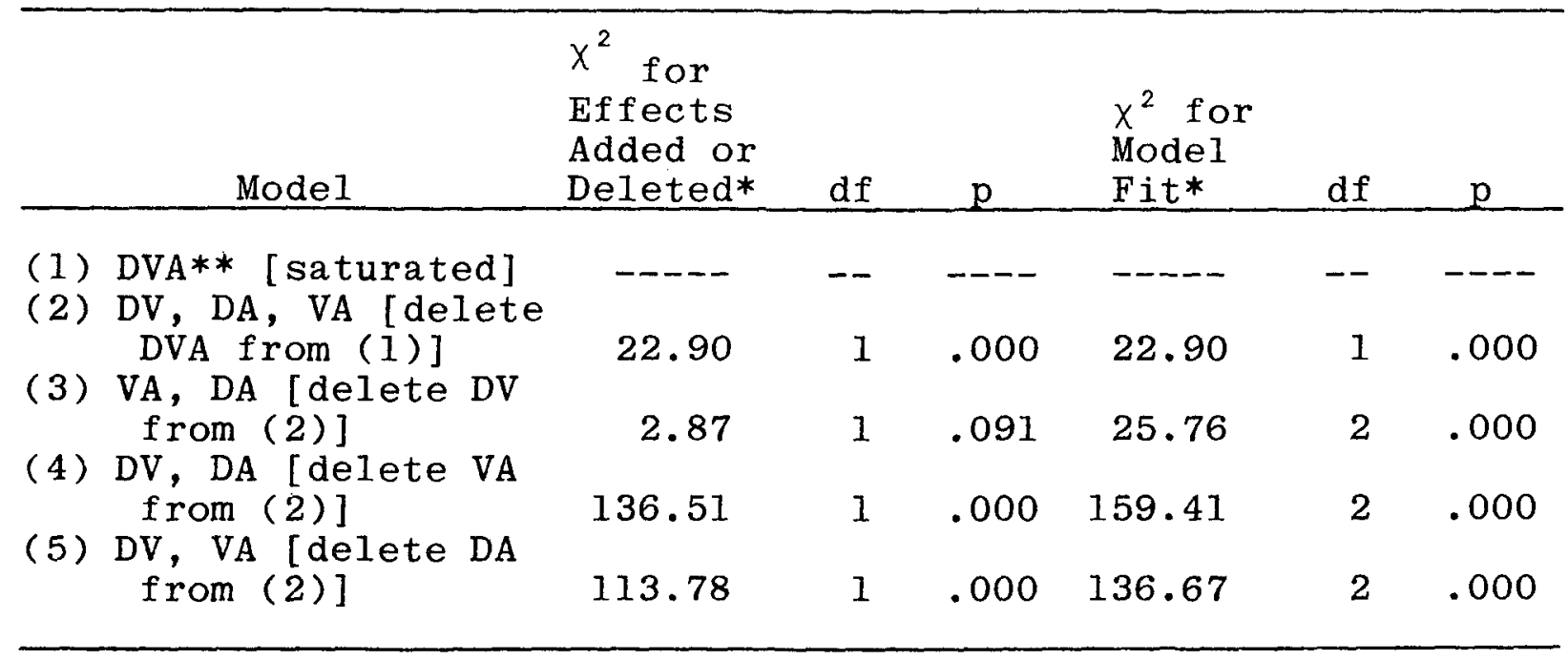

*Likelihood ratio $\chi^{2}$.

**Variable codes are as follows:

(D) DWI rearrest within 24 months

(V) Non-alcohol-related moving violation within 18 months

(A) Accident within 18 months.

\section{DWI Rearrest and LAI Scores}

Repeated requests for NHTSA by the Project evaluation staff for information about the validity of the LAI were met only with descriptions of the instrument's development such as that in Ellingstad and Struckman-Johnson (1977). Ellingstad and StruckmanJohnson describe the methods by which LAI items were selected and factors were determined, and present the results of the factor analyses.

The information available to the Project addressed only the content validity of the LAI scales. (That is, for example, Scale 3 was said to measure "family status" because it looked like the items measured family status.) But content validity was not the appropriate type of validity for the instrument. In order to be of any use to the present project or to any similar project it is necessary that, at a minimum, the predictive validity (Nunnally, 1978) of the LAI scales be demonstrated. That is, it must be shown that (for example) the "immoderate drinking behavior" scale actually predicts immoderate drinking behavior. The Project evaluation staff has not been made aware of any such studies. 
But even predictive validity of the scales would not be entirely sufficient to justify use of the LAI. The evaluation staff presumes that it is the intent of NHTSA to develop treatment modes which do not merely make "better people" of drunk drivers but which positively affect their driving behavior. In particular, the primary purpose of the treatments in the present project was to reduce drinking-and-driving; demonstration of behavior or lifestyle changes unrelated to drinking-and-driving would be of secondary interest at best.

Thus, the LAI scores cannot be considered valid criteria of treatment effectiveness unless they can be shown to predict DWI. To test the predictive validity of the LAI scales with respect to DWI, the scale scores for the initial LAI applications were compared for clients who were rearrested within 2 years and clients who were not rearrested within 2 years.

According to Ellingstad and Struckman-Johnson (1977), desirable lifestyles are represented by the following:

1. High Scale 1 (Employment/Economic Stability)

2. Low Scale 2 (Current Drinking Pattern)

3. High Scale 3 (Family Status)

4. High Scale 4 (Social Interaction/Involvement)

5. Low Scale 5 (Current Physical Health Problems)

6. Low Scale 6 (Immoderate Drinking Behavior).

Presumably nonrecidivists should have had the more desirable lifestyles.

Table E3 shows tests of the above hypotheses. The nu11 hypothesis had to be rejected only for Scale 4, Social Interaction/ Involvement. That is, recidivists scored significantly lower than nonrecidivists on items about "engaging in sedentary activities with others," buying gifts for others, entertaining others, performing "responsible activities," etc. It was shown in the text that social drinkers also scored higher than problem drinkers on that scale.

While the evaluation staff regards the tests in Table E3 to be the appropriate tests of the predictive validity of the LAI scales it might be argued that it is not life situations but changes in life situations which are related to DWI. Tables E4 and E5 show the results of a repeated measures ANOVA for recidivists and nonrecidivists. If change in life situations as measured by changes in the LAI scales were related to DWI rearrest the tests for interactions between rearrest and trends in the scale means should have been significant. Table E5 shows no significant interaction for any of the scales. A consistent and significant difference between recidivists and nonrecidivists on Scale 4 was found, but there were no trends in the scores and no differences between the trends for the two groups. 
TABLE E3. MEANS FOR SIX LAI SCALES (INITIAL APPLICATION) FOR RECIDIVISTS AND NONRECIDIVISTS

\begin{tabular}{clrrrrr}
\hline Scale & \multicolumn{1}{c}{ Group } & $\begin{array}{c}\text { Sample } \\
\text { Size }\end{array}$ & Mean & Statistic* & df & p* $^{*}$ \\
\hline \multirow{2}{*}{1} & Nonrecidivists & 521 & 526.62 & -1.16 & 618 & $-\ldots--$ \\
& Recidivists & 99 & 535.62 & & & \\
2 & Nonrecidivists & 613 & 460.66 & 0.19 & 725 & .422 \\
& Recidivists & 114 & 463.23 & & & \\
3 & Nonrecidivists & 583 & 501.61 & 0.17 & 696 & .240 \\
& Recidivists & 115 & 493.47 & & & \\
4 & Nonrecidivists & 563 & 502.16 & 2.14 & 668 & .017 \\
& Recidivists & 107 & 486.20 & & & \\
& Nonrecidivists & 576 & 479.64 & -1.16 & 686 & ---- \\
6 & Recidivists & 112 & 465.53 & & & \\
& Nonrecidivists & 581 & 489.80 & -0.06 & 689 & ---- \\
& Recidivists & 110 & 489.13 & & & \\
\hline
\end{tabular}

*One-sided test. A negative value of $t$ indicates difference in direction opposite that hypothesized (see text).

The findings in tables E3 and E5 do not reflect well on the validity of the LAI. Only one of the six scales predicts DWI recidivism at all (and an unlikely scale at that). Further, two scales purportedly measuring drinking behavior were totally unrelated to DWI. It must be concluded that in general the LAI cannot validly be used as a criterion of treatment effectiveness. 
TABLE E4. MEANS FOR LAI SCALES FOR DWI RECIDIVISTS AND NONREC IDIVISTS

\begin{tabular}{|c|c|c|c|c|}
\hline Scale & Application & Nonrecidivists & Recidivists & Marginal Mean \\
\hline \multirow[t]{2}{*}{1} & $\begin{array}{l}\text { Initial } \\
6 \text { Month } \\
12 \text { Month }\end{array}$ & $\begin{array}{l}536.03 \\
533.39 \\
534.69\end{array}$ & $\begin{array}{l}539.29 \\
527.47 \\
529.27\end{array}$ & $\begin{array}{l}536.50 \\
532.56 \\
533.93\end{array}$ \\
\hline & $\begin{array}{l}\text { Sample } \\
\text { Size } \\
\end{array}$ & 291 & 47 & 338 \\
\hline \multirow[t]{2}{*}{2} & $\begin{array}{l}\text { Initial } \\
6 \text { Month } \\
12 \text { Month }\end{array}$ & $\begin{array}{l}491.42 \\
479.42 \\
467.68\end{array}$ & $\begin{array}{l}466.54 \\
457.98 \\
463.11\end{array}$ & $\begin{array}{l}488.13 \\
476.58 \\
467.07\end{array}$ \\
\hline & $\begin{array}{l}\text { Sample } \\
\text { Size }\end{array}$ & 302 & 46 & 348 \\
\hline \multirow[t]{2}{*}{3} & $\begin{array}{l}\text { Initial } \\
6 \text { Month } \\
12 \text { Month }\end{array}$ & $\begin{array}{l}499.14 \\
493.49 \\
488.66\end{array}$ & $\begin{array}{l}491.78 \\
485.65 \\
482.48\end{array}$ & $\begin{array}{l}498.11 \\
492.39 \\
487.80\end{array}$ \\
\hline & $\begin{array}{l}\text { Sample } \\
\text { Size } \\
\end{array}$ & 411 & 67 & 478 \\
\hline \multirow[t]{2}{*}{4} & $\begin{array}{l}\text { Initial } \\
6 \text { Month } \\
12 \text { Month }\end{array}$ & $\begin{array}{l}504.04 \\
504.71 \\
499.21 \\
\end{array}$ & $\begin{array}{l}488.34 \\
478.23 \\
484.76 \\
\end{array}$ & $\begin{array}{l}501.82 \\
500.96 \\
497.17 \\
\end{array}$ \\
\hline & $\begin{array}{l}\text { Sample } \\
\text { Size } \\
\end{array}$ & 376 & 62 & 438 \\
\hline \multirow[t]{2}{*}{5} & $\begin{array}{l}\text { Initial } \\
6 \text { Month } \\
12 \text { Month }\end{array}$ & $\begin{array}{l}474.55 \\
484.28 \\
469.46 \\
\end{array}$ & $\begin{array}{l}457.94 \\
473.05 \\
478.90 \\
\end{array}$ & $\begin{array}{l}472.27 \\
482.71 \\
470.75 \\
\end{array}$ \\
\hline & $\begin{array}{l}\text { Sample } \\
\text { Size } \\
\end{array}$ & 396 & 63 & 459 \\
\hline \multirow[t]{2}{*}{6} & $\begin{array}{l}\text { Initial } \\
6 \text { Month } \\
12 \text { Month }\end{array}$ & $\begin{array}{l}519.05 \\
500.00 \\
496.00 \\
\end{array}$ & $\begin{array}{l}488.41 \\
485.20 \\
493.14 \\
\end{array}$ & $\begin{array}{l}513.33 \\
497.24 \\
495.71 \\
\end{array}$ \\
\hline & $\begin{array}{l}\text { Sample } \\
\text { Size } \\
\end{array}$ & 74 & 17 & 91 \\
\hline
\end{tabular}


TABLE E5. TESTS OF HYPOTHESES FOR LAI SCALES FOR RECIDIVISTS AND NONRECIDIVISTS

\begin{tabular}{|c|c|c|c|c|}
\hline Scale & Effect & F Ratio & $\mathrm{df}$ & $p$ \\
\hline 1 & $\begin{array}{l}\text { Rearrest } \\
\text { Linear Trend } \\
\text { Linear x Rearrest } \\
\text { Quadratic Trend } \\
\text { Quadratic x Rearrest } \\
\text { Trend } \\
\text { Trend x Rearrest }\end{array}$ & $\begin{array}{l}0.09 \\
0.92 \\
0.53 \\
0.93 \\
0.28 \\
0.92 \\
0.42\end{array}$ & $\begin{array}{l}1,336 \\
1,336 \\
1,336 \\
1,336 \\
1,336 \\
2,672 \\
2,672\end{array}$ & $\begin{array}{l}.763 \\
.339 \\
.466 \\
.337 \\
.600 \\
.399 \\
.656\end{array}$ \\
\hline 2 & $\begin{array}{l}\text { Rearrest } \\
\text { Linear Trend } \\
\text { Linear x Rearrest } \\
\text { Quadratic Trend } \\
\text { Quadratic } x \text { Rearrest } \\
\text { Trend } \\
\text { Trend x Rearrest }\end{array}$ & $\begin{array}{l}1.38 \\
1.68 \\
0.94 \\
0.22 \\
0.20 \\
1.09 \\
0.64\end{array}$ & $\begin{array}{l}1,346 \\
1,346 \\
1,346 \\
1,346 \\
1,346 \\
2,692 \\
2,692\end{array}$ & $\begin{array}{l}.241 \\
.196 \\
.333 \\
.640 \\
.653 \\
.337 \\
.527\end{array}$ \\
\hline 3 & $\begin{array}{l}\text { Rearrest } \\
\text { Linear Trend } \\
\text { Linear } x \text { Rearrest } \\
\text { Quadratic Trend } \\
\text { Quadratic x Rearrest } \\
\text { Trend } \\
\text { Trend x Rearrest }\end{array}$ & $\begin{array}{l}0.29 \\
3.16 \\
0.01 \\
0.06 \\
0.02 \\
1.93 \\
0.01\end{array}$ & $\begin{array}{l}1,476 \\
1,476 \\
1,476 \\
1,476 \\
1,476 \\
2,952 \\
2,952\end{array}$ & $\begin{array}{l}.593 \\
.076 \\
.916 \\
.809 \\
.891 \\
.146 \\
.986\end{array}$ \\
\hline 4 & $\begin{array}{l}\text { Rearrest } \\
\text { Linear Trend } \\
\text { Linear } x \text { Rearrest } \\
\text { Quadratic Trend } \\
\text { Quadratic } x \text { Rearrest } \\
\text { Trend } \\
\text { Trend } x \text { Rearrest }\end{array}$ & $\begin{array}{l}4.82 \\
0.99 \\
0.02 \\
0.62 \\
2.94 \\
0.82 \\
1.34\end{array}$ & $\begin{array}{l}1,436 \\
1,436 \\
1,436 \\
1,436 \\
1,436 \\
2,872 \\
2,872\end{array}$ & $\begin{array}{l}.029 \\
.321 \\
.883 \\
.431 \\
.087 \\
.440 \\
.263\end{array}$ \\
\hline 5 & $\begin{array}{l}\text { Rearrest } \\
\text { Linear Trend } \\
\text { Linear x Rearrest } \\
\text { Quadratic Trend } \\
\text { Quadratic x Rearrest } \\
\text { Trend } \\
\text { Trend x Rearrest }\end{array}$ & $\begin{array}{l}0.28 \\
0.97 \\
2.62 \\
1.46 \\
0.30 \\
1.22 \\
1.46\end{array}$ & $\begin{array}{l}1,457 \\
1,457 \\
1,457 \\
1,457 \\
1,457 \\
2,914 \\
2,914\end{array}$ & $\begin{array}{l}.598 \\
.325 \\
.106 \\
.227 \\
.586 \\
.297 \\
.233\end{array}$ \\
\hline 6 & $\begin{array}{l}\text { Rearrest } \\
\text { Linear Trend } \\
\text { Linear } x \text { Rearrest } \\
\text { Quadratic Trend } \\
\text { Quadratic x Rearrest } \\
\text { Trend } \\
\text { Trend } x \text { Rearrest }\end{array}$ & $\begin{array}{l}0.71 \\
0.25 \\
0.58 \\
0.33 \\
0.01 \\
0.28 \\
0.38\end{array}$ & $\begin{array}{l}1,89 \\
1,89 \\
1,89 \\
1,89 \\
1,89 \\
2,178 \\
2,178\end{array}$ & $\begin{array}{l}.401 \\
.618 \\
.448 \\
.570 \\
.928 \\
.758 \\
.686\end{array}$ \\
\hline
\end{tabular}




\author{
APPENDIX F
}

PROBLEMS ENCOUNTERED WITH THE LAI

\title{
General Remarks
}

As one of its contractual obligations the Tennessee DWI Probation Followup Demonstration Project was required to "measure ifestyle and attitude changes" in a sample of Project clients. This vaguely-worded requirement was originally understood to mean that the project could use a measuring instrument of its choice, and might possibly develop its own instrument. However, the Project was later informed by. NHTSA rehabilitation personnel that the South Dakota Life Activities Inventory Interview (Section 3 of the LAI) was to be used. Neither the substance nor the form of the Interview was to be changed for any purposes. Further, coding and punching were to be done exactly as described in the LAI coding instructions in a prescribed format; no equivalent, less cumbersome methods were to be employed. The project raised several points of concern about the use of the LAI. Those points were the following:

1. Two purposes for which the Project was to use the instrument were stated by NHTSA personnel: Validation of the instrument and use as a criterion of treatment effectiveness. The Project takes the following position:

a. The Project was not funded for the purpose of validating the South Dakota instrument.

b. If the instrument has not been validated, it is of no use to the evaluation staff as a criterion of project impact.

c. If Project data are used to validate the LAI, then the LAI cannot properly be used as a criterion of the Project's success; the two undertakings of validation of the instrument and use of the instrument as a criterion are mutually exclusive.

d. Different analytic procedures are appropriate for the two possible uses of the LAI data; NHTSA has not specified any analytic procedures to be used.

2. If the LAI is to be used as a criterion of treatment effectiveness then it is a proxy criterion, since the primary purpose of the treatments is not lifestyle change but prevention of drunk driving. The Project raises these objections:

a. There is little need for a proxy criterion since more direct measures of treatment success have been obtained. 
That is, there is no need (for evaluation purposes) to measure a variable that predicts recidivism if recidivism data are available.

b. It is not clear to the Project why there is interest in measuring attitude or lifestyle changes not related to drunk driving, if in fact the LAI is not supposed to predict recidivism.

3. The scoring procedures are far too complicated to be performed by probation counselors. Scoring requires knowledge of means and variances of all items, and application of the scoring formulae is convenient only with the aid of a programmable calculator or computer. Therefore, the LAI could be of no use to the counselors as a guide for treatment of individual offenders.

4. The collection of followup LAI data on clients not receiving supervised probation contaminates those clients, since by the original design of the Project those clients were not supposed to have long-term contact with the Probation Department. Administration of the followup LAIs constitutes an additional experimental treatment with recidivism-prevention potential. The true research design is more complicated than that originally described in the RFP, since an additional factor, the presence or absence of the LAI interviews, must be included in the analysis.

5. The LAI is cumbersome and time-consuming for the interviewer, and its contents are often inappropriate for the Project clientele. (See below.)

6. Procedures for coding and scoring the LAI are presently in a very crude and inconvenient-to-use state, suggesting that little effort has gone into development of the instrument. (See below.)

None of these issues have ever been adequately addressed in response to questions from Project Staff.

In the remainder of this appendix certain problems encountered by the probation and evaluation staffs are discussed. Results of analysis of the LAI are presented in the body of the report.

\section{Problems Encountered by Probation Counselors}

In administering the LAI, Probation Department personnel encountered a number of problems. Those problems, along with the procedures developed to solve or minimize the problems (where appropriate), are described below.

1. Probation counselors had negative feelings about the usefulness of the LAI. Those feelings were due in part to the opinion that the LAI was an inappropriate instrument for these reasons: 
a. The LAI was oriented to white collar respondents. The Memphis DWI population consists of large number of black, under-educated, and low-income clients, to whom many of the LAI items seem unrelated to life situations. Question wording and response requirements, may have led to misunderstandings, and incorrectly answered protocol items.

b. The rationale for LAI was that changes in alcohol use patterns would be reflected in reported behaviors in economic, social, and health aspects of the client's life situation. While this may be the case, traditional alcohol counseling techniques emphasize verbalized attitudes relating to specific drinking patterns. Counselors did not generally recognize the behaviorally oriented questions contained in the LAI protocol as being relevant to client attitudes concerning the use of alcohol or other drugs. They may be correct in this assessment because, to date, no LAI results have been produced to substantiate its theoretical assumptions. This is discussed further in Appendix E.

c. The purpose of the LAI was to demonstrate behavior changes in a population which included a large number of heavy drinkers. That goal may be incompatible with recognized characteristics of problem drinkers. Problem drinkers have a definite response bias toward denial of symptoms and behaviors reflecting difficulty in the use of alcohol, and are therefore prone to distort responses.

d. Responses to LAI items required the respondent to rely extensively on memory functions. Long term use of alcohol results in physiologically-based impairment of memory functions. Some clients may have honestly stated no changes simply because they were unable to recall life events, often from the day before, not to mention 6 months previous.

It was the responsibility of the evaluation staff to persuade the probation staff of the appropriateness of the LAI; that was very difficult, however, since the evaluation staff also regarded the LAI as inappropriate.

2. A considerable amount of negative affect (i.e., hostility) was often evident in clients who were completing LAI reinterviews.

Procedure developed: All clients who participated in the Memphis DWI Followup Project agreed to cooperate in the collection of required test data, and signed an agreement to that effect. However, there was no way to ensure that the clients enjoyed providing the data.

3. Clients were not very conscientious about the followup interviews. The first LAI interview was completed at the occasion of program entry, and is responded to in a thoughtful manner. Clients, when confronted with the same protocol the second and 
third times, did not see the need for having to answer the identical questions repeatedly. The importance of reporting behavior changes through time is not appreciated by clients, some of whom tend to give less than adequate attention to all protocol items. People seem to see themselves as unchanging through time, and are thus more likely to give retests more shallow consideration. Clients were observed to merely fill in response spaces with zeros, without pausing to read protocol items. When clients were asked why they responded to LAI items in a cavalier way, or when clients were questioned on their opinion of the LAI, several.responses were common: the LAI was an unnecessary hassle; questions did not apply to them; they could not remember; or the questions were an unwarranted invasion of privacy (questions on economic, family, or drinking behavior were likely to be mentioned).

4. The clients entered the testing situation with expectancies which might have resulted in less than truthful responses to protocol items. Clients were informed by counselors that excessive use of intoxicants could result in revocation of their probation or diversion status. In some instances, truthful responses to LAI items would potentially bring about a change for the worse in the client's standing in the legal system. Clients may have avoided incriminating themselves by answering questions in a way that precluded expected difficulties with probation counselors.

5. Location and notification of the LAI reinterviews was very time consuming for clients in nonperformance tracks (i.e., clients in control and rehabilitation groups who were not required to keep monthly contact with the probation office).

6. Conducting LAI interviews took as long as an hour and interfered with more pressing probation duties.

Procedure developed: Clients with sufficient reading skills self-administered the protocol, making it in effect a questionnaire. Only about $15 \%$ of the clients actually received interviews. This deviation from specified procedure was not corrected by evaluation personnel.

- 7. Because they saw no practical reason to conduct the LAIs, probation counselors were not likely to encourage clients to give the protocol serious consideration or to thoroughly check the finished protocol for inconsistencies and omissions. Counselor attention centered on the number of interviews conducted, with less emphasis on the quality of client responses. The need for accurate LAI data was not adequately communicated to the counselor by the evaluation staff, although repeated attempts were made.

8. Some clients refused to give followup interviews. 
Procedure developed: Those clients were classified noncompliant by the Memphis Probation Department. Noncompliant clients were not recommended for record expungement at the end of their I-year diversion or probation period. Noncompliant clients were given reset court dates by Judge Robert Love at the time of their court appearance for final expungement. In the interim period, clients completed any data collection required by the probation office; failure to have done so could result in revocation of the client's original diversion or probation agreement. Further resistance from clients was rare.

LAI .

9. Some noncompliant clients did not complete the 6-month

Procedure developed: Those clients were given the 6- and 12-month interviews at the same time, and told to respond to the 6-month interview "as if" they were answering it 6 months prior. While this procedure probably did not result in accurate data, it was consistent with the counselors' emphasis on quantity rather than quality (noted above).

10. Some clients had their probation or diversion status revoked because of another felony or misdemeanor arrest and were excluded from program participation; those clients were therefore not available for further data collection.

Procedure developed: None. Required interviews could not be collected from those clients.

11. Some clients had located outside of Shelby County and were not available for retesting.

Procedure developed: None. Required interview could not be obtained from those clients.

\section{Problems Encountered by Evaluation Personnel}

After completion, the LAI protocols were turned over to the evaluation staff in Nashville. The LAIs then underwent several stages of processing: coding, keypunching, scoring, and analysis. Approximately one-third of all data processing for the Project (excluding the processing of intake data) was devoted to initial and followup LAIs, and it is felt that the level of effort devoted to the LAIs far exceeded their value to the Project. A number of difficulties were encountered in attempting to implement procedures specified by NHTSA rehabilitation personnel:

1. The protocol does not directly request the information desired, thus requiring extensive manipulation and combination of responses in order to yield the variables from which the factor scales are computed. Further, much extraneous information is requested (information not used in computing the scales). This suggests that little effort has gone into refining the instrument 
for field use. It appears that the LAI was pretested and found wanting, but the instrument was not rewritten to reflect initial findings of inadequacy. Elaborate coding procedures for the original protocol were devised instead. Further support for this interpretation of the instrument's development can also be found in the fact that many of the questions are very poorly worded, suggesting that the instrument was hastily thrown together.

2. Project evaluation personnel were instructed by NHTSA rehabilitation personnel to code the LAIs as described in the LAI/CSQ Scoring Manual (Ellingstad, 1977). The LAI instructions run 16 pages, require excellent eyesight to read, and intense concentration to comprehend. The instructions are unrealistic since questionnaire coding is a task normally performed by clerical personnel.

Procedure developed: It was determined by the project evaluation staff that the coding instructions had been written by somebody inexperienced in questionnaire analysis and unaware of the advent of the electronic computer. Most of the complex instructions can be much more easily and cheaply implemented by a computer than by a human coder, provided the raw questionnaire responses are put in a computer-readable form. Therefore, since the actual project contract did not specify a coding method, raw interview responses were placed on coding sheets. Variables were later constructed from the raw data (in accordance with Ellingstad, 1977) by computer.

3. Project evaluation personnel were instructed by NHTSA rehabilitation personnel to punch the LAI data in a format given in the STR Abstract File Manual. That format was developed for the ASAPs and was designed to accommodate much data not collected for this project. It was an extremely inefficient method of storing data for this project.

Procedure developed: A format appropriate for the purposes of the present project was developed, and will be made available to NHTSA along with the Project data.

4. Despite NHTSA insistence that the Tennessee Project collect and analyze LAIs; no analytic procedures were ever specified, despite requests from the evaluation staff.

Procedure developed: Project evaluation personnel developed their own procedures (see data analysis).

\section{Summary}

It is the opinion of both the probation and evaluation staffs that the LAI served no useful purpose for the Project. 
Appendix G

\section{ADMINISTRATIVE COST ANALYSIS}

The primary task of this demonstration project is to determine the relative effectiveness of each of the four countermeasures for each major group of clients (problem drinkers and nonproblem drinkers). For these results to be fully meaningful to others who may be contemplating beginning their own countermeasure programs, however, these results must be analyzed in light of the relative cost of each countermeasure.

A costing model was developed for use with this program, and was specifically designed to be easily used by others in that various factors can be added or subtracted to calculate the costs of selected parts of the program. The following descriptions, and data are based on total program expenditures during the operational period of 2 yéars (September 1076-August 1978). A description of each of the variables will be given, and then calculations will be presented.

\section{Variable Descriptions}

Average cost figures are computed using the following six equations :

$$
\begin{aligned}
& x_{p 1}+x_{q}+A=C_{1}-----(1) \\
& x_{p 2}+x_{q}+A=C_{2}---(2) \\
& x_{p 3}+x_{q}+S+A=C_{3}---(3) \\
& x_{p 4}+x_{q}+S+A=C_{4}---(4) \\
& x_{p 3}+x_{q}+S+G+A=C_{5}--(5) \\
& x_{p 4}+x_{q}+S+G+A=C_{6}--(6)
\end{aligned}
$$

Where

$$
\begin{aligned}
\mathrm{x}_{\mathrm{p} 1}= & \text { Percentage of probation counselor time } \\
& \text { (in dollars) spend on Control group } \\
& \text { among both problem and nonproblem } \\
& \text { drinkers. } \\
\mathrm{s}_{\mathrm{p} 2}= & \text { Percentage of probation counselor time } \\
& \text { (in dollars) spent on "probation group" } \\
& \text { among both problem and nonproblem } \\
& \text { drinkers. }
\end{aligned}
$$




$$
\begin{aligned}
& \mathrm{x}_{\mathrm{p} 3}=\text { Percentage of probation counselor time } \\
& \text { (in dollars) spent on "rehab" clients } \\
& \text { among both problem and nonproblem } \\
& \text { drinkers. } \\
& \begin{aligned}
\mathrm{x}_{\mathrm{p} 4}= & \text { Percentage of probation counselor time } \\
& \text { (in dollars) spent on "probation plus }
\end{aligned} \\
& \text { rehabilitation" groups among both } \\
& \text { problem and nonproblem drinkers. } \\
& \mathrm{X}_{\mathrm{q}}=\text { Per capita cost of probation counseling } \\
& \text { management including clerical and secre- } \\
& \text { tarial support. } \\
& A=\text { Per capita overall administrative cost } \\
& \text { of the program. } \\
& S=\text { Cost per client in DWI School } \\
& G \text { = Cost per client assigned to group therapy. } \\
& C_{1}=\text { Average cost per client in control groups } \\
& \text { among problem and nonproblem drinkers. } \\
& \mathrm{C}_{2}=\text { Average cost per client assigned to } \\
& \text { "probation" groups from among the problem } \\
& \text { and nonproblem drinkers. } \\
& \mathrm{C}_{3}=\text { Average cost per client assigned to "rehab" } \\
& \text { group from among the nonproblem drinkers. } \\
& \mathrm{C}_{4}=\text { Average cost per client assigned to } \\
& \text { "probation plus rehabilitation" group } \\
& \text { from among the nonproblem drinkers. } \\
& \mathrm{C}_{5}=\text { Average cost per client assigned to } \\
& \text { "rehabilitation" from among the problem } \\
& \text { drinkers. } \\
& C_{6}=\text { Average cost per client assigned to } \\
& \text { "probation plus rehabilitation" from } \\
& \text { among the problem drinkers. }
\end{aligned}
$$

The average cost over all clients covered in this program therefore can be represented as the following:

$$
1 / 8\left(2 X_{p 1}+2 X_{p 2}+2 X_{p 3}+2 X_{p 4}+8 X_{q}+4 S+2 G+8 A\right)=C
$$

$C$ is the average cost in dollars. Similarly, the net cost to the program can be calculated by reducing average cost by the fee (F) charged from each client. Thus, new cost per client to the program $=C-F$. 
Variable Calculations

VARIABLE: $\quad \mathrm{x}_{\mathrm{p} 1}-\mathrm{x}_{\mathrm{p} 4}=\begin{aligned} & \text { Percentage of probation counselor time } \\ & \text { in dollars spent on each of the four }\end{aligned}$ groups.

From interviews with probation counselors and from observation, the following estimates of counselor time per task were determined:

$\begin{array}{rr}\text { *Initial intake interviews } & 10 \% \\ \text { *Pre/postsentence investigations } & 14 \% \\ \text { *Mortimer-Filkens (administration } & 15 \% \\ \text { and scoring } & 5 \% \\ \text { *Random assignment } & 8 \% \\ \text { *LAI administration (20\% of clients) } & 3 \% \\ \text { *Revocation procedures } & 45 \% \\ \text { *Client interaction/reports } & \\ \mathrm{P}+\mathrm{R} & =50 \% \\ \mathrm{P} & =40 \% \\ \mathrm{R} & =9 \% \\ \mathrm{C} & =1 \%\end{array}$

Estimates of counselor time spent on each of the program tracks are as follows:

*Control

*Rehabilitation

*Probation

*Probation plus rehabilitation
$14.2 \%$

$17.8 \%$

$32.75 \%$

$36.25 \%$

The cost per client for counselor time thus becomes the total counselor salaries times counselor time per particular group, all divided by the number of clients in that particular group. The following are results of these calculations for the variables $\mathrm{x}_{\mathrm{p} 1}-\mathrm{x}_{\mathrm{p} 4}$ :

$\mathrm{X}_{\mathrm{p} 1}$ CONTROL: $(\$ 298,479 \times 14.2 \%) / 1034=\$ 40.99$ per client X PFOBATION: $(\$ 298,479 \times 31.75 \%) / 1039=\$ 91.21$ per client $\mathrm{p} 2$ $\mathrm{x}$ p 3 REHABILITATION: $\quad(\$ 298,479 \times 17.8 \%) / 1037-\$ 51.23$ per client $\mathrm{X}_{\mathrm{p} 4} \quad$ PROBATION PLUS REHABILITATION: $(\$ 298,479 \times 36.25 \%) / 1038=\$ 104.24$ per client 
VARIABLE: $\quad \mathrm{X}_{\mathrm{q}}=$ Cost per client of probation management, including clerical and secretaril support.

The following costs were included in this variable (see also attachment 1):

$\begin{array}{lr}\text { Probation Manager salary, benefits and travel } & \$ 40,894 \\ \text { Clerical personnel salaries } & 40,896 \\ \text { Equipment and furniture } & 14,794 \\ \text { printing and office supplies } & 9,112 \\ \text { Communications } & 8,958 \\ \text { Space } & 28,668\end{array}$

The total cost for management of the probation effort thus is $\$ 144,322$. Dividing by the total number of clients provides the cost of this variable per client: $\mathrm{X}_{\mathrm{q}}=\$ 144,322 / 4148=\$ 34.79$ VARIABLE: $\quad A=$ Per client cost of overall administration of Project.

The total cost of project administration divided by the number of Project clients results in the following (see attachment 1 for allocation of costs between this variable and variable $\mathrm{x}_{\mathrm{q}}$ ):

$$
A=\$ 95,877 / 4148=\$ 23.11
$$

VARIABLE: $\quad S=$ The per client cost of the DWI School, based on average expenditures for 11 months in 1979. Included are the following:

$$
\begin{array}{lr}
\text { Personnel salaries } & \$ 4,235 \\
\text { School management } & 1,500 \\
\text { Supplies \& materials } & 1,777 \\
\text { Space } & 225
\end{array}
$$

The total cost of operating the school totals $\$ 7,737$ per month, and an average of 238 Project clients attended per month. Thus the per client cost for operation of the school is given by the following:

$$
S=\$ 7,737 / 238=\$ 32.50^{1}
$$

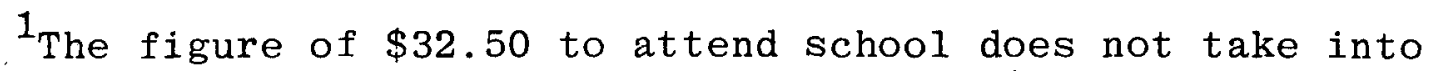
account the following factors; 1 ) Revenue is $\$ 12,200 /$ month of which 85\% is collectable - ave. actual dollars taken in by DWI operation is $\$ 10,387 /$ month. 2) Approximately $75 \%$ of DWI school budget is spent in conducting DWI school session and associates costs, $25 \%$ is used for dealing with SE clients, rehab cases, and juveniles. 3) Previously stated estimate of operational cost of $\$ 7,737 / \mathrm{month}$ does not take into account the fact that the DWI school is part of TSCC. If the school was operating independently; office space, supplies, and other overhead would be more expensive. 
VARIABLE: $G=$ The per client cost of attending therapy sessions. This cost is calculated based upon the estimated cost of DWI school (a prerequisite for therapy), plus the amount of additional time required for therapy. 
Cost Breakdown Figures Used

In Calculating Administrative

Cost Analysis Data

Attachemnt A -- DOT-HS-5-01199

\begin{tabular}{|c|c|c|c|c|c|}
\hline $\begin{array}{l}\begin{array}{c}\text { Date of } \\
\text { Service }\end{array} \\
\begin{array}{c}\text { to } \\
\text { to }\end{array} \\
9 / 30 / 79\end{array}$ & $\begin{array}{c}\text { Articles or } \\
\text { Services }\end{array}$ & $\begin{array}{c}\text { Total This } \\
\text { Quarter }\end{array}$ & $\begin{array}{c}\text { Total To } \\
\text { Date }\end{array}$ & $\begin{array}{c}\text { Total } \\
\text { Amount } \\
\text { Authorized }\end{array}$ & \\
\hline \multirow[t]{4}{*}{$\begin{array}{l}7 / 1 / 79 \\
\text { to } \\
9 / 30 / 79\end{array}$} & $\begin{array}{l}\text { I. Personnel } \\
\text { Services }\end{array}$ & $18,078.27$ & $367,927.09$ & $369,828.00$ & $T$ \\
\hline & $\begin{array}{l}\text { A. Salaries } \\
\text { B. Benefits }\end{array}$ & $\begin{array}{r}15,720.23 \\
2,358.04\end{array}$ & $\begin{array}{r}319,935.83 \\
47,991.26\end{array}$ & $\begin{array}{r}321,590.00 \\
48,238.00\end{array}$ & $\begin{array}{l}\mathrm{T} \\
\mathrm{T}\end{array}$ \\
\hline & II. Travel & 761.21 & $12,368.95$ & $16,621.00$ & $\mathrm{~T}$ \\
\hline & Total & $\$ 18,839.48$ & $\$ 380,296.04$ & $\$ 386,449.00$ & $\mathrm{~T}$ \\
\hline
\end{tabular}

Cost Breakdown

Total probation expenditure $\$ 380,296$

Salary probation manager

(\$953.00/month $\times 36$ months) $\quad 34,308$

Benefits probation manager $* 1.5 \%$ of salary $5,1.46$

Travel probation manager

( $\$ 40.00 /$ month $\times 36$ months) 1,440

Salries of clerical personnel 18,036

$1 @(\$ 501.00 /$ month $\times 36$ months $)$

$1 @(\$ 635.00 /$ month $\times 36$ months $)$

22,860

$x_{p}=\$ 298,479$

* Salaries above based on rate of pay in 2nd year of program. 
Probation manager salary, benefits \& travel $\$ 40,894$

Clerical personnel salaries $\quad 40,896$

Equipment \& furniture 15,794

Printing \& office supply 9,112

$\begin{array}{ll}\text { Communications } & 8,958\end{array}$

Office space $\lcm{28,688}$

$\mathrm{X}_{\mathrm{q}}=\$ 144,322 \mathrm{~T}$

Attachment B - DOT-HS-5-01199 Management

\begin{tabular}{|c|c|c|c|c|}
\hline $\begin{array}{l}\text { Date of } \\
\text { Service }\end{array}$ & $\begin{array}{c}\text { Articles or } \\
\text { Services }\end{array}$ & $\begin{array}{c}\text { Total This } \\
\text { Quarter }\end{array}$ & $\begin{array}{c}\text { Total To } \\
\text { Date }\end{array}$ & $\begin{array}{c}\text { Total } \\
\text { Amount } \\
\text { Authorized } \\
\end{array}$ \\
\hline $\begin{array}{l}7 / 1 / 79 \\
\text { to } \\
9 / 30 / 79\end{array}$ & $\begin{array}{l}\text { I. Personnel } \\
\text { Services }\end{array}$ & $6,608.87$ & $86,952.84$ & $141,799.00 \mathrm{~T}$ \\
\hline $100_{c}^{\circ} \mathrm{A}$ & $\begin{array}{l}\text { A. Salaries } \\
\text { B. Benefits } \\
\text { C. Burden }\end{array}$ & $\begin{array}{r}5,224.40 \\
783.66 \\
600.81\end{array}$ & $\begin{array}{r}68,737.38 \\
10,310.61 \\
7,904.85\end{array}$ & \\
\hline
\end{tabular}

II. Travel* Probation personnel (DWI probation Manager \& City Manager traveled to Nashville \& Washington DC, but included in A because was concerning program coordination with federal authorities and evaluation personnel.

$100 \% \mathrm{~A}$
A. In-state
B. Out-of-state
178.45
$1,904.94$
$4,346.00 \mathrm{~T}$
$1,555.82$
$7,190.00 \mathrm{~T}$.

I I . Equipment

\begin{tabular}{|c|c|}
\hline $100^{\circ}=\mathrm{X}_{\mathrm{q}}$ & $\begin{array}{l}\text { (Furniture, } \\
\text { Maintenance } \\
\text { Agreement, } \\
\text { Copier) }\end{array}$ \\
\hline
\end{tabular}

$368.87 \quad 15,794.66 \quad 18,164.00 \mathrm{~T}$ 


\begin{tabular}{|c|c|c|c|c|}
\hline $\begin{array}{l}\text { Date of } \\
\text { Service }\end{array}$ & $\begin{array}{c}\text { Articles or } \\
\text { Services }\end{array}$ & $\begin{array}{c}\text { Total This } \\
\text { Quarter }\end{array}$ & $\begin{array}{c}\text { Total To } \\
\text { Date }\end{array}$ & $\begin{array}{c}\text { Total } \\
\text { Amount } \\
\text { Authorized } \\
\end{array}$ \\
\hline $\begin{array}{ll}80 \% & x_{\mathrm{q}} \\
20 \% & \mathrm{~A}\end{array}$ & $\begin{array}{l}\text { IV. } \\
\text { Mirect } \\
\text { Materials } \\
\text { (Printing and } \\
\text { Supplies) }\end{array}$ & 731.47 & $11,390.15$ & $16,719.00 \mathrm{~T}$ \\
\hline $100 \% \mathrm{X}_{\mathrm{q}}$ & V. Communications & 668.45 & $8,958.83$ & $11,725.00 \mathrm{~T}$ \\
\hline \multirow{2}{*}{$\begin{array}{l}90 \% \mathrm{X}_{\mathrm{q}} \\
10 \% \mathrm{~A}^{\mathrm{q}}\end{array}$} & VI. Office Space & $2,535.99$ & $31,853.19$ & $39,801.00 \mathrm{~T}$ \\
\hline & Total & $\$ 11,092.10$ & $\$ 158,410.33$ & $\$ 240,184.00 \mathrm{~T}$ \\
\hline
\end{tabular}

\section{Cost Breakdown}

$\begin{array}{lr}A= & \$ 86,953 \\ \text { Travel-in-state } & 1,905 \\ \text { Travel-out-of-state } & 1,556 \\ \text { Printing \& office supply } & 2,278 \\ \text { Office space } & 3,185 \\ \text { Total } & \$ 95,877\end{array}$

\footnotetext{
Time in DWI School = 10 hours (5 sessions, 2 hours per session) Time in Therapy $\quad=16$ hours ( 3 sessions, 2 hours per session)

Cost for

Attending either $\quad=\$ 3.25$ per client per hour

The total cost per client for therapy can thus be calculated as:

$$
\mathrm{G}=\$ 3.25 \times 16 \text { hours }=\$ 52.00
$$
}




\section{Administrative Analysis Cost Equations}

(1) $\mathrm{C}_{1}=$ Average cost per client in control groups among problem and nonproblem groups.

$$
\begin{aligned}
& \mathrm{C}_{1}=\mathrm{x}_{\mathrm{p} 1}+\mathrm{x}_{\mathrm{C}_{1}}+\mathrm{A} \\
& \mathrm{C}_{1}=\$ 40.99+\$ 34.79+\$ 23.11 \\
& \mathrm{C}_{1}=\$ 98.89
\end{aligned}
$$

(2) $\mathrm{C}_{2}=$ Average cost per client in probation among problem and nonproblem groups.

$$
\begin{aligned}
& \mathrm{C}_{2}=\mathrm{x}_{\mathrm{p} 2}+\mathrm{x}_{\mathrm{q}}+\mathrm{A} \\
& \mathrm{C}_{2}=\$ 91.21+\$ 34.79+\$ 23.11 \\
& \mathrm{C}_{2}=\$ 149.11
\end{aligned}
$$

(3) $\mathrm{C}_{3}=\underset{\text { Average cost per client in rehabilitation for the }}{\text { nonproblem groups. }}$

$$
\begin{aligned}
& C_{3}=x_{p 3}+S+A \\
& C_{3}=\$ 51.33+\$ 34.79+\$ 32.50+\$ 23.11 \\
& C_{3}+\$ 141.63
\end{aligned}
$$

(4) $\mathrm{C}_{4}=$ Average cost per client in probation plus rehabilitation for nonproblem groups.

$$
\begin{aligned}
& C_{4}=x_{p 4}+x_{q}+s+A \\
& C_{4}=\$ 104.24+\$ 34.79+\$ 32.50+\$ 23.11 \\
& C_{4}=\$ 194.64
\end{aligned}
$$

(5) $\mathrm{C}_{5}=\begin{aligned} & \text { Average cost per client of rehabilitation for problem } \\ & \text { drinkers. }\end{aligned}$

$$
\begin{aligned}
C_{5}= & x_{p 3}+x_{q}+S+G+A \\
C_{5}= & \$ 51.23+\$ 34.79+\$ 32.50 \\
& +\$ 52.00+\$ 23.11 \\
C_{5}= & \$ 193.63
\end{aligned}
$$


(6) $\mathrm{C}_{6}=$ Average cost per client of probation plus rehabilitation for problem drinker groups.

$$
\begin{aligned}
C_{6}= & x_{p 4}+x_{q}+S+G+A \\
C_{6}= & \$ 104.24+\$ 34.79+\$ 32.50 \\
& +\$ 52.00+\$ 23.11 \\
C_{6}= & \$ 246.64
\end{aligned}
$$

The average cost over all clients in the Program can be represented'as the following:

$$
\begin{aligned}
& C=1 / 8( 2 x_{p 1}+2 x_{p 2}+2 x_{p 3}+2 X_{p 4} \\
&\left.+8 x_{q}+4 S+2 G+8 A\right) \\
& C=1 / 8( \$ 81.98+\$ 182.42+\$ 102.46 \\
&+\$ 208.48+\$ 278.32+\$ 130.00 \\
&+\$ 104.00+\$ 184.88) \\
& C=1 / 8(\$ 1,272.54) \\
& C=\$ 159.07
\end{aligned}
$$

By subtracting relevant factors from this overall average cost, various configurations of cost may be obtained. For example, by subtracting the factor involving rehabilitation costs from the total cost $C$, one can calculate an estimate of the average cost per client of a program using only control and probation modes. 


\title{
APPENDIX H
}

\author{
PROBATION EVALUATION: \\ BASED ON A REPORT BY \\ R.J. POLISKY, CONSULTANT \\ MARCH , 1979
}

\section{Acknowledgement}

Mr. Ed Manker and Judge Robert Love, the individuals who have had the overall responsibility for the administration and policy formulation of the DWI Probation Office, are to be complimented for having initiated this evaluation. It is very unusual for the administrators of an experimental demonstration project to have the courage to voluntarily lay open the operations, policies, and manangement of their program to an independent consultant when it is not required; their only motive was the desire for an honest and open appraisal of their program for the purpose of improving its future operations.

This evaluation would not have been possible without the support of the entire staff of the Memphis DWI Probation Office, especially Mr. Bobby Smyth, Supervisory Probation Counselor, and Ms. Catherine Walton, Department Manager of the Memphis City Court Probation and Diversion Department. As the direct supervisors of the DWI Probation Office, Mr. Smyth and Ms. Walton could have hampered the consultant's access to Program data and staff. However, on the contrary, they went out of their way to make certain that full access to Program data and staff was provided; furthermore, they saw to it that resources such as staff time and confidential meeting space were made available to the consultant.

It was indeed a pleasure working with Messrs. Lee Stewart and Jim Rice of the Nashville Urban Observatory on items relating to data collection efforts and the program evaluation design. As mentioned later in this report, the research design that was developed and utilized by the Urban Observatory to attempt to measure the overall performance of the Memhpis DWI Probation Office is one of the most comprehensive and rigorous evaluations of a probation office to be attempted in recent years.

Finally, sincere appreciation is extended to all of the "working people" of the Memphis DWI Probation Office, namely, the probation counselors and secretaries, without whom there would be no Program. Their willingness to disclose matters relating to their own job performance and to candidly discuss many of their concerns and suggestions for improved operations was invaluable to the consultant.

RJP

February 1979 
The Tennessee DUI Probation Followup Demonstration Project has been an attempt to demonstrate the effectiveness of probation for DUI's, as opposed to other forms of treatment and traditional sanctions. Major funding for the Demonstration Project has been provided by the National Highway Traffic Safety Administration of the US Department of Transportation (Contract \#DOT-HS-5-01199), and the operational phase ran from September 6, 1976 to August 31 , 1978. The overall Project included the tracks of probation only, probation plus rehabilitation, rehabilitation only, and a control group.

The Urban Observatory of Metropolitan Nashville/University Centers, as a subcontractor to the State of Tennessee, has been and continues to be responsible for the overall evaluation of the total Demonstration Project. That evaluation will include assessment of the achievement of the four major countermeasure objectives of the DUI Probation Office (also referred to in this report as the "Program"), as stated in the Detailed Plan. It was decided that, in order to keep costs and amount of overlap to a minimum, the present evaluation should not duplicate the efforts by the Urban Observatory. Instead, this report will concentrate on evaluating the degree to which the DUI Probation Office has adhered to the countermeasure activities, as identified in the Detailed Plan, from a "probation management" perspective.

For purposes of this report, Program Management includes: The Honorable Robert Love (City Court Judge); Mr. Ed Manker (Project Director); Ms. Catherine Walton (Department Manager, Memphis City Court Probation and Diversion Department); Mr. Bobby Smyth (Supervisory Probation Counselor); and $\mathrm{Mr}$. Lee T. Stewart (Evaluation Director). Toward the end of the operational phase of the Program, it was decided by program management that an administrative evaluation would prove useful for the following reasons:

1. In the event that the data generated by the overall Demonstration Project indicates that the DUI Probation Program has been no more effective than the other tested countermeasures, it will be important to be able to determine whether or not the Program operated according to sound organizational principles, especially from a probation perspective. This would assist the Urban Observatory in analyzing the data and in drawing conclusions as to the efficacy of probation in the adjudication of the drinking driver;

2. Additional input would be available to NHTSA regarding the effectiveness of DUI probation as a viable alternative to traditional sanctions for the adjudication of the drinking driver;

3. Program Management will be able to use such evaluation information in planning, programming, and budgeting for the continuation of the Program under local funding; and 
4. Other existing and future DUI Probation programs with access to this information may be able to use it to improve their operations, compare results, and share findings with the Memphis Program.

If discrepancies were found to exist between the Countermeasure Activities identifed in the Detailed Plan and actual Program operations, possible reasons for such deviations were postulated. If it was felt that the implementation of existing national probation standards into the Program operations would be beneficial, such standards were specifically mentioned.*

The consultant was initially requested to include, as part of the report, a "problem identification" section concerning Program operations. Although problems in the Program's operations that were thought to be relevant to the items discussed in this report will be mentioned whenever appropriate, the consultant has previously prepared and submitted, under separate cover, a detailed "problem identification" report to Program Management.

\section{Methods}

This evaluation was conducted during the period from October 25, 1978 to March 1, 1979. During that time, in-depth, face-to-face interviews were conducted (on site) on October 25 and 26, 1978; December 6 and 7, 1978; and January 15, 1979, with the following Program personnel:

- Mr. Ed Manker (Project Director), Deputy Administrator, Memphis and Shelby County Traffic Safety Coordinating Committee;

- Ms. Catherine Walton, Department Manager, Memphis City Court Probation and Diversion Department;

- Mr. Bobby Smyth (Supervisory Probation Counselor), DWI Probation Unit, Memphis, Tennessee;

- Mr. Lee T. Stewart (Evaluation Director), Urban Observatory of Metropolitan Nashville/University Centers, Nashville, Tennessee;

- Mr. Jim Rice (Research Assistant), staff member of the Urban Observatory located on site in Memphis, Tennessee;

- Honorable Robert H. Love, Judge of Division VIII, City Court, Memphis, Tennessee;

*The standards alluded to in this report are from The Manual of Standards for Adult Probation and Parole Field Services, sponsored by the American Correctional Association, copyright July 1977, and developed by the Commission of Accreditation for Corrections. 
- Mr. Ron Marshak, Executive Director, Memphis and Shelby County Traffic Safety Coordinating Committee;

- Mir. David Simmons, DWI School Senior Counselor, Memphis, Tennessee

- A11 DWI Probation Counselors (12) employed by the Program as of December 6, 1978; and

- All secretarial staff (2) employed by the Program as of December 6, 1978 .

Other sources of data used in this evaluation were:

-Monthly and Quarterly Reports;

-Detailed Plan, and any subsequent approved changes;

-Formal, written Program policies and procedures;

-Interoffice memoranda;

-Client files (all identifying data was first removed); and

-Program personnel records (partial).

It should be noted here that the Program has been modified somewhat since the end of its operational phase. Therefore, it was necessary to separate the "new" operations from the "old," and, when necessary in discussing Program operations, the differentiation between the two time periods has been noted.

\section{Countermeasure Activity \#1: Hiring and \\ Training of Probation Counselors}

Finding: (Hiring)

The Detailed Plan indicates that

All hiring of Probation Counselors will be done in line with regular city personnel procedures. ( $p, 42)$

It also says that

Probation Counselors will (as per existing city job description) have at least two years of college with one year's credit for every two years of similar job experience. ( $p .42$ ) 
A review of the qualifications possessed by both current and past probation counselors indicated that every probation counselor employed by the Program has possessed the minimum qualifications (as stated above). In fact, every probation counselor that has been employed by the Program thus far has possessed at least a baccalaureate degree, with several of them having Masters degrees.

Comment. It is commendable that the Program is able to boast such ahighly educated staff of probation counselors, one which, to the person, greatly exceeds the minimum requirements for probation counselors as set forth in the City of Memphis job description. However, the salaries they receive are below those of personnel who perform similar job functions in the Memphis area. For example, the City Probation Counselors' starting salary is currently $\$ 7,380$ per year, in contrast to an entry salary for state Probation Counselors of $\$ 9,672$ and County Pretrial Release Counselors of $\$ 9,144$.

Although the Program was initially going to utilize the probation counselors mainly as "referral agents," rather than as "counselors," the Program's Quarterly Report, which covered the period from April 1, 1978 to June 30, 1978, indicated that probation counselors are, in fact, expected to perform "counseling."

The client's meetings with his counselor may be in conjunction with some other form of rehabilitation. The counselors do not attempt alcoholism counseling as they are not trained in this area. However, counseling concerning court matters, highway safety and problems related to life is provided. (p.16)

This quarterly Report, which contains a section titled "Memphis DWI Probation--Its philosophy and Development," indicates probation counselors in the Program perform the same type of functions as do the State Probation Counselors, the County Pretrial Release Counselors, and most probation personnel throughout the country. These functions include, but are not limited to, counseling; interviewing; making referrals; making recommendations to the court; and administering, scoring and interpreting diagnostic instruments.

The American Correctional Association (ACA) Standards which address this issue are as follows:

Salary levels for all agency personnel are competitive with those of their parts of the jurisdiction's criminal justice system as well as with comparable occupational groups in the private sector. (Standard 3061)

An entry-level probation or parole officer possesses a baccalaureate degree in one of the social or behavioral sciences or a related field. (Standard 3048) 
It is felt that the hiring and retention of quality probation counselors could be enhanced not only,by upgrading the "official" job requirements and salary, but also by the employment of recovering alcoholics and the utilization of student interns and volunteers. By augmenting a staff of highly qualified professionals with paraprofessionals who could perform many of the "clerk-type" functions now being performed by probation counselors, maximum use of personnel could be realized. It is felt that these changes would also reduce the high turnover rate experienced by the Program thus far (over $100 \%$ during the operational phase). In addition, they would provide job opportunities for ex-offenders within the Program, encourage the involvement of community members in the Program, promote a symbiotic relationship between the Program and local colleges and universities, increase the efficiency of program oeprations, and, most importantly, improve the quality of services provided to the community and to the offender.

The following ACA Standards reference these issues:

Written policy and procedures exist for securing citizen involvement in the probation/parole process.

(Standard 3039)

There is provision for the recruitment and employment of ex-offenders. (Standard 3051)

Written policy and procedure provide for consulation with colleges and universities in an intership or practicum program to train persons for careers in corrections. (Standard 3036)

Finding: (Training)

According to the Detailed Plan, the first groups of probation counselors hired were to receive training in certain specific subject areas "in the month prior to handling clients" ( $p$. 43). A review of available records from 1976, as well as discussions with individuals who were with the Program at that time, indicated that such training was provided to all probation counselors in accordance with the training outline contained in the Detailed Plan. The Plan further states that:

This initial training session will be subjectively evaluated by project personnel to determine which elements are successful and should be included in further training of new counselors as they are brought on. ( $p .44)$

No such revised training plan could be found to exist in writing, although the Supervisory Probation Counselor did outline for the consultant the training program which is currently used in the Program. Program personnel are now provided with on-the-job training when they first begin employment with the Program. The basic day-to-day functions of a probation counselor are explained. 
to each new probation counselor by the Supervisory Probation Counselor, who appears to possess excellent knowledge of Program operations. The new probation counselor is exposed to the various tasks he or she is expected to perform and is assigned to various experienced probation counselors, who train him or her in an experimental fashion. In addition to the first two weeks of on-thejob training which are provided to each new probation counselor, there are continual inservice training seminars offered. During those seminars, individuals representing service-giving agencies within the community that can provide supportive services to the Program's clientele make presentations to the probation staff; the representatives describe their program's operations to the probation counselors and answer any questions they may have regarding referral procedures, criteria for program acceptance, etc. The amount of didactic training, especially with regard to specific courses in probation, casework recording, report writing, and the effects of alcohol, is minimal, if it exists at all.

Comment. Program staff report that the Supervisory Probation Counselor is very capable when it comes to imparting knowledge of the day-to-day functions to new probation counselors. However, a formalized, written training program would assist him in training new staff in a more efficient manner. Even techniques such as the use of "on-the-job checklists" could help ensure that each new probation counselor receives the same standardized instruction. While inservice seminars with community service-giving agencies are no doubt useful to the Program staff when making referrals, basic didactic and empirical subject matter needs to be transmitted to probation officers in any setting. This type of training need not cost money; reciprocal agreements could be arranged with local colleges and universities, and city, county, and state agencies (both public and private) could be called into play to provide necessary subject matter to Program staff.

In discussing training needs for probation staff, the ACA Standards suggest that:

All staff members receive a minimum of 40 hours of relevant training and education annually. (Standard 3066)

Inservice education and training programs are planned and developed jointly by the appropriate city, county, state and federal agencies, colleges and universities, and community organizations. (Standard 3067)

In the development of any comprehensive training program, it is advisable to request and secure input regarding curriculum content from the staff members themselves, since they are the ones who best know what information they need to know in order to perform their jobs more effectively. 
Countermeasure Activity $\# 2$ :

Diversion Checks

Findings

One of the major responsibilities of the DWI Probation Office has been to perform diversion checks for the Division VIII City DWI Court. The Detailed Plan reports that

A11 regular DWI probation unit personnel will perform diversion qualification checks on a rotating basis, with two probation counselors being in court at any one time. (p. 45)

It was learned from Judge Love that probation counselors do not sit in court throughout the day. However, he stated that, for the most part, he is extremely pleased with the quality and the timeliness of the diversion checks submitted by the Program probation counselors. He estimated that approximately $2 \%$ of all diversion checks submitted by Program staff had been late. This figure was verified by the Supervisory Probation Counselor; he stated that his records indicated that, in almost every case, it had been one probation counselor in particular who had been turning in the tardy diversion checks. A review of the Program records verified his statement. The Supervisory Probation Counselor in question had been reassigned, and, since that time, the number of late reports had reduced dramatically; subsequent checks of Program records showed this to be the case.

Comment. The most important aspect of the diversion checks performed by probation counselors of this Program are the "prior record" checks, which are done on a constant basis. The Judge depends upon the accuracy of the information submitted by probation counselors regarding the prior records of offenders. In a diversion program such as this, it is imperative that the court know as soon as possible whether or not the offender standing before the bench is a first offender. A detailed analysis of Program operations indicated that the Program staff (both probation counselors and secretaries) are highly efficient in their preparation and submission of diversion checks to the court. While the addition of a computer terminal (which has access to certain criminal records) to the DWI Probation Office has been accomplished, Program staff should be cautioned that too much reliance on the terminal may cause the accuracy of their work to suffer. In watching probation counselors attempt to retrieve actual data from the terminal, it was noticed, that, at times, the terminal produced confusing and even erroneous data. The probation counselors eventually had to manually research information; in such cases, they would have been better off getting the information manually to begin with. Of course, once the computer has been in operation for awhile and all of the "bugs" are ironed out, the terminal could conceivably save Program staff endless hours of manual labor. 
However, until that time, probation counselors should be instructed to be extremely wary of reporting any information to the court which is in any way questionable or unverified.

Much of the probation counselors' time is spent in researching criminal records in order to perform diversion qualification checks. A great deal of this clerical work (especially once the accuracy of the data retrieval from the computer terminal is improved) and could be performed by well-trained secretarial personnel, paraprofessionals, or student interns. The diversion check performed by a probation counselor is in many ways similar to the presentence investigation and report prepared by a probation officer. The use of other individuals in performing these functions would allow probation counselors more time for actual casework.

Regarding the aforementioned topics, the ACA Standards recommend that

Written policy and procedure permit the use of staff other than probation officers to collect information during the presentence investigation. (Standard 3198)

Countermeasure Activity \#3:

Postsentence Investigation

According to the Detailed Plan:

All regular DWI Probation Unit personnel will perform postsentence investigations for clients assigned to them. (p. 46)

A major function of the probation counselor is to collect all data necessary for the compilation of a postsentence report; this includes, at times, the administration, scoring, and analysis of diagnostic personality tests. Once all of the information is gathered by the probation counselors, it is their responsibility to prepare the report and to determine whether or not the client is a problem drinker. Depending on which of the tracks the client is assigned to, the probation counselor explains the responsibilities of Program participation to the client and collects and records certain additional client information.

No hard data could be found in any kind of compiled or combined form; assessment of the LAI and Mortimer-Filkins diagnostic instruments will be evaluated by the Urban Observatory in their overall evaluation of the total Demonstration Project. In discussing the value of these instruments with the probation counselors, they stated, in almost every instance, that they feel their time is being wasted in having to administer these instruments to their clients. They reported that they consider it to be busywork and perceive that the instruments have provided little, if any, predictive capability; in short, they fail to see any utility to either of the instruments. 
Comment. While the attitude of probation counselors with regard to the utility of the diagnostic instruments used for gathering data for the postsentence investigation seems to be negative, not enough is yet known from an empirical perspective to be able to draw any conclusions. It is hoped that more data will become available upon the completion of the major evaluation effort which is currently being undertaken by the Urban Observatory; this may enable inferences to be drawn from their findings and hopefully will lead to the further refinement of these instruments and their predictive capabilities.

In spite of the apparent lack of faith that the probation counselors reported to have in these instruments, available records indicate that the counselors have done an excellent job in administering both the Mortimer-Filkins and the LAI. It should be noted at this time that, even though the Detailed Plan indicated that both diversion checks and postsentence investigations will be performed by all probation counselors, the program has been changed in that not all probation counselors perform these functions. The Program's Monthly Report, dated February 28, 1978, states that

Restructuring of the DWI Program occured during February. Three counselors have been assigned to handle the presentence reports and the monitoring for rearrest of all nonprogram clients. As a result of this type of restructuring within the department, the additional ten counselors will be free to administer Mortimer-Filkins tests, making assignments into the Driver Improvement Program, counseling and monitoring for rearrest of all designated program people more effectively. (pp. 1-2)

The majority of probation counselors queried reported that the recent restructuring of the Program has made operations more efficient and has led to better utilization of Program personnel.

Countermeasure Activity $\# 4$ :

Client Meetings

Finding:

According to the Detailed Plan, probation counselors were to

schedule monthly meetings with each client assigned to one of the countermeasure interventions involving probation (i.e., probation only, probation and rehabilitation). (p. 48)

The meetings were not to exceed an average of thirty minutes per month. In addition to the monthly meetings, probation counselors were allowed to keep in touch with the client and the client's friends, spouse, employer, etc. via telephone. 
Nowhere in the Detailed Plan could any specific guidelines for casework supervision be found; there was nothing to indicate exactly what was supposed to occur during meetings between probation counselors and their clients. The consultant did locate certain "in-house" documents that identify some of the counseling objectives which were thought to be desirable in casework supervision. However, when asked about these documents, the Supervisory Probation Couselor reported that they must have been developed before he assumed his present position, since he was unaware of their existence. Also, while some general parmeters are provided in those documents (such as "attempt to improve motivation and behavior"), they do not provide the probation counselor with specific enough standards or instructions regarding casework services; however, they do a good job of defining quite clearly most of the other tasks probation counselors are expected to perform.

The Detailed Plan and subsequent literature state that each of the Program clients is supposed to be seen for no more than an average of thirty minutes per month. More than half of the probation counselors were asked whether or not they follow that guideline to the letter, and also if their casework notes accurately reflect the number of minutes they have spent each month with their clients. Every one of the probation counselors queried indicated that, although they attempt to restrict the time they spend with their clients to not more than thirty mintues per month, they usually find that they spend more time than that, on a face-toface basis. They further reported that in such instances they had not indicated the extra time spent, in their supervision notes. The reason they gave for spending the extra time was that the clients needed the additional support; as one probation counselor said: "Am I' supposed to turn them away when they come to me for help, just because I have already seen them that month for their allotted thirty minutes?"

During the on-site visits, the consultant had the opportunity, from time to time, to overhear client meetings taking place between probation counselors and the DWI offenders under their supervision; this was attributable to the open spaces and lack of private interviewing facilities in the DWI Probation Office. The meetings that were overheard indicated that probation counselors vary in the way in which they interact with their clients. Almost all probation counselors exhibited behavior which seemed to indicate genuine concern for their clients as people; those counselors interacted with the individuals assigned to them in what appeared to be a caring manner, treating them with respect and showing concern for their problems without condescension. There were some (but very few) client meetings overheard in which probation counselors seemed to be merely passing the time of day with the clients; in those few instances, it appeared that the probation counselors really had little to discuss with the offenders about their jobs, driving or drinking habits, Iifestyles, or any other problems they might have been encountering. 
Based on the client meetings that were overheard, on several occasions it did not appear as though the probation counselors handled the meetings in a goal-directed manner. Rather, in the majority of instances, the probation counselor's demeanor seemed to reflect a "shoot-from-the-hip" style of counseling; this was true even in those cases where the probation counselors were perceived by the consultant to be "caring" and 'concerned."

Although probation counselors have the latitude to make telephone calls to the clients' friends, spouses, and employers, there were no such supportive telephone contacts overheard during the consultant's visits. During discussions with probation counselors regarding this matter, they indicated that they do not have enough time to make such collateral contacts. However, they added that, if they did not have to worry about seeing each of their Program clients at least thirty minutes every month, then they would be able to make telephone contacts.

Comment. The above findings may be better understood when one remembers that a requirement of the Program was that probation counselors were mandated to spend an average of not more than thirty minutes per month with each client: The consultant interpreted this to mean that, had the probation counselors so chosen, they could have spent less than that period of time with each of their clients; the only requirement was that they not exceed the maximum. However, when Program management was queried concerning this matter, they reported the NHTSA had told them that each client was to be seen for thirty mintues each month.

The Program, then, during its operational phase, operated under the guidelines that each probation counselor had to see each of his or her Program clients for an average of thirty minutes per month, irrespective of the severity of the offense(s) committed, the type of drinker they were classified as, or the magnitude of the personal problems facing them. In discussing this matter with probation counselors and Program management alike, all agreed that the thirty minute requirement was, in retrospect, the most restrictive aspect of the Program during its operational phase. Program personnel were in unanimous agreement that, based on Program operations during the operational phase, not all DWI offenders had the same needs. While some did not necessarily need to have a monthly thirty minute face-to-face contact with a probation counselor in order to keep them from recidivating, other offenders might require weekly meetings, in excess of thirty minutes each. It is therefore evident why some probation counselors found it extremely difficult to spend an average of thirty minutes each month in goaldirected meetings with each of their clients; some cases were running smoothly and presented no unattained goals.

Another reason why many client meetings were nongoal-directed might be because there were no "supervision (or "treatment") plans" initially set up by the probation counselor and client. The 
supervision plan represents a goal-directed course of action that the offender takes to improve his or her 1 ife, and this plan is mutually agreed upon by the probation counselor and client. Without such a plan, casework is often hazy, and neither the client nor the probation counselor has any idea of what the end results of probation supervision are supposed to be.

While it is certainly understandable, based on their comments, why probation counselors oftentimes spent more than thirty minutes per month with each client, these laudable efforts by the probation counselors may cause the validity of some of the data generated by the Program during its operational phase to be questioned. Now that the thirty minute per client-per month guideline is no longer a requirement for the DWI Probation office, Program management may wish to consider implementing a "differential" approach, of some type, to caseload management in order to make maximum use of its resources in performing its function of supervising the offenders placed under its care by the court. During the consultant's last on-site visit, he suggested several types of caseload supervision techniques to Program management for possible implementation in order to increase Program efficiency.

Irrespective of what approach to casework is used, it would seem advisable that probation counselors receive training in the specific area of negotiating and constructing casework supervision plans. This would not only assist the probation counselors in the efficient management of their caseloads, but would also aid him to be able to better evaluate the quality of casework services being delivered by probation counselors to their clients. Also, in the event of staff absence or high staff turnover, it is much easier for another probation counselor to pick up a client's file and provide a continuity of counseling if a goal-directed supervision plan has been developed and followed during the time the offender has been under supervision. It might also prove beneficial for program staff to receive training in interviewing/counseling techniques, referral procedures, and casework recording.

It is important to stress that the present staff of probation counselors is both highly educated, and, for the most part, extremely conscientious about their responsiblities. It is felt that, with appropriate training, management guidance and supervision, and the introduction of some type of differential caseload approach into the Program, the probation counselor will provide excellent casework services to the offenders placed under their supervision.

Existing ACA Standards addressing the area of casework supervision are as follows:

Written policy and procedure govern supervision and classification of probation/parolees; criteria exist to ensure that no more surveillance or services are provided than are needed. (Standard 3117) 
The field officer and the offender jointly develop objectives and a supervisor plan, including its stated objectives. (Standard 3118)

The supervision plan requires that the field officer contact persons and agencies in the community that are familiar with the offender. (Standard 3121)

The supervision plan requires that the field officer maintain personal contact with the offender.

(Standard 3120)

Community supervision procedures specify the minimum number of contacts with the offender per time period, with provision at the local level to exceed this

minimum if warranted. (Standard 3123)

Countermeasure Activity $\# 5$ :

Client Record(s)

Finding:

The Detailed Plan indicates that

A11 DWI Probation Unit personnel, under the direction of the Supervisory Probation Counselor, will maintain complete and accurate records of a client's progress in a permanent client file to be located in the Probation office. (p. 49)

The Detailed Plan further specifies:

The counselors will make complete notes concerning all actions taken with each case. They will note length of meetings, topics discussed, telephone contacts made, conversations with friends, employers, etc. and opinions of client progress. ( $p .50)$

The consultant personally reviewed a random sample of "closed" client case files, including all supervision history notes, which were provided to him by the Urban Observatory after all identifying client information had been deleted. No current files were reviewed due to concern for maintaining the confidentiality of client information. NOTE: The findings and comments in this section should not be interpreted by the reader as necessarily indicative of all Client Records, since there was a relatively small random sample (approximately 15 to 20). Also, because they were all "closed" cases, most of the Client Records reviewed had been kept by probation counselors who are no longer employed in the Program.

For the most part, the files reviewed were complete, in that they did contain all required forms and various types of records, 
such as Diversion Qualification Checks and initial interview information to some degree.

The physical appearance of the supervision histories of those files reviewed left a lot to be desired, especially when one considers that the Urban Observatory will be faced with the onerous task of retrieving certain information from them for the purpose of coding and analysis. All supervision histories reviewed were handwritten, rather than typed; entries were often illegible and occasionally written in pencil, rather than ink; in several instances, the length of time of a client meeting was not recorded. Words were misspelled in almost all files reviewed, and, in general, the files were sloppy in appearance.

The files reviewed contained supervision histories which "said" very little about the client's progress, especially from the subjective opinion of the probation counselor assigned to the case, contrary to what was called for in the Detailed Plan. The entries from client meetings were usually dry recording of factual information regarding the status of the client's employment, whether or not the client had changed residences, whether or not the client had been arrested for any new offenses, etc. However, not much content could be found which would indicate to the reader specifically what the probation counselor was trying to achieve in his counseling of the offender in fact, no formal supervision plan was ever specifically identified in any of the files reviewed. In more than one instance, entries were found to indicate that clients had missed appointments, but no subsequent entries evidenced that the probation counselors in such cases had discussed the "missed meetings" with the clients.

The supervision histories were almost devoid of entries indicating that any collateral telephone contacts had been made to the employers, families, or friends of the clients by the probation counselors.

The supervision histories reflected the high turnover experienced thus far by the Program. A particular case might have been supervised by two or three different probation counselors during the period of supervision, which was less than one year. In each such instance, the most recently assigned probation counselor was at a disadvantage because of the dearth of information available to him or her regarding the previous casework that had been done with the client.

One thing which was glaringly absent from the supervision histories was any indication that the case files had been reviewed in any manner by the Supervisory Probation Counselor in charge of the DWI Probation Office at the time the material was recorded. 
Comment. It appears that, of all Countermeasure Activities proposed in the Detailed Plan, the one requiring complete notes of client casework has been the most difficult of the program to achieve. It must be pointed out that the absence of comprehensive, clearly written supervision histories does not necessarily mean that the probation counselors did not provide quality casework services to the offenders assigned to their supervision. However, in any casework (especially probation and parole casework), unless the supervision history entries clearly indicate what has transpired during the period of supervision, there is no way to ascertain the quality of the casework services being provided. Also, due to the legalistic aspect of probation supervision, comprehensive and accurate supervision histories are absolutely necessary in the event that the client is brought up on revocation or other charges; the records of a probation counselor are open to subpoena in such instances.

As previously mentioned, the client records were "complete" in that they contained all the required forms and records. However, they were very obviously lacking in content. The review of a random selection of cases reinforced the consultant's belief that counseling and casework services were provided in a nongoaldirected manner (see Comment for Countermeasure \#4). The supervision histories did not indicate that probation counselors had any conception of what they were hoping to achieve with the cases. The lack of subjective comments as to the progress of the clients evidenced this observation. This is understandable; if the probation counselor has no idea of where the case is going, that counselor will be hard-pressed to identify how well the client is progressing.

There were occasions when probation counselors made entries which indicated that the client was experiencing problems, but there was no evidence that the probation counselors assisted the clients with those problems; in some cases, the entries did not even reflect that the counselors had discussed the problems with the clients. For example, in more than one case there were entries stating that clients had been arrested for new charges related to alcohol, such as Drunk in Public, but the probation counselors did not report having any kind of dialogue with the clients about the need to refrain from drinking to excess. Entries were found to indicate that clients had missed meetings with their probation counselors; however, there were no subsequent entries showing that the counselors had attempted to discuss the missed meetings with the clients, or even that they had cautioned the offenders as to what might happen if future meetings were missed. In one particular case, the offender was a young woman who was pregnant outof-wedlock; she had no job, and her mother (with whom she lived) was extremely upset with her. She very obviously could have used some assistance in straightening out her life. If the probation counselor did not feel qualified to provide those services to her, one would expect to find some indication that one or more referrals had been made to other service-giving agencies in the community; 
however, no such entry could be found. The probation counselor assigned to that particular case merely entered the "facts" into the file.

Management review of supervision histories is an absolute necessity in any type of casework. However, there can be no review of casework unless each and every probation counselor has the same conception of the goal of casework in his or her agency. The specific requirements of casework supervision and recording (which include the overall philosophy of the agency), must be communicated in a consistent manner to every employee of the Program. If supervision plans are to be made part of each case file, then it is incumbent on management to provide all counselors with a clear understanding of what information management wants included in such plans. Unless this is done, the probation counselors cannot be expected to record their supervision histories in a manner which is conducive to review by management. The Program's Supervisory Probation Counselor reports that he has had no training thus far in management review of casework recording. Such training would indeed be helpful to him if he is to be responsible for the quality of casework services provided by the probation counselors under his administrative supervision.

Of a more general nature, none of the files reviewed indicated any kind of behavioral or attitudinal change during the period of supervision on the part of the client. Also, no evidence could be found which would indicate that there were any differences in the type of casework services provided to the various categories of clients. Another general area that needs to be mentioned is that there were no comprehensive "summary entries" upon the closing of cases, which would have provided some insight into the types of issues raised in this section of the current report; most often, the closing entry consisted of a single sentence indicating that the case was closed as of a certain date. Perhaps a series of training sessions on casework recording would assist the probation counselors in more accurately recording the type of services they provide to their clients and the type of attitudinal and/or behavioral changes (if any) that occur on the part of these clients.

The ACA Standards contain a section devoted exclusively to casework recording. Those Standards most applicable to the Program are as follows:

The agency has written policies and procedures concerning case record managment. (Standard 3082)

The agency maintains a master file that identifies active, inactive, transferred and destroyed case records. (Standard 3083)

The contents of case records are separated and identified according to an established format. (St andard 3085) 
A written report is prepared that summarizes the performance of the offender during the entire period of supervision. (Standard 3088)

Countermeasure Activity \#6: Authority and Reports

Finding:

The consultant had the opportunity to review all Monthly and Quarterly Reports of the Program since its inception; however, the Program's Yearly Reports were not supplied to him. Those reports that were reviewed indicated that they had been compiled in a comprehensive manner and that, for the most part, they accurately reflected relevant developments in the program. Reports compiled, at all levels were found to be timely, extremely clear, and concisely written. There were no indications that the Program had experienced any difficulties whatsoever in the compilation and submission of reports.

The Detailed Plan identifies (pp. 29-32) the Prime Contractor of the overall Demonstration Project as the Tennessee Office of Urban and Federal Affairs-Highway Safety Planning Division, and the three subcontractors are as follows:

1. The Memphis and Shelby County Traffic Safety Coordinating Committee (TSCC), which was charged with the overall management of the project, designated Mr. Ed Manker as Project Director of the overall Demonstration Project. In that capacity, Mr. Manker became responsible for the submission to both NHTSA and the Prime Contractor of all Quarterly, Annual, and Financial Reports. Additional responsibilities included monitoring all Countermeasures of the Demonstration Project, providing the various Countermeasures with suggestions for improving their operations, monitoring all fiscal expenditures. He also assumed primary responsibility for the administration and oversight of all activities regarding each Countermeasure of the Demonstration Project, including the Countermeasures involving the DWI Probation office.

2. The Memphis City Court Probation and Diversion Department, in the person of Ms. Catherine Walton, was charged with providing the hiring, training, and ongoing supervision of probation staff. She was given responsibility for the day-to-day management of the DWI Probation Office through the Program's Supervisory Probation Counselor.

3. The Urban Observatory of Metropolitan Nashville/University Centers was subcontracted to provide all evaluation of the overall Demonstration Project, including the Countermeasures involving the DWI Probation Office. 
In addition to the three subcontractors, Judge Love was identified in the Detailed Plan; he was given line authority over matters directly affecting or stemming from court policy.

Initially, the consultant perceived that major organizational, communications, and administrative problems among the various management staff would be evident since, at least on paper, it seemed that a great deal of confusion would be inherent due to the administrative involvement of so many different individuals. However, once the consultant had the opportunity to meet on more than one occasion with Program management, both as a group and individually, and to get a better understanding of the day-to-day operations of the Program, few problems of this nature were actually found to exist.

A11 of the specific organizational and administrative problems which did surface have been detailed in a separate "problem identification" report on the Program, previously submitted by the consultant; therefore, they will not be duplicated here. However, a problem not mentioned in that prior report that should be stressed at this time is the funding for the continuation of the Program. There has been no final decision made thus far as to whether or not the Program will receive local funding to continue operations beyond July 1, 1979; furthermore, no consensus has been reached regarding whose responsibility it is to fund the continuation should it be desired--the City of Memphis' or Shelby County's. At this point, the Program seems to be the stepchild of all but the responsibility of none.

Comment. The Program's organizational structure has been far from what many probation professionals would consider ideal, in that the Program, in some respects, is under the direction (of TSCC, although the DWI Probation Office staff and operations also answer in a "line" to the Department Manager of the Memphis City Court Probation Department, who, in turn, answers directly to the judge of Division VIII, Memphis City Court. In addition, directions regarding the Program's data collection efforts come from the Urban Observatory, which is not in a position of line authority over the Program since the role of the Urban Observatory has been that of subcontractor to the overall Demonstration Project.

With an organizational structure (both formal and informal) as described above, it is to the credit of Program management that the Program has not experienced any major administrative problems or internal role and power conflicts. It is believed that, more than anything else, this has been due to the individual personalities of the people who have been involved in the administration and evaluation of the Program. Each was perceived by the consultant to be extremely knowledgeable and capable in his or her specific area of operation, and their knowledge and capabilities have complemented one another throughout the life of the Program 
thus far. However, it is believed that the program could operate more efficiently if a different organizational structure were adopted.

It is recommended that the DWI Probation Program be joined with the "regular" City Probation Office and that the staffs be combined under one roof. With this accomplished, maximum utilization of existing resources could be reduced in those instances where an offender is reporting to both Probation offices at the same time; programming, planning, and budgeting would be easier to perform with one, unified program; probation policies and procedures could be more consistent; and it would be easier to provide training to both new personnel and existing staff. Furthermore, if the two programs were housed within the same facility, under the authority of one agency head and following one chain of command, it would be much easier to provide the necessary administration, logistical support, and direction to staff. A merger of the two Probation Offices would provide the misdemeanant courts of the City of Memphis with a unified, comprehensive, progressive, and innovative probation system which, in turn, would improve the delivery of services provided to the offenders placed on probation by the Memphis City Courts and enhance the overall quality of the human services delivery system of the City of Memphis.

as follows:

ACA Standards applicable to management of this Program are

The agency and its programs are managed by a single administrative officer. (Standard 3007)

Written policy delineates channels of communications. (Standard 3010)

All employees participate in staff meetings as frequently as required for effective performance of their respective duties. (Standard 3011)

The agency administrator is responsible for formulating agency goals, establishing policies and priorities related to them, and translating the goals into measurable objectives for accomplishment by field staff.

(Standard 3014)

The agency can document that all levels of staff participate in the development and review of organizational goals, policies, procedures, rules and regulations. (Standard 3017)

The administrator of field services consults with other agencies within the criminal justice system, as well as with community interest groups and service agencies, in the formulation of organizational policies, procedures, rules, and regulations. (Standard 3018) 
All written policy and procedures are dated and reviewed at least annualiy. (Standard 3019)

The agency administrator is responsible for developing and maintaining an administrative manual, which includes the policies, procedures, rules and regulations of the agency and is available to all staff. (Standard 3022)

The administrative manual is reviewed annually and updated as procedures change. (Standard 3023)

The duties and responsibilities of personnel and the delegation of authority are specified in writing. (Standard 3025)

The agency monitors the exercise of authority delegated to personnel. (Standard 3026)

Unless justification exists for deviation in the span of control a superior does not supervise more than six staff members. (Standard 3027)

The supervisory responsibilities of agency personnel are specified in writing. (Standard 3028)

\section{Additional Comments}

The consultant would be remiss in his analysis if he did not comment on several other items with reference to the Memphis DWI Probation Program:

1. Nowhere else has this consultant experienced a probation program of any kind that was initially developed in a manner as comprehensive as was the Memphis DWI Probation Program. Existing Program documents, in the form of letters, memoranda, and agreements between agencies and individuals, indicate that the planning for the Program was truly a joint effort. The coordination and cooperation that went into the Program have, in large part, allowed it to operate as smoothly as it has. Especially to be commended for their efforts in this regard are Mr. Manker, Ms. Walton, Mr. Stewart, and Judge Love.

2. The Evaluation design (especially for the Countermeasure involving probation), as developed by the Urban Observatory, is one of the most sophisticated research designs that has been developed in recent years to attempt to determine the effectiveness of probation. Although some of the data may prove to be less accurate than originally hoped for, it will not be due to a lack of effort on the part of the research designers or the on-site research assistant. It is felt that if more specific measurement criteria had been developed on the "front end" and if a more stringent management review of casework services and recording had 
occured during the operational phase of the Program there would have been a higher probability that the data generated by the probation counselors would be accurate and indicative of the services provided by the Program.

3. While overall administrative structure and support of the Program must be provided by "top management," the key position in the day-to-day operations of the Program is the Supervisory Probation Counselor. It is recommended that he be provided with additional training in the areas of management supervision, planning (possibly Management by Objectives), and staff organization and development; furthermore, in the future, he should be fully involved in the planning and budgeting of the Program's operations, as well as in the formulation of policies and procedures affecting the program. He should have a clear understanding of his authority and responsibilities and should report directly in a line to only one person. In addition, his span of control is too large (13 probation counselors and 2 secretaries), and if it is at all possible, it should be reduced to a more manageable number.

4. During a meeting with Judge Love, he expressed his extreme satisfaction with the DWI Program and especially with the DWI Probation Counselors. He is of the opinion that they are very dedicated individuals and reported that he has a great deal of confidence in their judgement. He said that the only major problem serious enough to have hampered the effectiveness of the Program relative to his court had been the high rate of staff turnover, which he attributed to low salary structure and to the lack of a career ladder within the system. According to Judge Love, the DWI Probation Program is of benefit to some probationers, to the community and to the Court. Even if the final Program evaluation does not show the Program to be effective from a quantifiable standpoint, Judge Love feels that the Program is valuable because:

a) It assists some "problem" drinkers who are on probation to curtail their drinking-driving behavior and prevents some of the "social" drinkers who are on probation from escalating their drinking habits by the early identification and referral of those offenders to alcohol education and treatment;

b) It provides the Judge with valuable information which he needs for rational decision making regarding the adjudication of DWI cases; and

c) It provides the community with an additional and necessary service-delivery system.

In discussing the future of the Program, Judge Love reported that he feels very strongly that it should be continued and also stated that he will do whatever he can to support the Program's attempts to secure local funding. 
Appendix $H$ (Cont.)

Report By R.J. Polisky March 1979

Summary

While it appears that the Memphis DWI Probation Program is in need of some refinements to improve its overall administrative efficiency, all in all it is a very good beginning for what could prove to be an excellent probation program. However, it must be realized that it is primarily a criminal justice program, rather than an alcohol treatment or highway safety program even though it may also serve as a vehicle for these other functions. Accordingly, the Program should be placed, administratively if not physically, wholly within an existing probation system, preferably the Memphis City Probation Office. The staff is both educated and dedicated; what they need most at this point is administrative direction and additional training, specifically in the areas of goal-directed counseling techniques, casework recording, and general probation topics. The Supervisory Probation Counselor needs additional support, direction, and supervision from top management and should be more involved in the planning, budgeting, and policy development of future Program operations. Additionally, all Program staff should be upgraded in salary, and the official job qualifications for the position of probation counselor should be raised to include a minimum of a baccalaureate degree, rather than the existing requirement of 2 years of college, if the probation counselors are to perform counseling and other casework services rather than simply gather data. Existing probation staff should be augmented with volunteers, student interns, and paraprofessionals such as reformed alcoholics, and a differential caseload system of some type should be implemented by the Program.

The Program should continually evaluate its effectiveness even when not required to do so by NHTSA, or any other outside funding source. It would be unfortunate indeed if the excellent research effort which began in 1976 were discontinued simply because it is no longer mandated by outside sources. Program. management should learn from the two year operational phase and make alterations in the Program's operations based both on their experience thus far and on what has been learned in other probation systems, especially other DWI Probation Programs. Existing national standards should be used as guidelines for change whenever applicable. In general, the Program should build on what has gone before rather than try to reinvent the wheel. There should also be more of a comprehensive planning effort in the future, gathering input from all levels of Program personnel and other agencies in the community involved in the drinking-driver problem, rather than planning in a vacuum. Until comprehensive planning is accomplished and sufficient resources are provided, the Memphis DWI Probation Program, in spite of its suspicious beginnings, will not realize its full potential. 
APPENDIX I-I

REPORT PERIOD $9 / 76$ to 9 i9

PROBATION $\because$ I.S. REPORT

PROGRLI ASSICNUET COMLETIONS

\begin{tabular}{|c|c|c|c|c|c|c|c|c|c|c|c|c|c|}
\hline & $\begin{array}{l}\text { PREV. } \\
\text { TOTAL }\end{array}$ & $\begin{array}{l}1978 \\
\text { OCT. }\end{array}$ & Non: & DFC. & $\begin{array}{l}1979 \\
\text { JiN. }\end{array}$ & FEB. & SAR. & $A P R$. & MY & JLNe: & JULY & ALC. & SEPT. \\
\hline Control & 443 & 72 & 45 & 27 & 47 & 60 & 76 & $20^{-}-$ & 72 & 66 & -50 & 55 & \\
\hline Probation & 444 & 90 & 54 & 36 & 47 & 54 & 75 & 16 & 57 & 71 & 49 & 54 & \\
\hline Rehabilitacion & 466 & 79 & 46 & 32 & 43 & 57 & 41 & 20 & 63 & $\frac{11}{53}$ & $\frac{49}{34}$ & $\frac{-34}{63}$ & \\
\hline$\frac{\text { Prob. \& Reliab. }}{\text { Total }}$ & -485 & 81 & 64 & 27 & 36 & $-\frac{51}{02}$ & $\frac{73}{295}$ & 18 & 63 & 57 & 37 & 49 & \\
\hline Total & 1838 & 322 & 209 & 122 & 173 & 222 & & 77 & 255 & 247 & 170 & 221 & 4148 \\
\hline
\end{tabular}

PROGRAM REVOCATIONS

\begin{tabular}{|c|c|c|c|c|c|c|c|c|c|c|c|c|c|}
\hline . & $\begin{array}{l}\text { PREV. } \\
\text { TOTAL }\end{array}$ & $\begin{array}{l}197 \mathrm{~S} \\
\text { OCT. }\end{array}$ & Nor: & DEC. & $\begin{array}{l}1979 \\
\text { JN1. }\end{array}$ & FEE. & TAR. & $A P R$. & $M A Y$ & JUAE & JULY & ALC. & SEPT \\
\hline 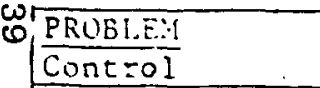 & 9 & 0 & 0 & 0 & 2 & 4 & 1 & 0 & 3 & 1 & 0 & 2 & 2 \\
\hline Probation & 9 & 0 & 0 & 1 & 1 & 4 & 2 & 0 & 6 & 0 & $\frac{5}{4}$ & 0 & 4 \\
\hline Rehabilitation & 7 & 0 & 2 & 1 & 2 & 0 & 1 & 0 & 0 & 3 & 1 & 2 & 0 \\
\hline Prob. \& Rehab. & 3 & 0 & 3 & 2 & 1 & 2 & 2 & 1 & I & 2 & $I$ & 2 & 1 \\
\hline$\frac{\text { NON-PROBLEM }}{\text { Control }}$ & 8 & 1 & 0 & 0 & 0 & 4 & 0 & 0 & 4 & 1 & 3 & 1 & 2 \\
\hline Probation & 3 & 1 & 1 & 1 & 0 & 2 & 2 & 0 & 4 & $T$ & 3 & 2 & 3 \\
\hline Rehabilitation & 8 & 1 & 2 & 0 & 1 & 2 & 1 & 0 & 2 & 1 & 5 & $I$ & 0 \\
\hline Prob. \& Rehab. & 8 & 0 & 1 & 1 & 2 & 3 & 1 & 0 & $T$ & 2 & 2 & 1 & 2 \\
\hline
\end{tabular}

OTHER REVOCATIONS

\begin{tabular}{|c|c|c|c|c|c|c|c|c|c|c|c|}
\hline $\begin{array}{l}19 i \mathrm{~S} \\
\text { OCT. }\end{array}$ & Nor. & DEC. & $\begin{array}{l}1979 \\
\text { JAL. }\end{array}$ & FES. & MAR. & APR. & MHY & $\mathrm{J}: \cdots$ & JELY & AL'G. & SEPI \\
\hline 2 & 4 & 1 & 3 & 4 & 8 & 8 & 8 & 8 & 7 & 3 & 2 \\
\hline
\end{tabular}


APPENDIX I-2

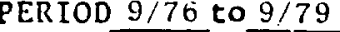

PROBATION M. T.S. REPORT

SILELBY COUNTY ARRESTS

\begin{tabular}{|c|c|c|c|c|c|c|c|c|c|c|c|c|c|}
\hline & $\begin{array}{c}1.978 \\
\text { TO DATE }\end{array}$ & OCT. & Nov. & DEC. & $\begin{array}{l}1979 \\
\text { JAN. }\end{array}$ & FEB. & MAR. & $\mathrm{APR}$. & MAY & JUNE & JULY & AUG. & SEPT. \\
\hline Memphis & 3554 & 398 & 429 & 512 & 391 & 473 & 591 & 426 & 454 & 394 & 433 & 397 & 435 \\
\hline $\begin{array}{l}\text { S.C.S.D. and } \\
\text { Other agencies }\end{array}$ & 905 & 122 & 101 & 113 & 96 & 145 & 149 & 145 & 146 & 136 & 143 & 139 & 118 \\
\hline Average B.A.C. & & & & & .167 & .150 & .158 & .164 & .166 & .172 & .164 & .170 & .163 \\
\hline
\end{tabular}

CLIENT INTERVIEWS for PRE-SENTENCE INVESTIGATIONS

\begin{tabular}{|c|c|c|c|c|c|c|c|c|c|c|c|c|c|}
\hline & $\begin{array}{c}1978 \\
\text { TO DATE }\end{array}$ & OCT. & NOY. & DEC. & $\begin{array}{l}1979 \\
\text { JAN. }\end{array}$ & FEB. & MAR. & APR. & MAY & JUNE & JULY & AUG. & SEPT. \\
\hline Division I-VII & 0 & 0 & 0 & 0 & 0 & 0 & 0 & 0 & 0 & 0 & 0 & 0 & 0 \\
\hline Division VIII & 4812 & 250 & 240 & 206 & 293 & 294 & 298 & 160 & 465 & 169 & 199 & 243 & 175 \\
\hline General Sessions & 228 & 30 & 31 & 19 & 41 & 47 & 53 & 43 & 65 & 55 & 0 & 0 & 0 \\
\hline Germantown & 58 & 4 & 7 & 6 & 2 & 9 & 9 & 5 & 0 & $\overline{0}$ & 0 & 0 & 0 \\
\hline Collierville & 6 & 5 & 2 & 0 & 3. & 1 & 6 & 1 & 4 & 0 & 0 & 0 & 0 \\
\hline Bartlett & 28 & 2 & 0 & 3 & 1 & 1 & 3 & e & 3 & 4 & 2 & 0 & 0 \\
\hline Other & 0 & 0 & 0 & 0 & 0 & 0 & 0 & 0 & 0 & 0 & 0 & 0 & 0 \\
\hline Total & 5132 & 291 & 280 & 234 & 340 & 352 & 369 & 209 & 537 & 228 & 201 & 243 & 175 \\
\hline
\end{tabular}

PLACED ON PROBATION

\begin{tabular}{|c|c|c|c|c|c|c|c|c|c|c|c|c|c|}
\hline & $\begin{array}{l}1978 \\
\text { TO DATE }\end{array}$ & OCT. & NOV. & DEC. & $\begin{array}{l}1979 \\
\text { JAN. }\end{array}$ & FEB. & MAR. & APR. & MAY & JUNE & JULY & AUG. & SEPT. \\
\hline Division I-VII & 0 & 0 & 0 & 0 & 0 & 0 & 0 & -0 & 0 & 0 & -0 & 0 & 0 \\
\hline Division VIII & 171 & 230 & 211 & 150 & 273 & 233 & 256 & 151 & 363 & 160 & 283 & 328 & 194 \\
\hline General Sessions & 23 & 31 & 34 & 20 & 41 & 24 & 32 & 48 & 53 & 42 & 2 & $I$ & 0 \\
\hline Germantown & 11 & 4 & 4 & 10 & 4 & 4 & 11 & 5 & 3 & 1 & 1 & 0 & $\Omega$ \\
\hline Collierville & 1 & 5 & 2 & 0 & 3 & 1 & 6 & 1 & 3 & 0 & 0 & 0 & 0 \\
\hline Bartlet & 5 & 2 & $\Omega$ & 3 & 1 & 1 & 4 & 0 & 3 & 4 & 2 & 0 & 0 \\
\hline Cither & 0 & 3 & 0 & 0 & 0 & 0 & 0 & 0 & 0 & 0 & 0 & 0 & 0 \\
\hline Toral & 211 & 272 & 251 & 183 & 322 & 263 & 309 & 205 & 425 & 207 & 288 & 329 & 194 \\
\hline
\end{tabular}


APPENDIX I- 3

Client Flow Chart

Field Stop

Field BAC Test

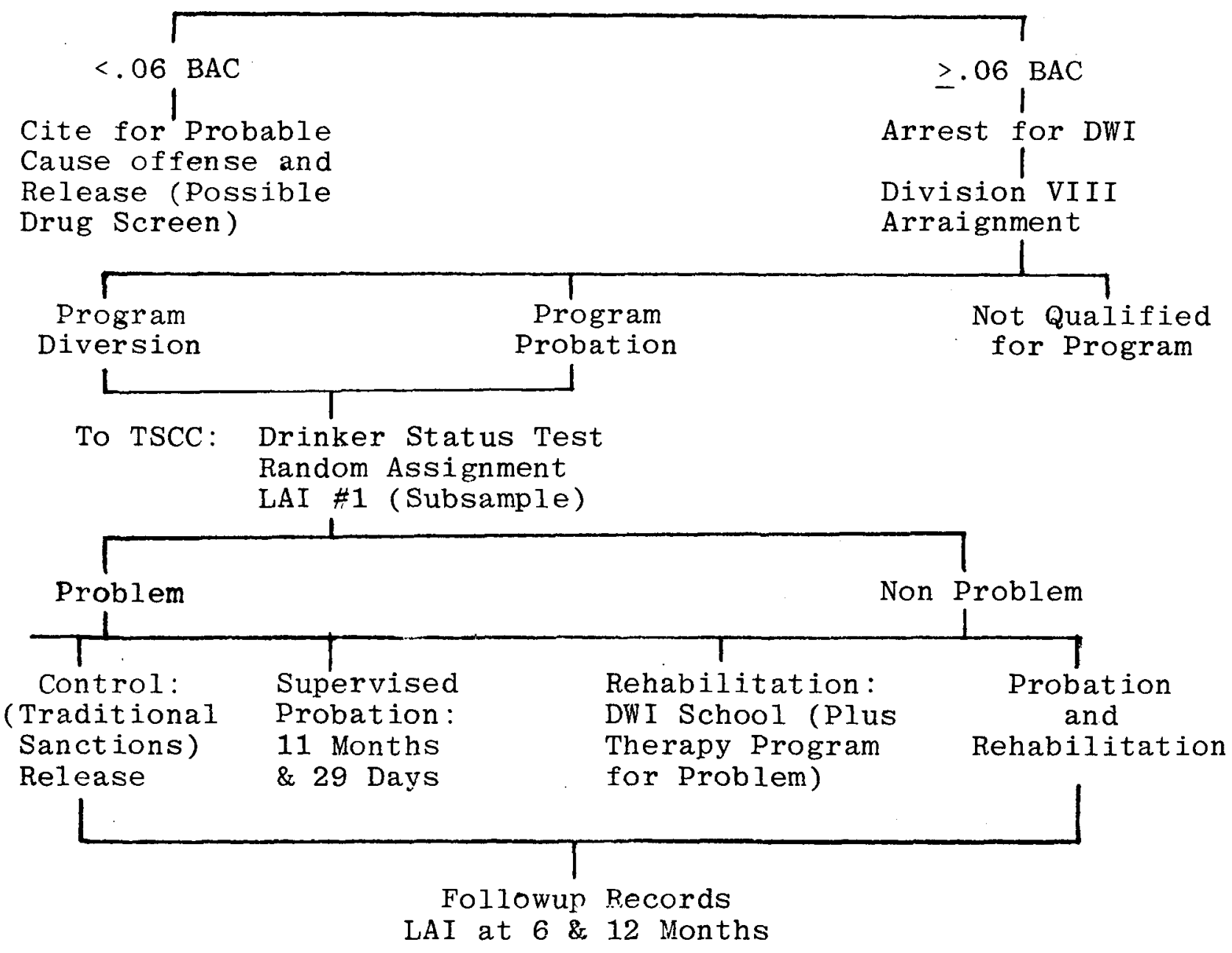


APPENDIX I-4

Fiscal Summary

\begin{tabular}{|c|c|c|}
\hline & \multicolumn{2}{|c|}{ edera1 Funds } \\
\hline & \multicolumn{2}{|c|}{ Cumulative Total } \\
\hline & Planned & Actual \\
\hline MANAGEMENT & $235,453.00$ & $209,783.51$ \\
\hline $\begin{array}{l}\text { Personnel Services } \\
\text { Equipment } \\
\text { Other Direct Costs } \\
\text { Travel }\end{array}$ & $\begin{array}{r}141,799.00 \\
18,604.00 \\
68,245.00 \\
6,805.00\end{array}$ & \\
\hline PROBATION & $386,449.00$ & $386,313.22$ \\
\hline $\begin{array}{l}\text { Personnel Services } \\
\text { Trave1 }\end{array}$ & $\begin{array}{r}369,828.00 \\
16,621.00\end{array}$ & \\
\hline EVALUATION & $372,289.22$ & $367,277.48$ \\
\hline $\begin{array}{l}\text { Personnel Services } \\
\text { Consultants } \\
\text { Travel } \\
\text { Equipment } \\
\text { Other Direct Costs } \\
\text { Indirect Costs }\end{array}$ & $\begin{array}{r}230,055.16 \\
3,600.00 \\
18,036.08 \\
2,405.00 \\
22,988.73 \\
95,204.25\end{array}$ & . \\
\hline TOTAL & $994,191.22$ & $963,379.21$ \\
\hline
\end{tabular}




\section{D.H.I. PROBATION FOLLONUP}

INTERVIEIER REFERRED FROM

INTERVIEW DATE

CONGLETION DATE COUNSElor

NATE

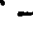

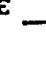

ADDRESS

HOW LONG AT THIS ADDRESS ASSIGNMENT No. B. OF I. NO. PHONE: HOSE BUSINESS

SOCIAL SECURITY NO. ATTORNEY PREVIOUS ADDRESS CHARGE (S) REPORT DATE IRIAI DATE (1) (2). D. O.B. STATE

RECOMMENDED FOR DYVERSION IF No, WHY

DISPOSITION DATE

DIVERSION: DIVERTED UNTIL PRobation: TIME FINE/COSTS. OTHER DISPOSITION

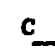
DATES

LAI

$\cdot$

ARREST DATE

BAC.

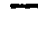

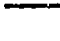

PRIOR ARREST: cruage

ST:

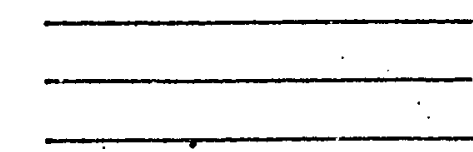

EVER ON PROBATION OR PAROLE COROENTS:
TYPE RELEASE OTHER CRTTERTA SUSPENDED PAID .8Y
PAID BY

costs. PROBATION PERIOD
CITY

STATE


Appendix I-5 Cont inved
SPOUSE(BOYFRIEND/GIRLFRIEND) NAME

ADDRESS

PHONE

NO. OF MARRIAGES

DATE(s)

NO. OF CHILDREN

HIGIIEST GRADE COMPLETED

$\therefore$ AGES VOCATIONAL OR SPECIAL. TRAINING

PRESENT ENPLOYER ADDRESS

LENGTH OF ENP.

TYPE OF BUSINESS

SALARY TITLE

PREVIOUS EAPLOYER

LENGTH

LENGTH

TYPE

MILITARY SERVICE (BRANCH)

CLASSIFICATION

SERYICE NO.

WELFARS

AMOUNT

DISABILITY

ANOUNT

OTHER SOURCES OF INCOME

CASETYORKER

TRE ON WELFARE IYPE DISC.

(2) REFERENCES (NAME, ADDRESS, PHONE:

UNEYPLOYMTNT AMOUNT AHOUNT

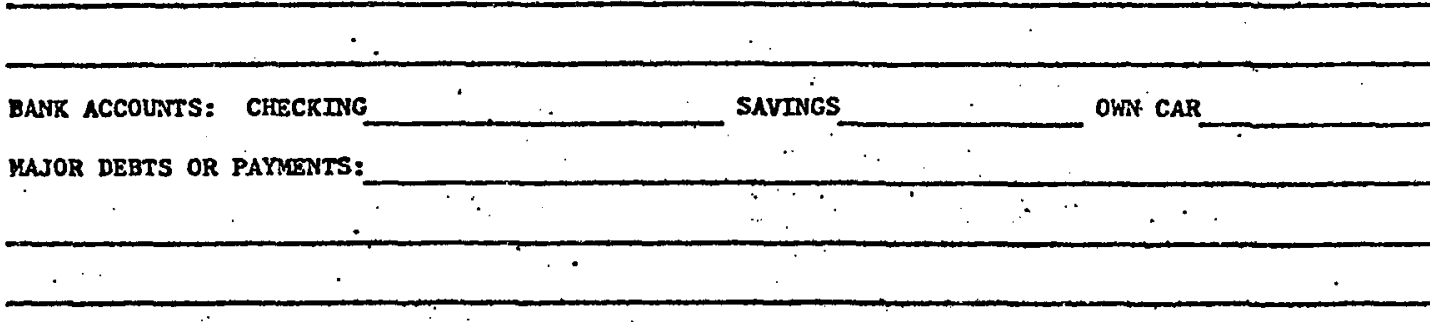

FIRST MMPRESSTON:

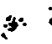

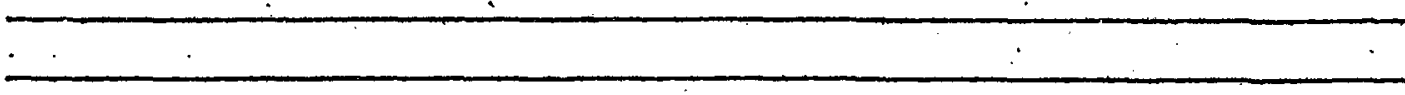

DATE

RE-ARREST RECORD

OFFENSE

DIspositron

REVOCATION HEARING

DATE

RESULTS

RESOURCES USED AND RESULTS: 